\title{
Mycorrhizal roles in broomsedge plants under phosphorus limitation and aluminum toxicity
}

Jianchang Ning

West Virginia University

Follow this and additional works at: https://researchrepository.wvu.edu/etd

\section{Recommended Citation}

Ning, Jianchang, "Mycorrhizal roles in broomsedge plants under phosphorus limitation and aluminum toxicity" (2000). Graduate Theses, Dissertations, and Problem Reports. 1214.

https://researchrepository.wvu.edu/etd/1214

This Dissertation is protected by copyright and/or related rights. It has been brought to you by the The Research Repository @ WVU with permission from the rights-holder(s). You are free to use this Dissertation in any way that is permitted by the copyright and related rights legislation that applies to your use. For other uses you must obtain permission from the rights-holder(s) directly, unless additional rights are indicated by a Creative Commons license in the record and/ or on the work itself. This Dissertation has been accepted for inclusion in WVU Graduate Theses, Dissertations, and Problem Reports collection by an authorized administrator of The Research Repository @ WVU.

For more information, please contact researchrepository@mail.wvu.edu. 


\title{
Mycorrhizal Roles in Broomsedge Plants Under Phosphorus Limitation and Aluminum Toxicity
}

\author{
Jianchang Ning
}

Dissertation submitted to the Eberly College of Arts and Sciences

at West Virginia University in partial fulfillment of the requirements for the degree of

\section{Doctor of Philosophy \\ in Biology}

\author{
Jonathan R. Cumming, Ph. D., Chair \\ Keith Garbutt, Ph. D. \\ James B. McGraw, Ph. D. \\ Joseph B. Morton, Ph. D. \\ Richard B. Thomas, Ph. D. \\ Department of Biology
}

Morgantown, West Virginia, USA 2000

Keywords: Aluminum, Broomsedge, Mycorrhizal, Phosphorus

Copyright 2000 Jianchang Ning 


\section{ABSTRACT}

\section{Mycorrhizal Roles in Broomsedge Plants Under Phosphorus Limitation and Aluminum Toxicity}

\section{Jianchang Ning}

This dissertation examined roles of arbuscular mycorrhizal fungi, of which Glomus clarum is the primary species, in broomsedge (Andropogon virginicus) plants under limited Pi and elevated $\mathrm{Al}$ conditions in four studies. The inoculum originated from an acidic coal-mining site in Morgantown, WV. The inoculum of Glomus clarum from INVAM collection, which originated from an alkaline coal-mining site in WV, was also used in two of the studies. Plants were grown in an acid-washed sand culture system with a modified Hoagland's nutrient solution in a growth chamber.

Mycorrhizal fungal colonization pronouncedly enhanced growth of broomsedge plants under limited Pi and/or elevated Al conditions. Under Pi limiting conditions, mycorrhizal broomsedge plants made more investment on roots, drew down solution Pi concentrations to lower level, all of which leads to increasing exploited Pi pool, and increased phosphorus use efficiency. Moreover, mycorrhizal plants balanced accumulation of nutrients under varying Pi availability. All these brought about by mycorrhizal symbioses benefit broomsedge plants overcoming Pi deficiency and supporting optimal growth of host plants under limited Pi availability.

Broomsedge plants do not have an inherent mechanism to block Al influx and tolerate $\mathrm{Al}$ toxicity. Mycorrhizal association with AM fungi significantly conferred Al resistance in broomsedge plants by facilitating Pi uptake in the early stages, reducing Al influx, suppressing Al translocation within plants, altering profiles of organic acids, releasing a great amount of organic acids, and improving nutrition of host plants. However, different fungal isolates had differential effects on Pi acquisition, $\mathrm{Al}$ influx and translocation, nutrient uptake, and exudation 
of organic acids as Al concentrations changed. These differences may be associated with the differential adaptations of these two AM fungal strains to their original habitats.

Moreover, two AM fungal isolates differentially altered physiology of host plants under different $\mathrm{Pi}$ and $\mathrm{Al}$ levels, such as stomatal conductance, photosynthesis, leaf respiration, root protein, and root acid phosphatase examined in this study. These adjustments of physiological traits might be related to other changes of plants that support sustainable growth of host broomsedge plants.

Therefore, broomsedge plants rely on AM fungi to grow and establish in adverse habitats. 


\section{ACKNOWLEDGEMENT}

I would like to take this opportunity to express my sincere appreciation to my advisor, Dr. Jonathan Cumming, for his knowledge, guidance, support, and encouragement through my study here and this project. I also wish to extend my appreciation to my advisory committee members: Dr. Keith Garbutt, Dr. Jim McGraw, Dr. Joseph Morton, and Dr. Richard Thomas, for their assistance, advise, and support. I am heartedly grateful to Dr. Jim McGraw for his support and encouragement in the first year of my study here. I would like to thank the Department of Biology for the opportunity and the support during the course of my study here. I also thank Dr. Martin Christ, Bill Wheeler, Beth Thomas, and fellow graduate students in the Department of Biology for their help.

Without the faiths and loves of my parents on me, I would not have gone so far. I owe them a life. Without the friendships of many childhood fellows, classmates, roommates, colleagues, teachers, and many others -- too many to list, I would not have overcome innumerable difficulties and gone through several crucial passes. I am indebted to all of them.

Special thanks are given to my wife, Weilin, and little boy, Jibin, for their patient, understanding, support, and loves. They made my work more enjoyable. A word of special thanks is extended to my parents-in-law for their encouragement and support. 


\section{TABLE OF CONTENTS}

Title Page $\quad$ i

Abstract ii

Acknowledgement iv

Table of Contents $\quad \mathrm{V}$

List of Figures vi vi

List of Tables vii

General Introduction 1

Chapter I: Effects of Mycorrhizal Fungal Colonization on Responses of Broomsedge Plants to Varying Pi Availability 21

Chapter II: Mycorrhizal Roles in Al Resistance of Broomsedge $\quad 40$

Chapter III: Differential responses of Different Mycorrhizal and NonMycorrhizal Broomsedge Plants to Aluminum 73

Chapter IV: Phosphorus and Aluminum Interactive Effects on Different Mycorrhizal and Non-Mycorrhizal Broomsedge Plants 98

Summary

123

References 126

Vitae 


\section{LIST OF FIGURES}

0.1. Pi availability as influenced by $\mathrm{pH} \quad 3$

0.2. Bi-direction transfers at root cell-fungus interfaces $\quad 8$

0.3. Pi uptake as influenced by root and soil characters 11

0.4. Model for relationships among soil, mycorrhizas, and plants 14

0.5. Bioassay of soils 17

1.1. Growth 26

1.2. PUE 29

1.3. Tissue nutrients $\quad 32$

2.1. Leachate $\mathrm{pH} \quad 46$

2.2. Biomass from Multiple Harvests 48

2.3. Apase deom Multiple harvests $\quad 50$

2.4. Growth from Extended Dose Response 56

2.5. Colonization percentage $\quad 58$

2.6. Tissue Al from Extended Dose Response $\quad 60$

2.7. Shoot nutrients $\quad 63$

2.8. Root nutrients $\quad 65$

2.9. Relationships between resistance index and inhibition of nutrient uptake 67

3.1. Tissue mass $\quad 80$

3.2. Tissue $\mathrm{Al} \quad 82$

3.3. Citrate and lactate $\quad 85$

3.4. Total organic acids $\quad 87$

$\begin{array}{ll}\text { 3.5. Tissue nutrients } & 91\end{array}$

4.1. Tissue mass 105

4.2. Root protein and APase 110

4.3. Tissue $\mathrm{P} \quad 114$

4.4. Tissue Al 116 


\section{LIST OF TABLES}

$\begin{array}{ll}\text { 1.1. Tissue } P & 28\end{array}$

1.2. $P$ values for tissue nutrients $\quad 31$

1.3. Pi uptake rate and $\mathrm{C}_{\min }$

2.1. $P$ values for leachate $\mathrm{pH} \quad 45$

2.2. Tissue Al 53

2.3. Tissue $P \quad 54$

2.4. $P$ values for nutrients $\quad 62$

3.1. Organic acids $\quad 84$

3.2. $P$ values for tissue nutrients 90

$\begin{array}{ll}\text { 4.1. } P \text { values for physiological traits } & 108\end{array}$

4.2. Stomatal conductance, photosynthesis, and respiration 109

4.3. $P$ values for tissue $\mathrm{Al}, \mathrm{P}, \mathrm{K}, \mathrm{Ca}$, and $\mathrm{Mg} \quad 113$

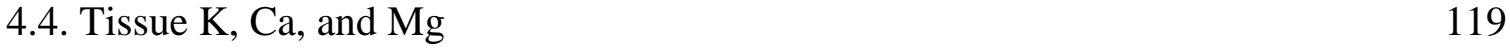




\section{GENERAL INTRODUCTION}

Acidic soils occupy over $50 \%$ of the total arable land worldwide (von Uexkull and Mutert 1995). These soils present several challenges to plants, since they are characterized by limited phosphorus (Pi) availability and elevated aluminum (Al) levels. Acidification of soils may be the result of natural weathering processes in areas dominated by granitic parent material and high levels of precipitation. Soil acidification is additionally exacerbated by increased nitrogen (N) inputs, and is a problem in regions receiving high $\mathrm{N}$ in deposition or through monotonous agricultural practice. Further, local perturbations, such as coal extraction, often leave behind acidic overburdens that may limit plant growth. Thus, increasing attention has been attracted to sustainable agricultural systems and environmental quality due to the limited Pi availability and elevated $\mathrm{Al}$ resulting from the soil acidification.

\section{Phosphorus and Aluminum Chemistry in Soils}

Phosphorus is an essential mineral nutrient to a plant, comprising about $0.2 \%$ of a plant's dry weight. It is a key substrate in energy metabolism and biosynthesis of nucleic acids and membranes. It is also involved in photosynthesis, respiration, and regulation of a number of enzymes. Phosphorus is one of the three most frequently limiting macro-nutrients for plant growth (two others are N and K) (Schachtman et al. 1998; Raghothma 1999). Soluble Pi exists in soil solutions as $\mathrm{H}_{2} \mathrm{PO}_{4}^{-}$or $\mathrm{HPO}_{4}^{2-}$, and primarily comes from three sources: native minerals, organic materials, and commercial fertilizers. Native phosphorus minerals, such as apatites $\mathrm{Ca}_{10}(\mathrm{X})_{2}\left(\mathrm{PO}_{4}\right)_{6}$, where $\mathrm{X}$ is $\mathrm{Cl}^{-}, \mathrm{F}, \mathrm{OH}^{-}$, or $\mathrm{CO}_{3}^{2-}$, release $\mathrm{Pi}$ into the soil solution through natural weathering processes. Phosphorus is released from organic materials as it is mineralized by microorganisms (Snoeyink and Jenkins 1980). Commercial fertilizers are the primary Pi source in the crop fields. Alterations in rhizosphere properties mediated by plant roots and rhizosphere microbes may change the availability of Pi for plant acquisition and utilization. This available Pi is solely delivered to root/fungal hyphal surfaces by a diffusion process (Marschner 1995).

Aluminum is the most abundant metal and the third most abundant element in the Earth's crust, making up about $7 \%$ of its mass, but it is not required by plants for normal growth. The mineral forms of $\mathrm{Al}$ exist in soils as hydrous oxides, alumino-silicates, sulphates, and 
phosphates. The major factor influencing the rates of dissolution or precipitation of $\mathrm{Al}$ minerals is proton $\left(\mathrm{H}^{+}\right)$activity. Soluble Al released from Al minerals is toxic to plants (Haug 1984; Ritchie 1995). Exchangeable $\mathrm{Al}$ in soils is a poor indicator of potential Al toxicity to plants due to the complicated chemistry of Al (Andersson 1988; Delhaize and Ryan 1995). When the soil solution $\mathrm{pH}$ is less than 5.0, soluble $\mathrm{Al}$ exists mainly as octahedral hexahydrate, $\mathrm{Al}\left(\mathrm{H}_{2} \mathrm{O}\right)_{6}{ }^{3+}$, for convenience, called $\mathrm{Al}^{3+}$. As the $\mathrm{pH}$ increases, $\mathrm{Al}(\mathrm{OH})^{2+}$ and $\mathrm{Al}(\mathrm{OH})_{2}{ }^{+}$are formed. At neutral $\mathrm{pH}, \mathrm{Al}$ is precipitated as $\mathrm{Al}(\mathrm{OH})_{3}$ (gibbsite). When the $\mathrm{pH}$ increases to the value commonly found in the cytoplasm (about 7.4), $\mathrm{Al}(\mathrm{OH})_{4}^{-}$dominates $\mathrm{Al}$ speciation. In the process of $\mathrm{pH}$ alteration, triskaidekaaluminium, $\mathrm{AlO}_{4} \mathrm{Al}_{12}(\mathrm{OH})_{24}\left(\mathrm{H}_{2} \mathrm{O}\right)_{12}{ }^{7+}$, often referred as $\mathrm{Al}_{13}$, may be unexpectedly formed (Kinraide 1991; Kochian 1995). Soluble Al complexes with organic acids, phosphate, sulphate, and macromolecules (e.g. proteins, DNA) whenever these compounds are present. Root exudates and microbial activities may alter Al speciation in the rhizosphere.

Phosphorus fixation mainly by $\mathrm{Al}$ and $\mathrm{Fe}$ and their hydroxides is recognized as an important factor contributing to the low available Pi in acid soils, whereas precipitation of Pi and $\mathrm{Ca}$ becomes important at higher pH (Figure 0.1). Through precipitation and/or adsorption of $\mathrm{AlPO}_{4}$, bioavailable $\mathrm{Pi}$ is thus greatly reduced. Therefore, $\mathrm{Al}$ toxicity and Pi deficiency, often cooccur and are the primary factors limiting plant growth and production in acidic soils (Snoeyink and Jenkins 1980, de Miranda and Rowell 1989).

\section{Plant Responses to Limited Pi Availability and Elevated Al}

Plant adaptation to a particular environment is driven by natural selection (Antonovics et al. 1971; Humphreys and Bradshaw 1976; Chapin 1980). In response to environmental stress, plants are able to adjust their biochemical, physiological, and phenological characters in the short term, which is called acclimation, and alter genetic composition in the long term, which is called adaptation.

Under limited Pi availability, reduction of growth rate is a typical adaptive mechanism at the plant level (Chapin 1980, 1983), leading to low Pi demand and slow tissue turnover and high Pi retention (Aerts and Chapin 2000). These plant species have high nutrient use efficiency (Aerts and Chapin 2000), but may experience Pi luxury consumption, resulting in low Pi use efficiency (Chapin 1980) when Pi is readily available. Root growth is favored, resulting in a 
Figure 0.1. Phosphorus (Pi) precipitation and availability in a soil solution is changed as the soil solution $\mathrm{pH}$ changes.

(After the Soil Fertility course by Dr. Louis McDonald at West Virginia University) 


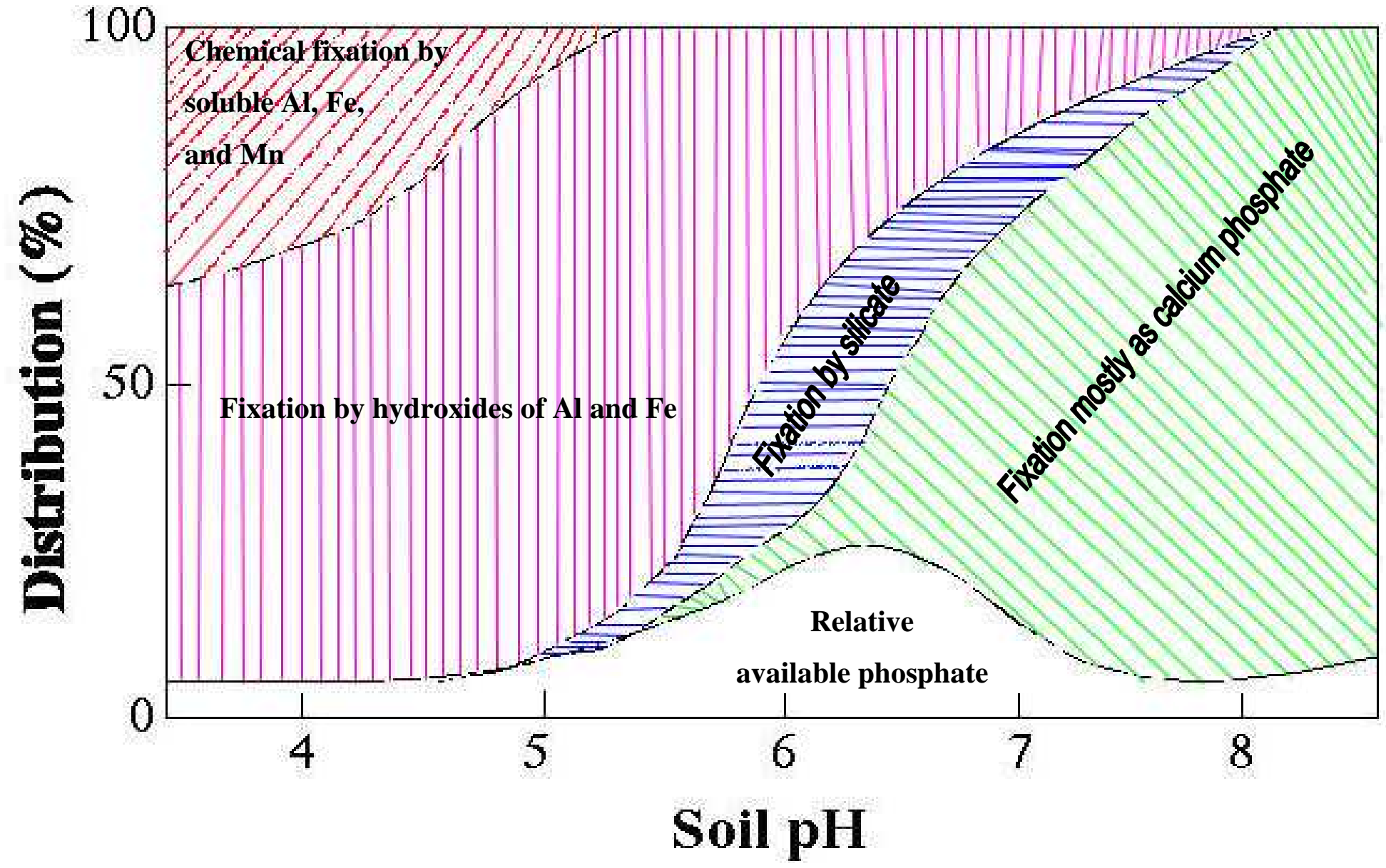


large ratio of root to shoot (Chapin 1980; Marschner 1995). High specific root length (root length per unit root mass) is another trait characteristic of plants growing in infertile soils, leading to a large root absorption area (Hajabbasi and Schumacher 1994; Aerts and Chapin 2000). Root distribution may be uneven in the soil. The root system exploits a large volume of soil and tends to proliferate in local Pi rich patches temporally and/or spatially (Caldwell 1989; Lambers et al. 1998). Under deficient Pi condition, roots typically form symbiotic associations with mycorrhizal fungi. Low Pi availability is more detrimental to aboveground tissues than belowground tissues. For example, shoot growth is retarded, reproduction is delayed, and flowers, fruits, and seeds are reduced, all of which may be related to reduced photosynthetic efficiency resulting from carbon limitation (Chapin 1980; Marschner 1995).

At the cell and molecular level, plants may adjust activities of enzymes and enzymatic kinetic parameters, such as $\mathrm{H}^{+}$-ATPase, $\mathrm{K}_{\mathrm{m}}$, and $\mathrm{V}_{\max }$, up-regulate expression of specific genes, such as Pi transporters, and use an alternative respiration pathway (Clarkson 1985; Theodorou and Plaxton 1993; Mimura 1995; Lambers et al. 1998; Schachtman et al. 1998; Raghothama 1999). Plants are also capable of actively mining Pi from limited sources by altering rhizosphere properties by exudating compounds (e.g. organic acids, acid phosphatases), releasing protons $\left(\mathrm{H}^{+}\right)$, and favoring activities of some microbes (Clarkson 1985; Marschner 1991; Barrett-Lennard et al. 1993; Ae and Otani 1997; Lambers et al. 1998; Schachtman et al. 1998; Raghothama 1999). In addition, Pi availability affects acquisition, translocation, and metabolism of other nutrients by plants, resulting in changes of nutrient composition in plants (Pacovsky 1986).

The toxic effects of $\mathrm{Al}$ on plants are mainly exerted through the high affinity of $\mathrm{Al}$ for many compounds and macromolecules in plants. The most easily recognized symptom of Al toxicity is the inhibition of root elongation (Kinraide et al. 1985; Andersson 1988). Therefore, most studies focus on root responses to elevated Al. When exposed to elevated Al, plants may experience stubby, brittle, and brown roots, reduced initiation of lateral roots, and retardation of root growth (Foy 1983; Andersson 1988; Roy et al. 1988; Taylor 1988). The root apex is believed to be the primary target of Al lesion (Andersson 1988; Kochian 1995). Root tips are swollen and discolored under elevated $\mathrm{Al}$ conditions and their structure is often damaged (Andersson 1988; Kochian 1995). The cells of root tips reduce or stop division and expansion, become vacuolated, the cell wall is rigid, their organelles are disordered, and integration and fluidity of the membrane is damaged (Taylor 1988; Kochian 1995). At the biochemical level, DNA synthesis in root tips is inhibited, root respiration is reduced, activity of some enzymes and 
uptake of nutrients, such as Pi and Ca, are disrupted (Foy 1983; Roy et al. 1988; Taylor 1988; Kochian 1995). Thus, plants accumulate Al, have low nutrient concentrations, and are susceptible to water stress under elevated Al conditions (Foy 1983; Andersson 1988; Taylor 1988; Kochian 1995; Marschner 1995). After a long-term exposure to Al, plants show Al toxicity symptoms aboveground, for example, slowed shoot growth, Pi deficiency symptoms, and reduced leaf chlorophyll and photosynthesis (Andersson 1988; Roy et al. 1988; Taylor 1988). Al-tolerant plants limit Al translocation to aboveground tissues, produce organic acids to detoxify $\mathrm{Al}$ internally and/or externally, change rhizosphere properties to affect $\mathrm{Al}$ speciation, influence microbial actitivies in the rhizosphere to reduce Al availability, form symbiotic association with mycorrhizal fungi to protect the root system, up-regulate gene expression of resistant proteins to reduce Al entry, and enhance nutrient uptake (Marschner 1991, 1995; Delhaize and Ryan 1995; Kochian 1995; Clark 1997). Some other plants like tea (Camellia sinensis) accumulate much $\mathrm{Al}$ in leaves and tolerate it (Rengel 1996), but this tolerance mechanism is not completely understood. On the other hand, low Al levels (usually $<5 \mathrm{ppm}$ ) stimulate plant growth. Although this beneficial effect of $\mathrm{Al}$ on plants is not understood, it may be related to $\mathrm{Al}$ altering the distribution of growth regulators in roots and serving as a fungicide (Foy 1983; Roy et al. 1988).

\section{Arbuscular Mycorrhizas}

Arbuscular mycorrhizas (AM) are the most common mycorrhizal symbioses, which are formed between various plants, from fern to higher plants, and obligately symbiotic fungi in the Glomales, including Acaulospora, Entrophospora, Gigaspora, Glomus, Scutellospora, and Sclerocystis. These AM fungi are mainly characterized by asexual reproduction, aseptate and multi-nucleate mycelium, and intraradical structures. They can not live alone, and must rely on host plants for carbohydrates as energy sources. Their spores can germinate, but produce little mycelium in absence of plant roots. Soluble exudates or extracts from roots of host plants, mainly flavonoids, stimulate hyphal growth and branching. When the hyphae from propagules of three inoculum sources (spores, infected root fragments, and hyphae) contact roots, colonization of roots is initiated by the formation of swollen appressoria at hyphal tips. After a short recognition reaction, the hyphae penetrate the root epidermis and cell walls via biochemical and mechanical processes. The intraradical hyphal branches pass into and grow longitudinally in 
the intercellular spaces of the middle and inner cortex of roots. These branches give rise to arbuscules, highly branched structures that form invaginations into cortical cells. Sometimes intercellular hyphae produce a storage structure, called vesicles. Once the fungus is established in roots, external mycelia grow extensively in soils and extremely extend root zones, finally produce spores (Smith and Read 1997).

Intracellular arbuscules are relatively short-lived (about a week), and these are believed to be major site for transfer of mineral elements (especially Pi). The plasma membrane of root cells around the arbuscules, called periarbuscular membrane (PAM), is greatly expanded, thus the membrane surface of the root cells increases considerably, and its properties and functions may be altered. For example, its $\mathrm{H}^{+}$-ATPase activity is enhanced (Gianinazzi-Pearson et al. 1991). These changes would favor Pi transfer across the interface. In the processes of Pi and carbon transfers, the proton motive force (PMF) generated by $\mathrm{H}^{+}$-ATPase may play an important role. Carbohydrate transfer is suggested to occur between the interface of the intercellular hypha and root cell membrane (Figure 0.2A). However, there is a suggestion of bi-directional transfers of $\mathrm{Pi}$ and carbon occurring on the arbuscules simultaneously (Figure 0.2B), because active ATPases are present on both root and fungal membranes in the arbuscular interface. In either case, passive efflux along concentration gradients from the donor, Pi from fungus and carbon (possible sucrose) from root cell, into the interfacial apoplast is followed by active uptake by receiver, Pi by root cell and hexose by fungus. The sucrose effluxed from root cells might be hydrolyzed by an acid invertase from the root cells then converted into hexoses, which are absorbed by the fungus. For the uptake of Pi by fungus from soil, the fungus forms polyphosphate in the hyphae (Bucking and Heyser 1999), which may establish and maintain the driving force for Pi uptake into the hyphae (Smith and Read 1997).

An AM fungus can infect a variety of plant species from lower to higher vascular plant species. An individual plant can be colonized by multiple AM fungi simultaneously. Extensive external mycelia extend from one plant to other plants, forming a hyphal net among plants, which consequently increases colonization of root systems by fungi from the standpoint of the plant community. The hyphal links may play important roles in retaining stability and integration of the plant community by sharing nutrient resources and saving carbon investment 
Figure 0.2. Schematic representation of the speculative spatial distribution of $\mathrm{H}^{+}$-ATPase and associated transfer processes in AM interfaces.

A. Transfer of Pi from fungus to plant across an arbuscular interface, and transfer of sucrose from plant to fungus across the interface between cortical parenchyma cells and intercellular hypha.

B. Bi-directional transfer of sucrose and Pi across the same arbuscular interface.

PAM: peri-arbusculaar membrane; FPM: fungal plasma membrane

(After Smith and Read 1997) 


\section{A. Spatial Separation of Transfer of Carbon and Pi}
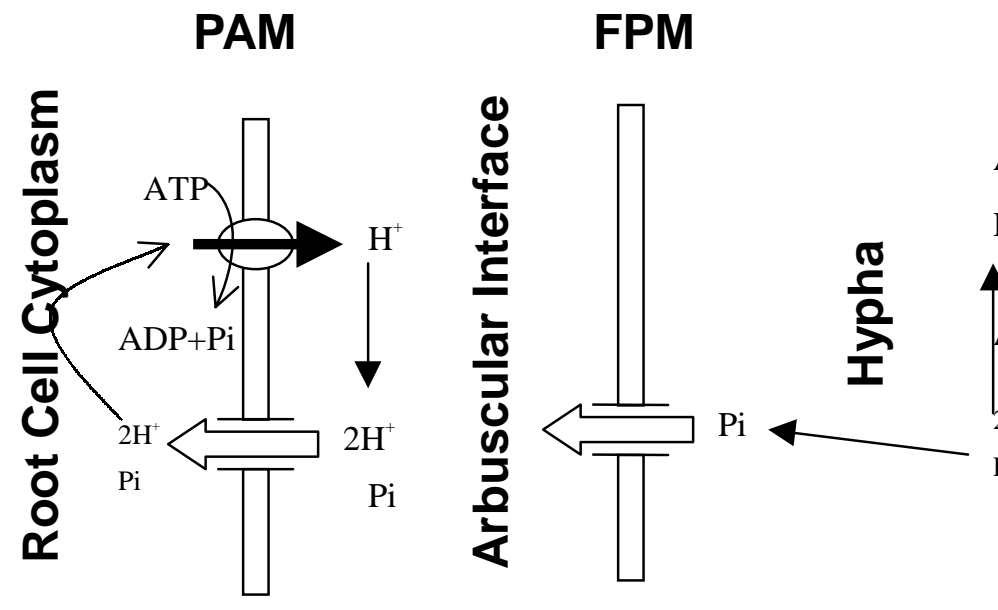

FPM
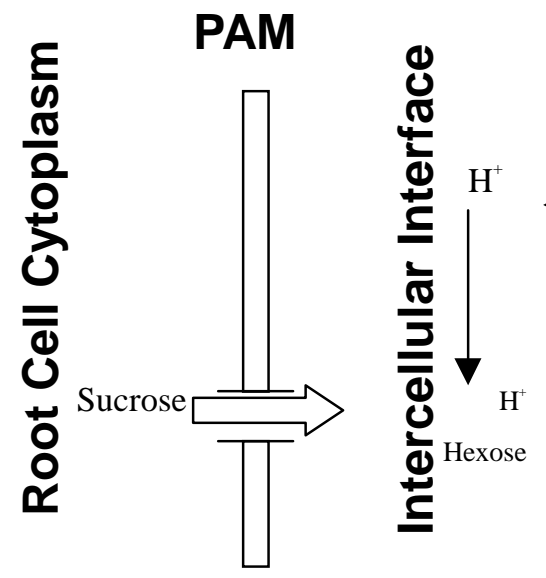

FPM

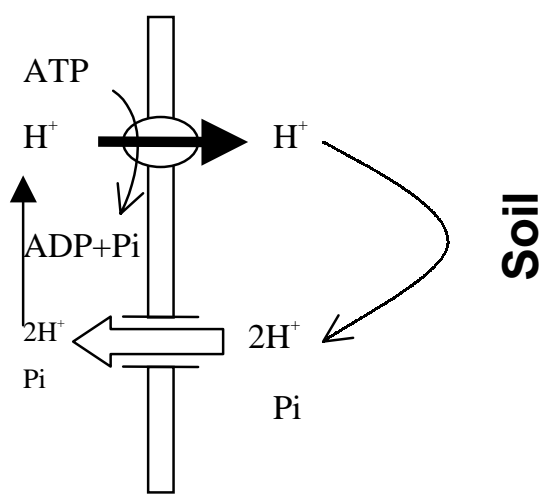

\section{FPM}

B. Bidirectional Transfer of Carbon and Pi Across the Same Interface
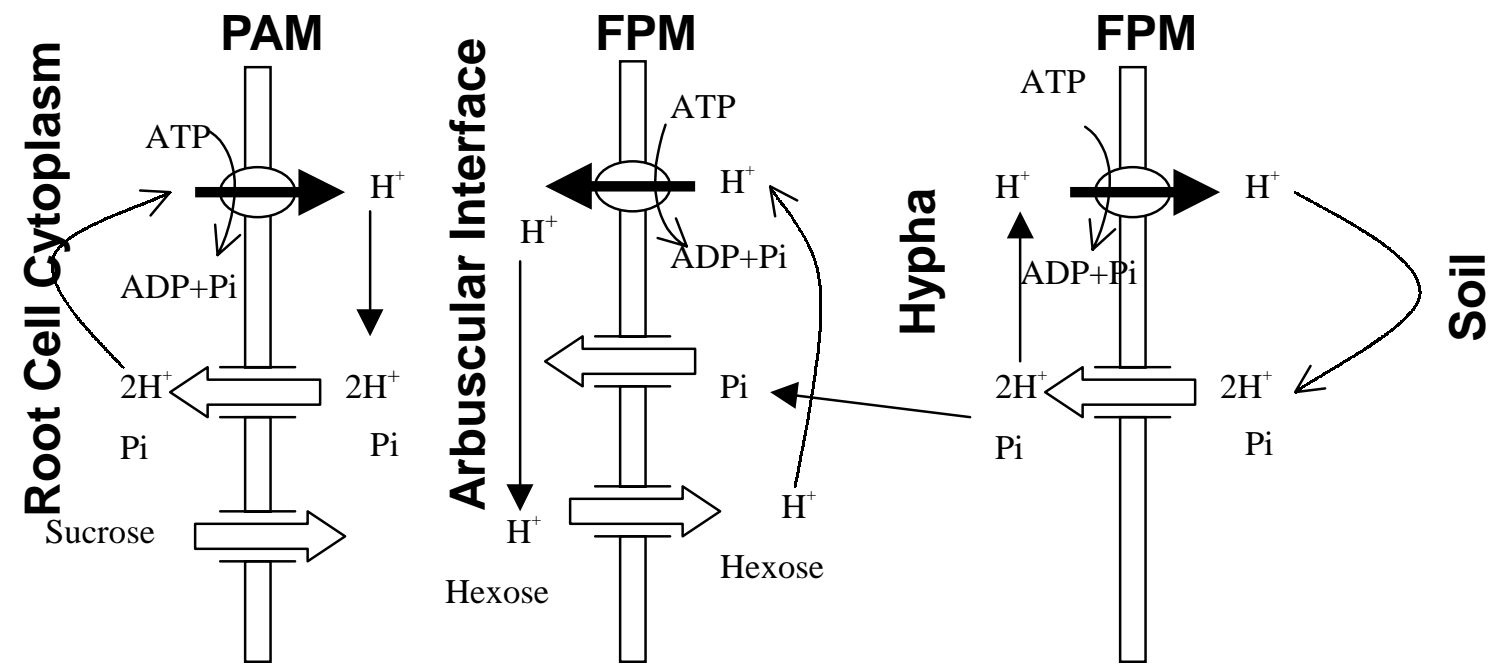
on nutrient acquisition structures. These roles undoubtedly aid rapid establishment of seedlings, and help overcome localized stress (Smith and Read 1997).

\section{Benefits Provided by AM Fungal Colonization}

Arbuscular mycorrhizas are the most common underground symbioses and have existed for several hundred million years. There exists a wide range of habitat preference by AM fungi, even within the same fungal species. These fungi differentially affect performance of the host plant species. Some fungi may facilitate nutrient uptake and stimulate plant growth, while others may suppress plant growth or have no effect on plant nutrient uptake or/and growth, but provide other benefits to plants. There is no clear relationship between percentage root colonization and plant growth (Clark 1997; Johnson et al. 1997; Smith and Read 1997). Apparently, the functions of AM symbioses go beyond the simple capture of mineral nutrients. So there must be some selection advantage(s) for their wide-spread occurrence.

Several advantages brought about by AM fungal colonization enhance both AM fungal and plant fitness. Experiments have demonstrated that AM fungal colonization ameliorated the effects of adverse edaphic factors on host plants, increased seedling survival, and improved plant growth (Danielson 1985). The most documented benefit provided by AM fungi is increasing acquisition of diffusion-limited mineral nutrients, such as $\mathrm{Pi}, \mathrm{Cu}, \mathrm{Zn}$, and $\mathrm{NH}_{4}^{+}$. It is reported that AM fungal colonization also improved water relations of host plants in the western USA (Allen et al. 1981) and other parts of the world (Kothari et al. 1990). Moreover, AM fungi conferred metal resistance to the host plants, e.g., Zn and Cd (Gildon and Tinker 1981). Finally, AM fungi aided host plants against invasion and infection of other microorganisms. On the other hand, AM fungi may suppress growth of non-mycorrhizal plants, thus indirectly aiding the establishment of mycorrhizal plants (Francis and Read 1994). All of these factors may increase host plant fitness. Of course, improved plant growth would provide more available carbon for the fungi to utilize, consequently increasing AM fungal fitness (see below) (Newsham et al. 1995; Smith and Read 1997). 
Figure 0.3. Effects of changing parameter values on simulated Pi uptake by roots.

k: rate of root elongation; $\mathbf{C}_{\mathrm{li}}$ : initial $\mathrm{Pi}$ concentration; $\mathbf{r}_{\mathbf{0}}$ : root diameter; $\mathbf{b}$ : soil buffering power; $\mathbf{D}_{\mathbf{e}}$ : Pi diffusion coefficient; $\mathbf{I}_{\text {max }}$ : maximum Pi inflow rate; $\mathbf{v}_{\mathbf{o}}$ : transpiration rate; $\mathbf{r}_{\mathbf{i}}$ : root density; $\mathbf{C}_{\min }$ : Pi concentration of no Pi influx; $\mathbf{K}_{\mathrm{m}}$ : Pi concentration at where Pi uptake rate is $\mathrm{I}_{\max } / 2$.

(After Clarkson 1985) 


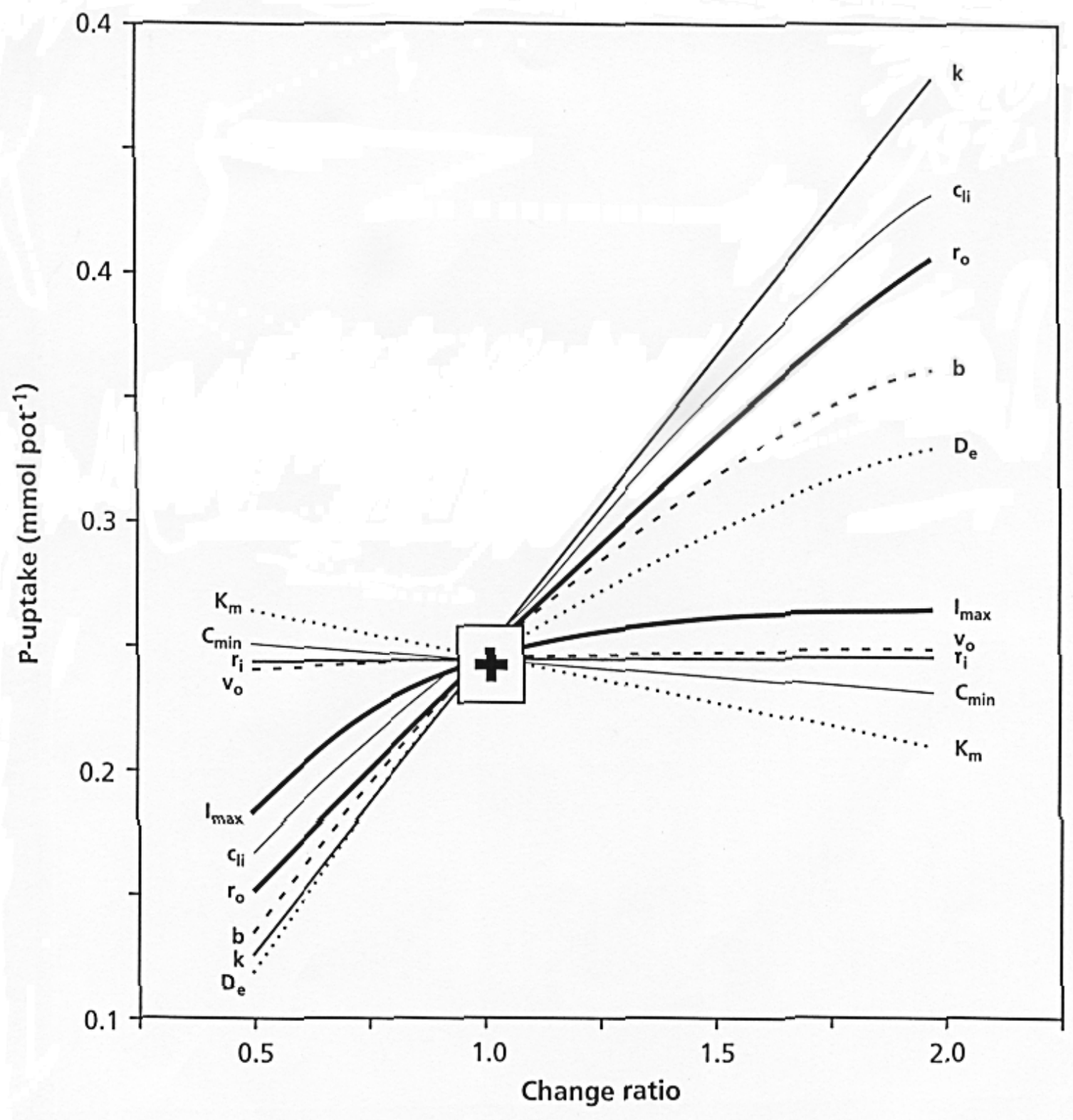




\section{Relationships between Root Systems and Nutrient Acquisition}

The delivery rate of a nutrient to the root surface $\left(\mathbf{F}\right.$, mol m $\left.\mathrm{m}^{-2}\right)$ by diffusion and mass flow is given by:

$$
F=-D_{e} * \frac{d C}{d r}+v^{*} C
$$

and diffusion coefficient of the nutrient $\left(\mathbf{D}_{\mathrm{e}}, \mathrm{m}^{2} \mathrm{~s}^{-1}\right)$ and nutrient uptake rate $(\mathbf{d C})$ are separately determined by:

$$
\begin{aligned}
& \mathrm{D}_{\mathrm{e}}=\theta * \mathrm{f} * \mathrm{D}_{0} \\
& I_{n}=\frac{I_{\text {max }}\left(C-C_{\text {min }}\right)}{K_{m}+\left(C-C_{\text {min }}\right)}
\end{aligned}
$$

where $\mathbf{C}$ is the nutrient concentration $(\mathrm{mol} \mathrm{m}), \mathbf{r}$ is root radius $(\mathrm{m}), \mathbf{v}$ is water flux rate $\left(\mathrm{m}^{3} \mathrm{~m}^{-2} \mathrm{~s}^{-}\right.$ ${ }^{1}$ ), $\boldsymbol{\theta}$ is water status, $\mathbf{f}$ is diffusion path (tortuosity factor), $\mathbf{D}_{\mathbf{0}}$ is diffusion coefficient of the nutrient in free solution $\left(\mathrm{m}^{2} \mathrm{~s}^{-1}\right), \mathbf{I}_{\mathbf{n}}$ is net influx rate of the nutrient $\left(\mathrm{mol} \mathrm{m}^{-2} \mathrm{~s}^{-1}\right), \mathbf{I}_{\max }$ is maximal influx rate of the nutrient $\left(\mathrm{mol} \mathrm{m}^{-2} \mathrm{~s}^{-1}\right), \mathbf{K}_{\mathrm{m}}$ is the nutrient concentration at one-half of $\mathrm{I}_{\max }(\mathrm{mol} \mathrm{m}$ ${ }^{3}$ ), and $\mathbf{C}_{\min }$ is the minimum nutrient concentration at which no influx occurs (mol $\mathrm{m}^{-3}$ ). For any given nutrient, according to the above equations (1), (2) and (3), its delivery rate to the root surface is determined by root uptake system $\left(\mathbf{I}_{\max }, \mathbf{K}_{\mathrm{m}}\right.$, and $\mathbf{C}_{\min }$ ), root geometry (r), water status $(\mathbf{v}, \boldsymbol{\theta})$, the nutrient property $\left(\mathbf{D}_{0}\right)$ and its concentration $(\mathbf{C})$. As to those nutrients delivered solely by diffusion, such as $\mathrm{Pi}$, the term $\mathbf{v}^{*} \mathbf{C}$ is omitted from the equation (1), as mass flow does not contribute. Thus, the concentration, the nutrient uptake system, and root extension into unexploited soil regions are of great importance in acquisition of diffusion-limited nutrients (Clarkson 1985, Lambers et al. 1998). Mathematical models predict that root geometry is more important than the uptake kinetic parameters (Figure 0.3) (Clarkson 1985). Thus, mycorrhizal colonization can improve the exploratory geometry of the root system through the extension of external fungal hyphae into the soil far beyond regions the root system reaches and greatly increase the root surface area:volume ratio (Berta et al. 1993, Smith and Read 1997). Furthermore, these external hyphae may alter the properties of the surrounding soil, which affects availability of nutrients and Al.

In acidic soils, low $\mathrm{pH}$, low $\mathrm{Pi}$, and high $\mathrm{Al}$ may directly interfere with acquisition and metabolism of mineral nutrients, limiting plant growth. AM fungal colonization may facilitate 
Figure 0.4. Schematic model of relationships among acidic edaphic factors (e.g. limited Pi and elevated $\mathrm{Al}$ ), nutrient acquisition by plants, mycorrhizas, and plant growth.

Low available $\mathrm{Pi}$ and high $\mathrm{Al}$ negatively affect nutrient acquisition, and mycorrhizas facilitate nutrient acquisition and may alter plant physiology, consequently affecting plant growth; improved nutrition status enhances plant growth; carbon availability of plant affects mycorrhizal symbiosis.

Solid arrows indicate positive associations, whereas open arrows reflect negative relationships. 


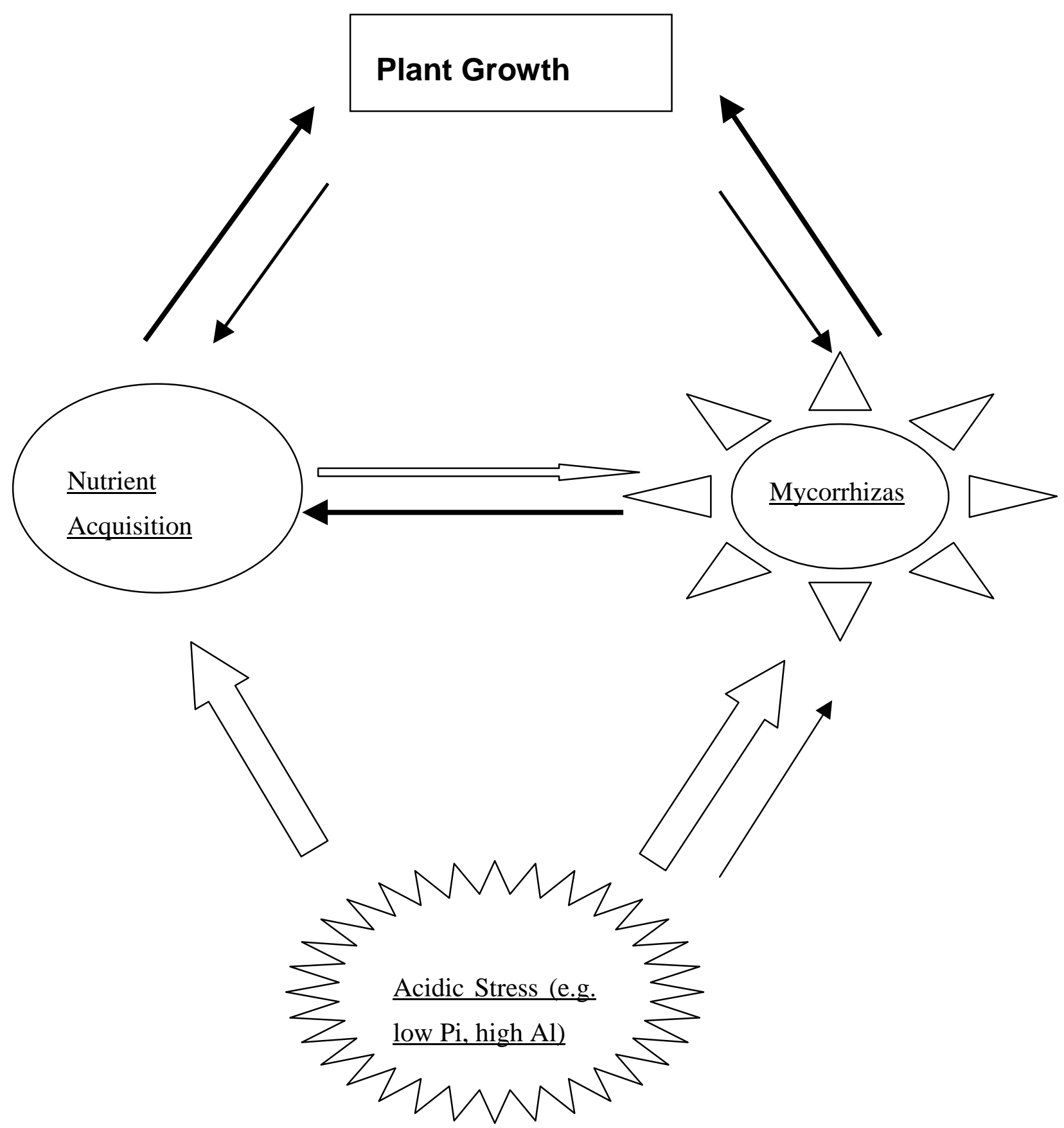


acquisition and metabolism of mineral nutrients, in turn stimulating plant growth on acidic soils. Additionally, AM fungi may directly alter the physiology and biochemistry of host plants. For example, AM fungal colonization changed hydraulic conductance (Allen et al. 1981), photosynthesis and respiration (Allen et al. 1981; Eissenstat et al. 1993; Peng et al. 1993; Aguilera-Gomez et al. 1998), hormone production (Allen et al. 1980; McArthur and Knowles 1992), root protein production (Gianinazzi-Pearson et al. 1991; McArthur and Knowles 1993; Bago et al. 1997; Benabdellah et al. 1999), and gene transcription and expression in host plants (Harrison 1999). These alternations undoubtedly affect plant performance. Improved plant growth further stimulates nutrient acquisition and metabolism, and produces more carbohydrates that are available for AM fungi to utilize, leading to increased AM fungal activities (Figure 0.4).

\section{OBJECTIVES}

During the initiation of this project, I was surprised by the consistent occurrence of broomsedge (Andropogon virginicus L.) on most of the abandoned coal mining sites in the area. This plant species is also found under other adverse edaphic habitats (Chapman and Jones 1975; Gibson and Risser 1982; Campbell 1983; Nellessen and Ungar 1993). What makes this plant species have such a distribution pattern? After analysis of the soil and the roots from an abandoned coal mining site in Field Crest, Morgantown, WV, I found that the soil is very acidic, $\mathrm{pH}$ from 3.0 to 3.3, and contains very low Melich-extractable Pi (3.76 $\mathrm{mg} \mathrm{kg}^{-1}$ ) and high $\mathrm{Al}$ (363.12 $\mathrm{mg} \mathrm{kg}^{-1}$ ). The plant roots were heavily colonized by AM fungi. A bioassay using wheat (Triticum aestivum L.) demonstrated that these soils are very poor (Figure 0.5). Therefore, the questions arose: do the AM fungi aid the plants by allowing them to overcome the Pi limitation and Al toxicity under these conditions? How would this be achieved?

In this project, I used broomsedge plants and AM fungi isolated from the Field Crest coal-mining site near Morgantown, WV. The primary fungal species was Glomus clarum Nicolson and Schenck. Also I used some fungal propagules of the same fungal species from the INVAM collection, which originated from a coal mining site in Mingo County, WV, where the soil contains $\mathrm{NaHCO}_{3}$-extractable $\mathrm{Pi}$ of $19 \mathrm{mg} \mathrm{kg}^{-1}$ with $\mathrm{pH}$ of 6.6 , as a contrast in the last two experiments. This study has four main goals: 
Figure 0.5. Bioassay of abandoned coal-mining soils from Field Crest in Morgantown, WV, using wheat (Triticum aestivum L.).

The bioassay was conducted in the greenhouse of Biology Department, West Virginia. Pots were filled with the mining soil (SM), neighbor outcrop soil (SH), and potting soil (RF), and 10 seeds of each of two wheat cultivars, one is Al-resistant and another is Al-sensitive, were sown in each of the pots. After a month, these wheat plants were harvested, and their dry weight from each pot was determined after being dried in an oven at $62^{\circ} \mathrm{C}$ overnight. $P$ values for each treatment are: soil $<0.001$, genotype $=0.0429$, and soil $\mathrm{x}$ genotype interaction $=0.595$. 


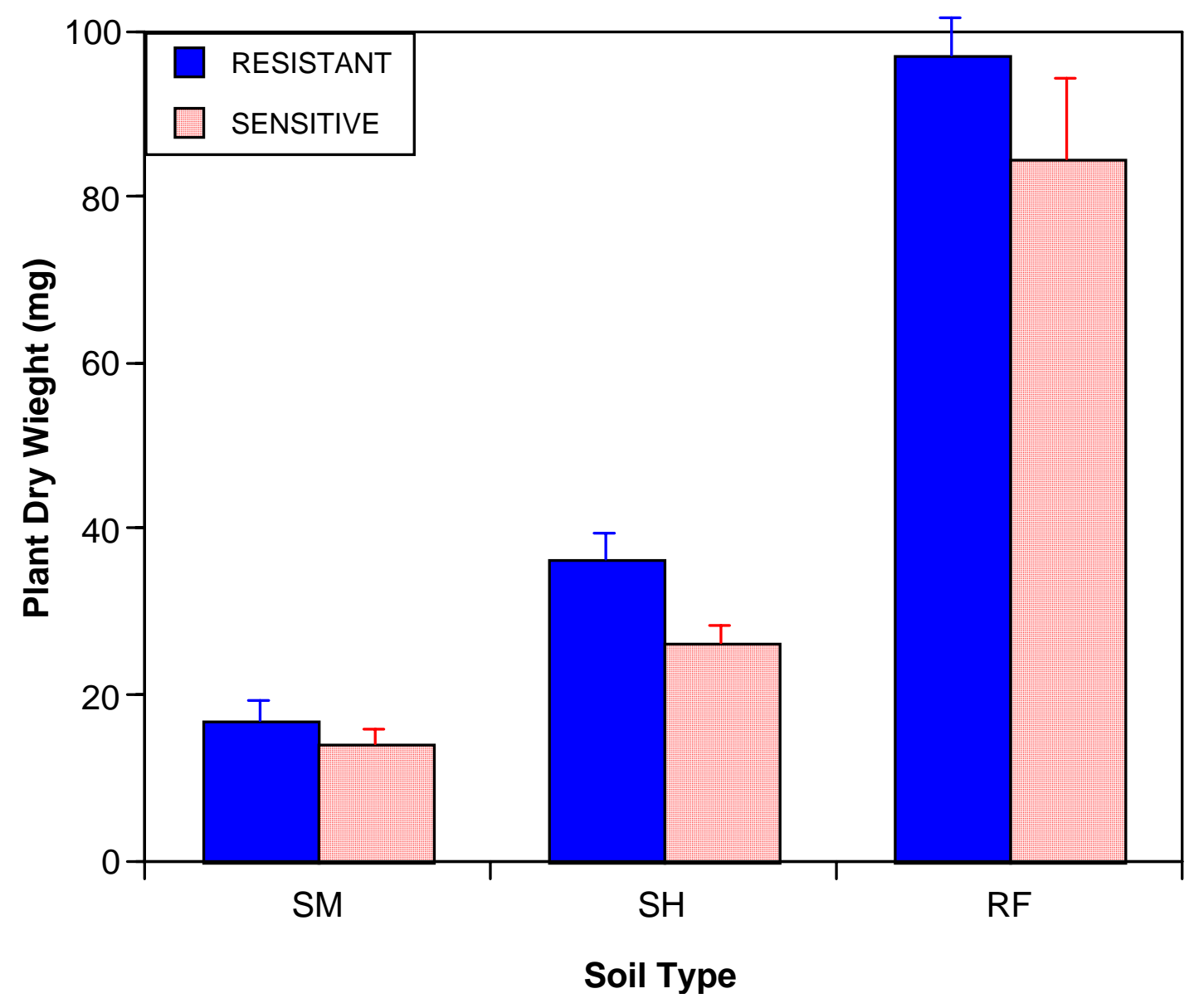


(1) Determine the roles of mycorrhizas under a range of Pi regimes, from low to high availability;

(2) Investigate if mycorrhizas confer $\mathrm{Al}$ resistance in plants exposed to elevated $\mathrm{Al}$;

(3) Investigate whether different fungal isolates differentially affect the performance of plants exposed to $\mathrm{Al}$;

(4) Examine what physiological changes would be brought about in the plants by AM fungal colonization under different $\mathrm{Pi}$ and $\mathrm{Al}$ treatments, and if there are differencesof physiology between these two types of mycorrhizal plants exposed to different applications of Pi and Al.

In order to address these goals, a series of experiments were designed and conducted in the growth chambers:

(i) Phosphorus Study. This study included two experiments. The first was a plant growth response experiment with pre-colonized broomsedge plants by the native AM fungi in a growth chamber with a completely randomized block factorial design. Plant growth and nutrition status were analyzed to address differential responses of mycorrhizal and non-mycorrhizal plants in growth and nutrition to varying Pi levels; The second experiment was a Pi depletion experiment with the same growth conditions as in the above experiment to determine enzymatic kinetic parameters of Pi uptake system in the plants.

(ii) First Aluminum Study. This study used pre-colonized broomsedge plants by the native AM fungi, including two experiments. The first was a multiple harvest dose response experiment with a 2 x 5 factorial design. Three harvests were conducted in the week 4, 6, and 8, respectively. Rhizosphere $\mathrm{pH}$ and $\mathrm{Al}$ concentrations were monitored over the experimental period, and plant growth, root acid phosphatase activity, and tissue $\mathrm{Al}$ concentrations were analyzed at each harvest, to investigate the interactions between mycorrhizal and $\mathrm{Al}$ treatment along the development of broomsedge plants; The second experiment was an extended dose response experiment with a $2 \times 4$ factorial design. Plant growth, tissue Al concentration, and nutrition were determined at the final harvest to examine the roles of mycorrhizas in $\mathrm{Al}$ resistance of broomsedge plants.

(iii)Second Aluminum Study. This study used pre-colonized broomsedge plants separately by each of the two isolates of Glomus clarum from the two mining sites 
using a 3 x 4 factorial design. Rhizosphere organic acids were extracted at the final harvest time and analyzed with Dionex. Plant growth, tissue Al concentration, and nutrition status were also determined at the final harvest. This study was to address the differential effects of the two AM fungal isolates on the exudation of organic acids, plant growth, and nutrition, and the roles of organic acids in Al resistance of mycorrhizal and non-mycorrhizal broomsedge plants.

(iv)Physiology Study. This study used pre-colonized broomsedge plants separately by each of the two isolates of Glomus clarum from the two mining sites using a 3 x 2 × 2 factorial design. Leaf photosynthetic rate, leaf respiratory rate, chlorophyll concentration, nitrogen concentration, root acid phosphatase activity, and root protein production, and also plant growth and tissue $\mathrm{Al}$ and macronutrient concentrations were determined to examine interactive effects of $\mathrm{Pi}$ and $\mathrm{Al}$ on physiology and growth of mycorrhizal and non-mycorrhizal plants. 


\section{CHAPTER I}

\section{Effects of Mycorrhizal Fungal Colonization on Responses of Broomsedge Plant to Varying Pi Availability}

\section{Introduction}

The benefits accrued to plants by their mycorrhizal symbionts are often ascribed to enhanced phosphorus (Pi) nutrition (Smith and Read 1997). Increased phosphorus acquisition by plants as a result of arbuscular mycorrhizal (AM) fungal colonization may result from: (1) the exploration of a larger soil volume by extraradical hyphae; (2) a greater movement of Pi into mycorrhizal fungal hyphae due to high efficiency of $\mathrm{Pi}$ absorption systems, more effective competition for Pi with soil microorganisms, and formation of polyphosphate inside hyphae; and (3) the solubilization of poorly available phosphorus sources by modification of the rhizosphere (Hayman 1983; Bolan 1991; Smith and Read 1997). However, AM fungal enhancement of plant growth may not be fully explained by the facilitation of Pi acquisition by AM fungi (Ross 1971; Plenchette et al. 1983; Pacovsky et al. 1986). Mycorrhizal fungi also enhance the uptake of other nutrient elements, including copper (Cu) and zinc (Zn) (Ross 1971; Pacovcky 1986; Leake and Read 1989). Thus, fostering nutrient balance in the host plant may be more critical than the acquisition of any one nutrient element.

The regulation of nutrient uptake in roots leads to the internal nutrient balance of the plant (Clarkson 1985; Marschner 1995; references therein). This balance in nutrient acquisition by the plant under edaphic stress, as modulated by mycorrhizal fungi, may be critical to its growth and survival. For example, the amelioration of Al toxicity by mycorrhizal fungi in Liriodendron tulipifera is associated not only with the maintenance of $\mathrm{P}$ acquisition, but also with higher and more stable concentrations of $\mathrm{Ca}, \mathrm{Cu}$, and $\mathrm{Zn}$ in the roots or shoots (Lux and Cumming 1999). Similarly, Cumming and Weinstein (1990) found that Pi limitation led to the loss of Na exclusion from shoots of non-mycorrhizal Pinus rigida seedlings, whereas this effect was not noted in seedlings colonized by the ectomycorrhizal fungus Pisolithus tinctorius. In addition, both AM and ectomycorrhizal fungi may suppress the uptake of other elements, such as 
$\mathrm{Al}, \mathrm{Fe}$, and Mn, that may be present at toxic levels in some soils (Pacovsky 1986; Cumming and Weinstein 1990; Kothari et al. 1991). Thus, mycorrhizal fungi play a role in whole-plant nutrient balance by aiding in the uptake of limiting nutrients, maintaining nutrient uptake, or both under edaphic stress.

Broomsedge (Andropogon virginicus L.) is a dominant bunch-grass found colonizing extreme edaphic environments in the eastern United States (Chapman and Jones 1975; Gibson and Risser 1982; Campbell 1982, 1983, Morton 1986; Nellessen and Ungar 1993). Improvement of soil conditions, such as through the application of nitrogen fertilizers, can exclude this species from a plant community. Preliminary studies demonstrated that broomsedge is a highly mycotrophic species (Ning, unpublished data). These patterns suggest that broomsedge is adapted to infertile habitats and may rely on AM fungi to maintain nutrient balance under both nutrient-limiting and stressful edaphic conditions.

The goals of this study were to assess the capacity of broomsedge to grow under varying solution Pi levels and to investigate the role AM fungi play in aiding growth and nutrient acquisition of this plant species. I hypothesize that broomsedge plants rely on AM fungi to overcome the Pi limitation through changes in $\mathrm{Pi}$ acquisition and/or utilization. Further, this enhancement of Pi acquisition would enable broomsedge plants to maintain a more balanced accumulation of other nutrients under variable Pi environments.

\section{Materials and Methods}

\section{Source of AM Fungal Inoculum}

AM fungal inoculum was generated from broomsedge plants collected from the Field Crest abandoned coal mine in Morgantown, West Virginia, USA. Although the site has been abandoned for about 50 years, much surface soil remains devoid of vegetation. The vegetated surface consists of a broomsedge sward surrounding stunted red maple (Acer rubrum) and bigtoothed aspen (Populus grandidentata) trees. Soil pH ranged from 3.0 to 3.3 and extractable Pi by Melich III was $3.76 \pm 0.54 \mathrm{mg} \mathrm{kg}^{-1}$.

To produce the inoculum of AM fungi, broomsedge plants with intact mycorrhizal roots and adhering soil from the mine site were transplanted into $15 \mathrm{~cm}$ diameter pots containing a 
mixture of autoclaved mine-soil and sand (1:3 v/v). After a month, the pot contents became the source of infective inoculum for the experiment.

Preparation of Plants

Broomsedge seeds were sown around the transplants in nursery pots (15 cm diameter). Broomsedge seeds also were sown in pots containing sterile-germinated sudan-grass and the mixture of autoclaved mine-soil and sand (1:3 v/v) with the bacteria extracted from the minesoil. Seedlings from these pots served as non-mycorrhizal controls. After four weeks growth, roots of a small subset of seedlings ( $c a$. 10) were examined to determine mycorrhizal status. Tissue P status was analyzed after wet digestion (Parkinson and Allen 1975) by the molybdate blue method (Olsen and Sommers 1982). Tissue phosphorus concentrations and tissue dry weights between mycorrhizal and non-mycorrhizal plants did not differ significantly.

Nutrient Solution and Growth Conditions

Mycorrhizal and non-mycorrhizal broomsedge seedlings were transplanted and grown in D16 Deepots (5 cm diameter x $18 \mathrm{~cm}$ height) (Stuewe and Sons, Inc., Corvallis, Oregon, USA) pre-filled with $220 \mathrm{~cm}^{3}$ of a 3:1 (v/v) mixture of coarse:fine acid-washed sand. Deepots were placed into a growth chamber with 14 hours of light at $28^{\circ} \mathrm{C}, 60 \% \mathrm{RH}$, and 10 hours of darkness at $21^{\circ} \mathrm{C}, 50 \% \mathrm{RH}$. Average light intensity at pot height in the chamber was $260 \mu \mathrm{mol} \mathrm{m} \mathrm{s}^{-1}$ from mixed fluorescent and incandescent sources. Plants received a baseline nutrient solution containing $\mathrm{Ca}(0.675 \mathrm{mM}), \mathrm{K}(0.79 \mathrm{mM}), \mathrm{Mg}(0.25 \mathrm{mM}), \mathrm{NO}_{3}(1.5 \mathrm{mM}), \mathrm{NH}_{4}(0.5 \mathrm{mM}), \mathrm{SO}_{4}$ (0.25 mM), B (23.14 $\mu \mathrm{M}), \mathrm{Fe}(25 \mu \mathrm{M}), \mathrm{Mn}(4.57 \mu \mathrm{M}), \mathrm{Zn}(0.38 \mu \mathrm{M}), \mathrm{Cu}(0.16 \mu \mathrm{M})$, and Mo $(0.06 \mu \mathrm{M})$. Pi as the treatment was added separately. All solutions were adjusted to $\mathrm{pH} 4.0$ before application. Solutions (approximately $15 \mathrm{ml}$ ) were automatically delivered to the plants three times each day for eight weeks.

\section{Growth Response Experiment}

Treatments consisted of five Pi concentrations (10, 20, 40, 60, and $100 \mu \mathrm{M}$ as $\left.\mathrm{NaH}_{2} \mathrm{PO}_{4}\right)$, which were delivered in the nutrient solutions outlined above. After eight weeks, sand was removed from roots under running de-ionized water, and shoots were rinsed in distilled water. Roots were excised, and shoots and roots were dried at $62^{\circ} \mathrm{C}$ and weighed. Percentage mycorrhizal colonization of roots was assessed on a $5 \%$ root sub-sample by the gridline intersect 
method (Giovannetti and Mosse 1980). Roots and shoots from the same block were pooled, ground, and digested (Parkinson and Allen 1975). Phosphorus concentrations of digest solutions were determined spectrophotometrically (Olsen and Sommers 1982). All other mineral elements (Fe, Mn, Mg, Ca, Zn, Cu, Na, and K) of the digests were analyzed by ICP (Leeman PS 950) by the National Research Center for Coal and Energy Analytical Laboratory at West Virginia University.

Pi Depletion Experiment

Plants were grown for eight weeks as noted above and treated with 20, 40, 60, and 100 $\mu \mathrm{M} \mathrm{Pi}$ as $\mathrm{NaH}_{2} \mathrm{PO}_{4}$ in the base solution. Plants were removed from sand, roots were gently washed in running distilled water, and plants were transferred into $200 \mathrm{ml}$ glass tubes containing the appropriate treatment solution. Solutions were aerated and changed every 12 hours for 48 hours. Following the last solution change, each tube was sampled at 5, 10, 15, 30, 60, 90, 120, 150, 180, 240, 300, and 360 minutes. Phosphate concentrations of these samples were determined by the molybdate blue method (Olsen and Sommers, 1982) when Pi concentration was higher than $5 \mu \mathrm{M}$ and the malachite green method (Motomizu et al. 1983) when Pi concentration was lower than $5 \mu \mathrm{M}$. Roots and shoots were dried and weighed.

Experiment Design and Data Analysis

Within the growth chamber, treatments were arranged in a randomized complete block factorial (Pi-by-mycorrhizal fungal treatment) design, with three blocks accounting for environmental variation within the chamber. Each treatment had 3 or 4 replicates within a block.

Phosphorus use efficiency (PUE) (Chapin 1980; Baon et al. 1993) was calculated as:

\section{(plant dry weight) / (plant P amount).}

For the $\mathrm{Pi}$ depletion experiment, the $\mathrm{Pi}$ instantaneous uptake rate and the minimum solution Pi concentration $\left(\mathbf{C}_{\min }\right)$ at which net Pi influx is zero for each treatment were determined by fitting a $2^{\text {nd }}$-order polynomial equation $\left(\mathbf{Y}=\mathbf{a} \mathbf{X}^{2}+\mathbf{b X}+\mathbf{c}\right)$ to the experimental data (Claassen and Barber 1974), where $\mathbf{Y}$ is Pi concentrations in solutions and $\mathbf{X}$ is time (minute).

Taking the derivative yields: 


$$
\mathbf{Y}^{\prime}=\mathbf{2} \mathbf{a X}+\mathbf{b}
$$

where $\mathbf{Y}^{\prime}$ is the change in solution Pi concentrations with the time $\mathbf{X}$.

According to the derivative, the $\mathrm{Pi}$ instantaneous uptake rate at the time $\mathbf{X}=\mathbf{0}$ is equal to the coefficient $\mathbf{b}$.

To find $\mathbf{C}_{\min }$, firstly, solve the above derivative equation to obtain the time at when the $\mathbf{C}_{\min }$ is reached, then the value of time was placed back into the $2^{\text {nd }}$-order polynomial equation, after re-arranging, the following equation was derived:

$$
C_{\min }=c-\left(b^{2} /(4 a)\right)
$$

Data were analyzed by analysis of covariance with solution Pi concentration treated as a covariate and regression analysis using the statistical package JMP (SAS Institute, Cary, North Carolina, USA).

\section{Results}

Mean percentage mycorrhizal colonization in broomsedge plants was about $70 \%$ across the treatments (data not presented). Phosphate treatment had no significant effect on percentage colonization. None of the non-mycorrhizal plants were contaminated by the mycorrhizal fungi. Mycorrhizal and non-mycorrhizal plants differed significantly in their patterns of growth in response to Pi availability (Figure 1.1). Mycorrhizal fungal colonization significantly enhanced plant growth at $40 \mu \mathrm{M}$ Pi and below, where non-mycorrhizal plants exhibited extremely limited growth. At $60 \mu \mathrm{M}$ Pi, Pi-deficiency symptoms, such as purple leaf margins, in non-mycorrhizal plants disappeared, but the pronounced difference in growth still remained between mycorrhizal 
Figure 1.1. Influence of Pi treatments on shoot (circle) and root (triangle) dry weights (A), and cumulative height (circle) and number of tillers (triangle) (B) of mycorrhizal (solid) and nonmycorrhizal (open) broomsedge (A. virginicus) plants.

$P$ values from ANCOVA:

A. Shoot dry weight:

Myc: $<0.001, \mathrm{Pi}:<0.001$, and $\mathrm{Myc} * \mathrm{Pi}:<0.001$;

Root dry weight:

Myc: < 0.001, Pi: < 0.001, and Myc* Pi: $<0.001$.

B. Cumulative height:

Myc: < 0.001, Pi: < 0.001, and Myc * Pi: <0.001;

Number of tillers:

Myc: < 0.001, Pi: < 0.001, and Myc* Pi: 0.020. 

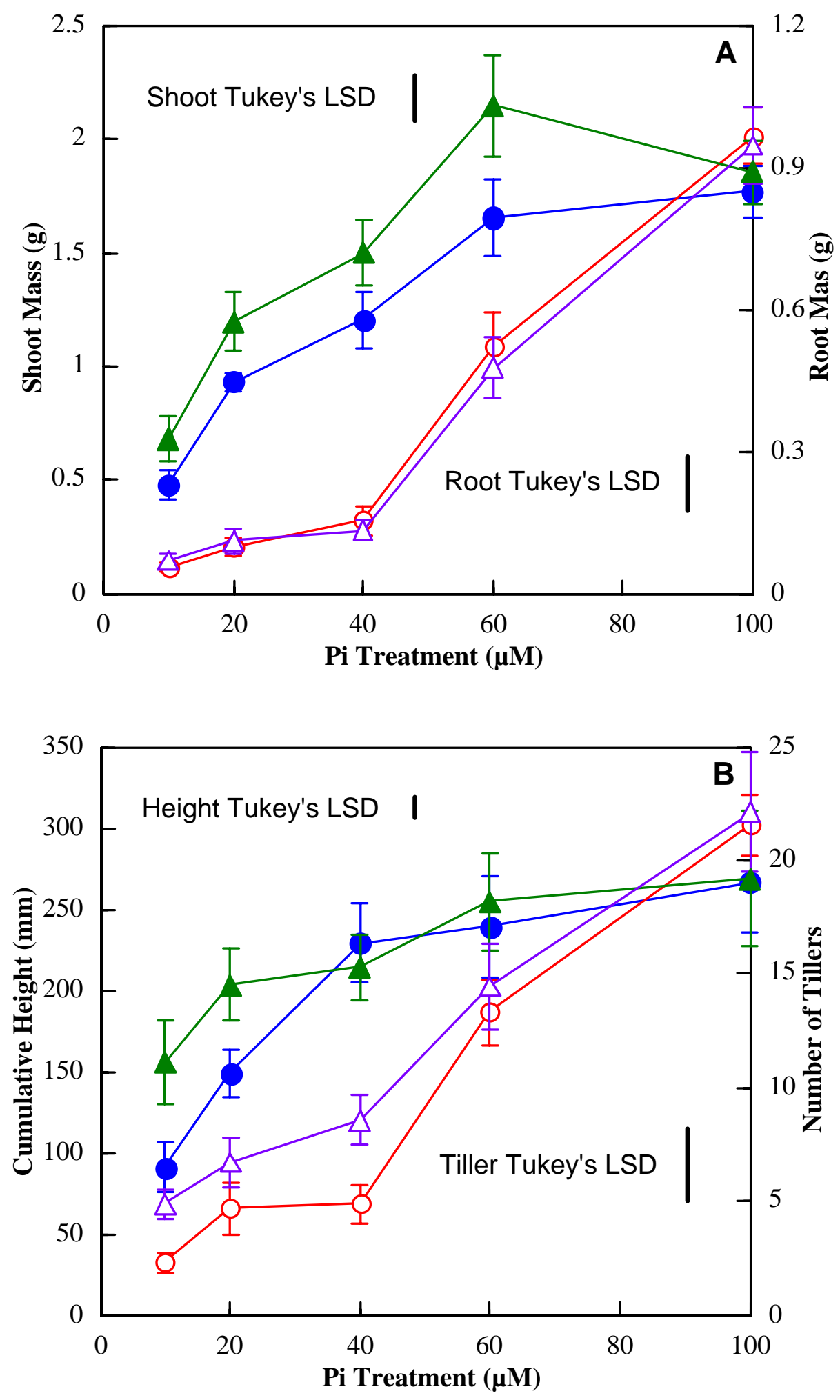
Table 1.1. Shoot and root $P$ concentrations and $P$ transfer percentage to shoot in mycorrhizal and non-mycorrhizal broomsedge (A. virginicus) plants as influenced by Pi treatment.

\begin{tabular}{|c|c|c|c|c|}
\hline $\begin{array}{c}\mathbf{P i} \\
\text { Treatment } \\
(\mu \mathrm{M})\end{array}$ & Мyc & $\begin{array}{c}\text { Shoot } \mathbf{P} \\
\text { Concentration } \\
\left(\mathrm{mg} \mathrm{g}^{-1}\right)\end{array}$ & $\begin{array}{c}\text { Root } \mathbf{P} \\
\text { Concentration } \\
\left(\mathrm{mg} \mathrm{g}^{-1}\right)\end{array}$ & $\begin{array}{c}\text { P Transfer } \\
(\%)\end{array}$ \\
\hline \multirow[t]{2}{*}{10} & + & $0.872(0.083)$ & $0.444(0.011)$ & $73.79(0.068)$ \\
\hline & - & $1.303(0.204)$ & $0.541(0.095)$ & $79.32(2.328)$ \\
\hline \multirow[t]{2}{*}{20} & + & $0.694(0.016)$ & $0.506(0.095)$ & $69.57(4.013)$ \\
\hline & - & $1.112(0.137)$ & $0.663(0.061)$ & 75.59 (3.820) \\
\hline \multirow[t]{2}{*}{40} & + & $1.054(0.245)$ & $0.604(0.104)$ & 75.76 (1.949) \\
\hline & - & $1.840(0.306)$ & $0.925(0.050)$ & 79.29 (1.285) \\
\hline \multirow[t]{2}{*}{60} & + & $1.296(0.205)$ & $0.704(0.110)$ & 74.97 (4.110) \\
\hline & - & $1.368(0.203)$ & $0.811(0.110)$ & 79.24 (1.323) \\
\hline \multirow[t]{2}{*}{100} & + & $2.155(0.281)$ & $1.081(0.074)$ & 79.67 (2.409) \\
\hline & - & $1.760(0.291)$ & $0.889(0.185)$ & 76.18 (2.994) \\
\hline \multirow[t]{2}{*}{$P$ values } & Myc & 0.007 & 0.019 & 0.013 \\
\hline & $\begin{array}{l}\mathbf{P i} \\
\mathbf{M v c} * \mathbf{P i}\end{array}$ & $\begin{array}{l}<0.001 \\
0.028\end{array}$ & $\begin{array}{l}<0.001 \\
0.092\end{array}$ & $\begin{array}{l}0.168 \\
0.060\end{array}$ \\
\hline
\end{tabular}


Figure 1.2. Influence of Pi treatment on $P$ use efficiency (PUE) of mycorrhizal (solid) and nonmycorrhizal (open) broomsedge (A. virginicus) plants.

Slopes and $P$ values from the regression:

Mycorrhizal:

Slope: -0.012 , and $P$ value: $<0.001$;

Non-mycorrhizal:

Slope: -0.004 , and $P$ value: 0.046 . 


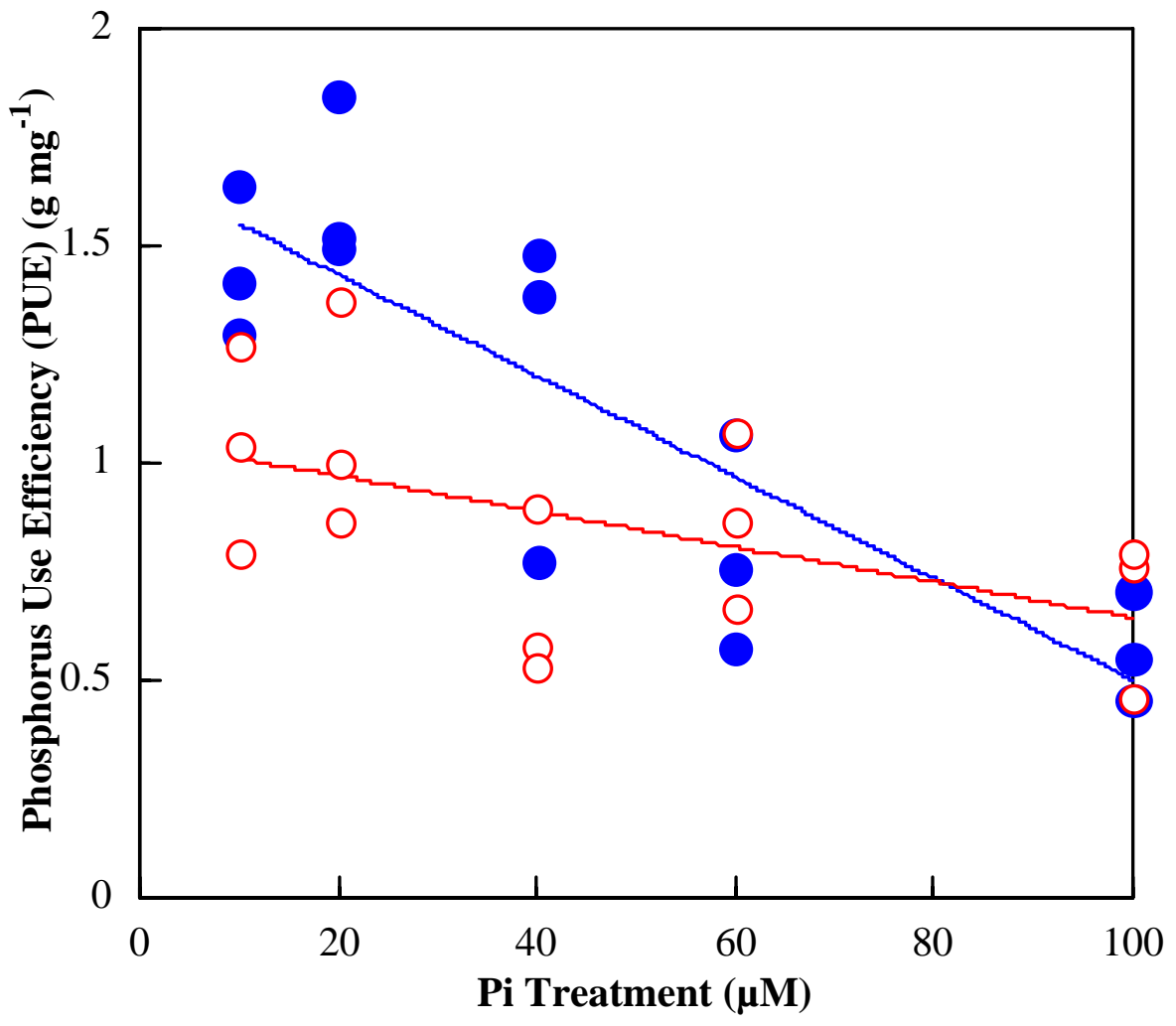


Table 1.2. $P$ values from ANCOVA for nutrient concentrations of shoots and roots in broomsedge (A. virginicus) plants as influenced by mycorrhizal (Myc) and Pi treatments.

\begin{tabular}{|c|c|c|c|c|c|c|}
\hline \multirow{2}{*}{ Element } & \multicolumn{3}{|c|}{ Shoot } & \multicolumn{3}{|c|}{ Root } \\
\hline & Мyc & $\mathbf{P i}$ & Мyc * Pi & Мyc & $\mathbf{P i}$ & Мyc $*$ Pi \\
\hline $\mathbf{K}$ & $<0.001$ & 0.015 & 0.006 & ns & ns & ns \\
\hline $\mathbf{C a}$ & $\mathrm{ns}^{\dagger}$ & $<0.001$ & ns & 0.020 & $<0.001$ & ns \\
\hline Mg & 0.028 & 0.002 & ns & $<0.001$ & 0.003 & 0.003 \\
\hline $\mathbf{F e}$ & 0.007 & $<0.001$ & 0.026 & ns & ns & ns \\
\hline Mn & $<0.001$ & 0.001 & 0.001 & $<0.001$ & $<0.001$ & $<0.001$ \\
\hline $\mathrm{Cu}$ & $<0.001$ & 0.040 & ns & $<0.001$ & $<0.001$ & ns \\
\hline $\mathbf{N a}$ & $<0.001$ & $<0.001$ & 0.002 & ns & ns & ns \\
\hline
\end{tabular}

${ }^{\dagger} \alpha=0.05$, the same hereafter. 
Figure 1.3. Influence of $\mathrm{Pi}$ treatment on shoot $\mathrm{K}(\mathbf{A}), \mathrm{Fe}(\mathbf{B}), \mathrm{Mn}(\mathbf{C})$, and $\mathrm{Na}$ (D) concentrations, and root $\mathrm{Mg}(\mathbf{E})$ and $\mathrm{Mn}(\mathbf{F})$ concentrations of mycorrhizal (solid) and nonmycorrhizal (open) broomsedge (A. virginicus) plants.

Slopes and $P$ values from the regression:

A. Shoot K:

Mycorrhizal:

Slope: 0.02 , and $P$ value: ns;

Non-mycorrhizal:

Slope: 0.473 , and $P$ value: 0.007 .

B. Shoot Fe:

Mycorrhizal:

Slope: -0.271 , and $P$ value: $<0.001$;

Non-mycorrhizal:

Slopes: - 1.446 (linear) and 0.009 (quadratic), and $P$ value: 0.004 (linear) and 0.033 (quadratic).

C. Shoot Mn:

Mycorrhizal:

Slope: -0.271 , and $P$ value: $<0.001$;

Non-mycorrhizal:

Slope: -1.689 , and $P$ value: 0.002 .

D. Shoot Na:

Mycorrhizal:

Slope: -0.332 , and $P$ value: ns;

Non-mycorrhizal:

Slope: -13.884 (linear) and 0.090 (quadratic), and $P$ value: 0.003 (linear) and 0.021 (quadratic).

E. Root Mg:

Mycorrhizal:

Slope: 0.007 , and $P$ value: $<0.001$;

Non-mycorrhizal:

Slope: $>-0.001$, and $P$ value: ns.

F. Root Mn:

Mycorrhizal:

Slope: -0.267 , and $P$ value: ns;

Non-mycorrhizal:

Slope: -2.118 , and $P$ value: $<0.001$. 

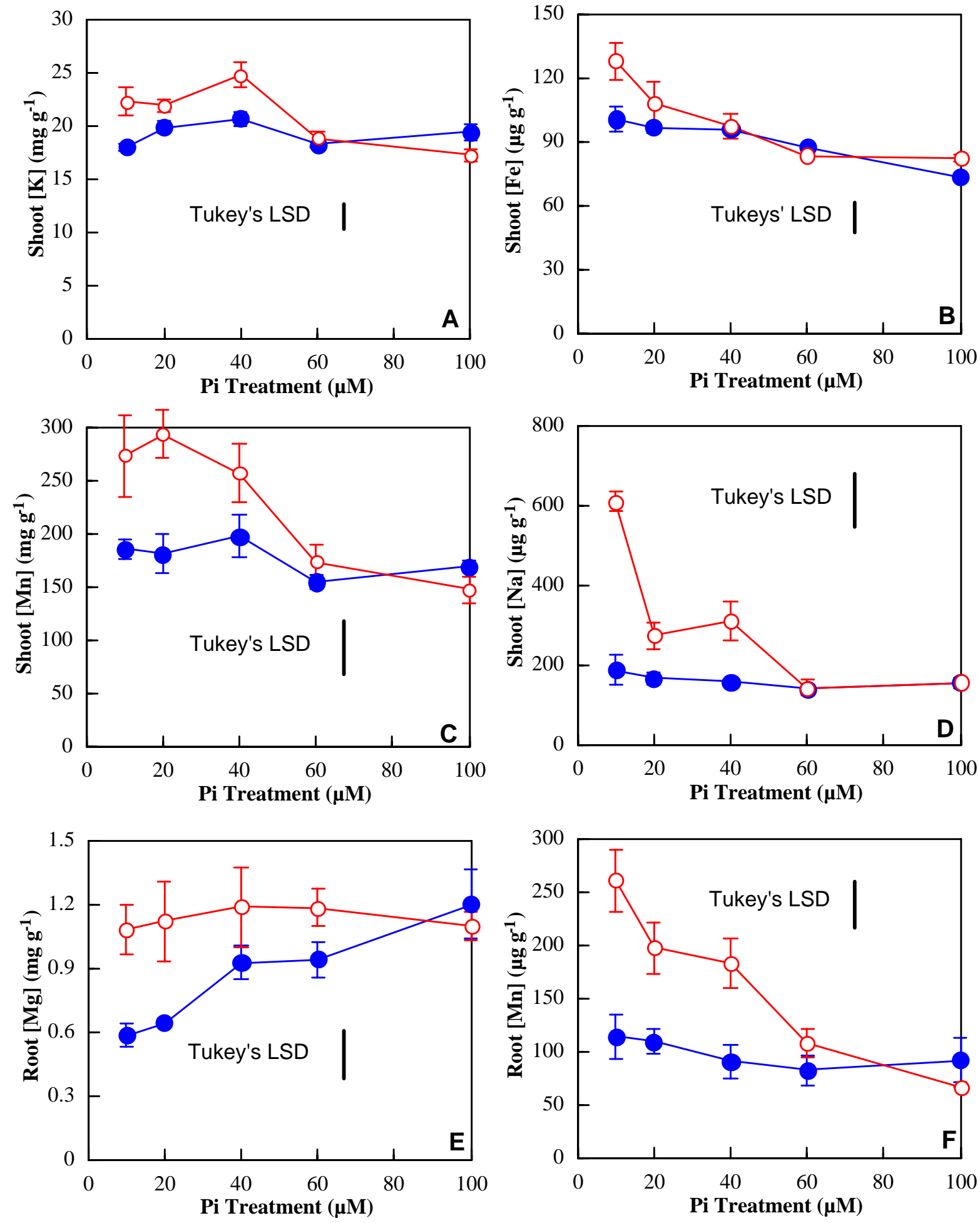
and non-mycorrhizal plants. At $100 \mu \mathrm{M}$ Pi, all growth traits (shoot and root mass, cumulative height, and number of tillers) were similar between mycorrhizal and non-mycorrhizal plants. Mycorrhizal plants allocated more biomass to roots at all Pi concentrations except $100 \mu \mathrm{M}$ (Figure 1.1).

Differential effects of mycorrhizal fungal colonization as a function of Pi concentrations were observed for shoot $\mathrm{P}$ concentrations (Table 1.1). At low Pi availability, shoot $\mathrm{P}$ concentrations of mycorrhizal plants were actually less than those of non-mycorrhizal plants. For root $\mathrm{P}$ concentration (Table 1.1), however, mycorrhizal and non-mycorrhizal plants had similar response patterns to Pi treatment, and non-mycorrhizal plants had significantly higher root $\mathrm{P}$ concentrations than mycorrhizal plants. Furthermore, mycorrhizal plants retained more $\mathrm{P}$ in roots than non-mycorrhizal plants (Table 1.1), reflecting a change in $\mathrm{P}$ allocation resulting from mycorrhizal fungal colonization.

Phosphorus use efficiencies (PUE) of mycorrhizal and non-mycorrhizal broomsedge plants depended on Pi availability (Figure 1.2) (ANCOVA: Myc, $P<0.001$; Pi, $P<0.001$; and Myc*Pi, $P=0.006)$. Phosphorus use efficiency in mycorrhizal plants was higher than nonmycorrhizal plants at the low Pi treatments, but mycorrhizal and non-mycorrhizal plants had similar PUE at the high Pi treatment (Figure 1.2).

The different patterns of growth, shoot P concentrations, and PUE between mycorrhizal and nonmycorrhizal plants suggested that mycorrhizal fungal colonization may have altered some nutrient relationship other than P. Mycorrhizal plants contained significantly higher shoot concentrations of $\mathrm{Mg}$ (Myc: $2.164 \mathrm{mg} \mathrm{g}^{-1}$ and non-myc: $1.838 \mathrm{mg} \mathrm{g}^{-1}$ ) and $\mathrm{Cu}$ (Myc: $14.0 \mu \mathrm{g} \mathrm{g}^{-1}$ and non-myc: $9.1 \mu \mathrm{g} \mathrm{g}^{-1}$ ) and root concentrations of $\mathrm{Ca}$ (Myc: $2.608 \mathrm{mg} \mathrm{g}^{-1}$ and non-myc: 2.025 $\mathrm{mg}^{-1}$ ) and $\mathrm{Cu}$ (Myc: $22.7 \mu \mathrm{g} \mathrm{g}^{-1}$ and non-myc: $9.1 \mu \mathrm{g} \mathrm{g}^{-1}$ ), but significantly lower shoot $\mathrm{Na}$ (Myc: $0.161 \mathrm{mg} \mathrm{g}^{-1}$ and non-myc: $0.299 \mathrm{mg} \mathrm{g}^{-1}$ ) concentration than non-mycorrhizal plants (Table 1.2). The mycorrhizal and $\mathrm{Pi}$ treatments interacted in influencing shoot $\mathrm{K}, \mathrm{Fe}, \mathrm{Mn}$, and $\mathrm{Na}$ concentrations and root $\mathrm{Mg}$ and $\mathrm{Mn}$ concentrations (Figure 1.3). Consistently, the response of nutrients to the Pi treatments were less in mycorrhizal plants than in non-mycorrhizal plants, reflecting greater stability in shoot and root nutrient relations of mycorrhizal plants, such as shoot K, Fe, Mn, and Na concentrations, and root Mn concentrations (Figure 1.3).

In addition to measuring plant tissue $\mathrm{P}$ concentrations and within plant allocation, the $\mathrm{Pi}$ depletion technique was used to measure Pi uptake rates by root systems of mycorrhizal and non- 
Table 1.3. Pi instantaneous uptake rates and minimum solution Pi concentrations $\left(\mathrm{C}_{\text {min }}\right)$ for Pi influx in mycorrhizal and non-mycorrhizal broomsedge $(A$. virginicus) plants as influenced by Pi treatment.

\begin{tabular}{lccc}
\hline $\begin{array}{l}\text { Pi } \\
(\mu \mathrm{M})\end{array}$ & Myc & $\begin{array}{c}\text { Uptake Rate } \\
\left(\mu \mathrm{mol} \mathrm{g}^{-1} \mathrm{~min}^{-1}\right)\end{array}$ & $\begin{array}{c}\mathbf{C}_{\min } \\
(\mu \mathrm{mol} \mathrm{L})\end{array}$ \\
\hline $\mathbf{2 0}$ & + & 0.082 & 0.359 \\
& - & 0.158 & 5.018 \\
$\mathbf{4 0}$ & + & 0.074 & 1.670 \\
& - & 0.118 & 6.980 \\
$\mathbf{6 0}$ & + & 0.069 & 11.923 \\
& - & 0.121 & 22.532 \\
$\mathbf{1 0 0}$ & + & 0.076 & 50.085 \\
& - & 0.119 & 48.636 \\
LSD & & 0.030 & 5.491 \\
\hline $\boldsymbol{P}$ & Myc & 0.003 & 0.010 \\
Values & Pi & $\mathrm{ns}$ & $<0.001$ \\
& Myc x Pi & $\mathrm{ns}$ & $\mathrm{ns}$ \\
\hline
\end{tabular}

†Tukey’s least significant difference at 0.05 level with $n=10$. 
mycorrhizal broomsedge plants. Mycorrhizal plants had significantly lower Pi uptake rate than non-mycorrhizal counterparts under the same Pi level (Table 1.3). Pi uptake rates of mycorrhizal roots averaged $0.075 \mu \mathrm{mol} \mathrm{g}^{-1} \mathrm{~min}^{-1}$ and were independent of Pi treatment. In contrast, Pi uptake rates by non-mycorrhizal roots increased when Pi became severely limited (20 $\mu \mathrm{M} \mathrm{Pi)}$ (Table 1.3). In addition, the uptake data indicated a significant divergence in the minimum $\mathrm{Pi}$ concentration $\left(\mathrm{C}_{\min }\right)$ to which mycorrhizal and non-mycorrhizal plants could draw down Pi in the nutrient solution (Table 1.3). Mycorrhizal root systems drew Pi down to lower concentrations than non-mycorrhizal plants at 20,40, and $60 \mu \mathrm{M}$ Pi treatments.

\section{Discussion}

Arbuscular mycorrhizal fungi play important roles in enhancing host plant growth under adverse soil conditions (Daft and Nicolson 1974; Daft and Hacskaylo 1976; Lindsey et al. 1977; Allen and Allen 1980; Lambert and Cole 1980; Danielson 1985). The results of the present study are consistent with these previous reports. When Pi availability was low, mycorrhizal fungal colonization significantly increased number of tillers and their heights, consequently leading to greater biomass accumulation in mycorrhizal than non-mycorrhizal plants (Figure 1.1). When Pi was readily available, the AM mycorrhizal fungi no longer exerted a beneficial effect on host plant growth. Thus, the AM fungi may switch from mutualistic symbiosis under Pi-limited conditions to a mildly parasitic association when Pi is readily available (Johnson et al. 1997; Smith and Read 1997). In addition, mycorrhizal fungal colonization altered biomass allocation (Figure 1.1). More biomass was allocated to roots in mycorrhizal plants and nonmycorrhizal plants when Pi availability is low (Figure 1.1), which undoubtedly increases the acquisition of limited resources (Chapin 1980, 1991).

Differences in nutrient concentrations between mycorrhizal and non-mycorrhizal plants can be related to differences in acquisition, transport, and/or utilization within the plant (Marschner 1995). In non-mycorrhizal broomsedge shoots and roots, biomass production was modulated to maintain tissue $\mathrm{P}$ concentrations within narrow bounds (Table 1.1), which may reflect the general regulation of $P$ homeostasis observed in higher plants (Mimura 1995). In contrast, mycorrhizal plants had lower shoot $\mathrm{Pi}$ concentrations when $\mathrm{Pi}$ is limiting and accumulated $\mathrm{P}$ to high levels when $\mathrm{Pi}$ is readily available, which appears to indicate that the $\mathrm{P}$ homeostasis of the plants was altered by AM fungal colonization. 
Phosphorus translocation to the shoot of mycorrhizal plants was less than nonmycorrhizal plants under limited Pi availability, but increased as Pi levels increased (Table 1.1). This tendency of mycorrhizal plants to limit $\mathrm{P}$ translocation from roots under low Pi availability reflects an increased investment of a limiting resource $(\mathrm{Pi})$ into belowground biomass production (roots/hyphae) (Figure 1.1), which would serve to increase the acquisition of this limiting resource (Chapin 1980, 1991). When Pi was readily available, more P was transported to shoots, which leads to P luxury consumption (Chapin 1980) or Pi storage that would be used in the future to support long-term growth (Aerts and Chapin 2000). In support of this observation, the change observed in PUE as available Pi changed and the differences in this response between mycorrhizal and non-mycorrhizal plants suggest that mycorrhizal fungal colonization alters within-plant Pi utilization to overcome Pi limitation under low Pi availability and to support sustainable growth under variable Pi environments (Chapin 1980; Aerts and Chapin 2000).

The rates of Pi uptake measured by the Pi depletion technique in the present study reflect the difference in the overall $\mathrm{P}$ status and $\mathrm{P}$ demand of the mycorrhizal versus non-mycorrhizal plants. The Pi uptake rates were less in mycorrhizal than non-mycorrhizal plants for any given $\mathrm{Pi}$ treatment. Since Pi uptake rates increase in plants under Pi limitation (Clarkson and Scattergood 1982; Clarkson and Luttge 1991), it would appear that mycorrhizal broomsedge plants were under less Pi limitation than their non-mycorrhizal counterparts. In the sand culture system, mycorrhizal plants dominated the root zone to a greater extent than non-mycorrhizal plants. Greater root biomass and associated mycorrhizal hyphae would more effectively exploit the pool of $\mathrm{Pi}$ available in the root zone. In addition, mycorrhizal plants could draw down solution Pi concentrations to lower levels (Table 1.3), further increasing the total Pi pool exploited and increasing the diffusive gradients to mycorrhizal plant roots. Thus, mycorrhizal plants, with higher PUE (Figure 2), greater belowground exploitation (Figure 1.1), and lower $\mathrm{C}_{\min }$ (Table 1.3), more effectively acquired Pi and were under less Pi stress at the lower Pi treatments. As a consequence, mycorrhizal broomsedge plants, overall, did not exhibit any increase in root Pi uptake rates (Table 1.3). These findings are contrary to those of Cress et al. (1979), where mycorrhizal tomato plants were shown to have greater Pi uptake rates. However, taken together with the patterns of growth and $\mathrm{P}$ utilization within broomsedge plants, our findings suggest that mycorrhizal plants adapt to Pi limitation not by increasing the amount of Pi transport systems, but primarily by allocating more effort to root zone exploitation, which is consistent with model 
predictions (Clarkson 1985). This allocation change would be, in the long term, an effective mechanism of overcoming Pi limitation (Chapin 1980, Lambers et al. 1998).

Other nutrient responses suggest that AM fungi effectively improve the nutrient status of the host plants (Table 1.2, Figure 1.3). Copper concentrations of both shoots and roots in mycorrhizal plants were significantly elevated by AM fungi. A similar pattern has been observed in mycorrhizal soybean (Pacovsky 1986). Copper is an important component of many enzymes involving redox reactions (Marschner 1995). Copper deficiency affects electron transfer in PS I (Marschner 1995), often results in decreases in the activities of anti-oxidative enzymes (Yu et al. 1998), and limits the growth of plants (Cook et al. 1997). Enhanced Cu uptake by the mycorrhizal symbiosis in broomsedge could also contribute to the observed increases in the plant growth and may be involved in altered PUE exhibited in mycorrhizal plants. For example, if mycorrhizal plants were more effective at energy capture and carbohydrate transformations as a result of enhanced $\mathrm{Cu}$ nutrition, then these plants would be able to capture more carbon given a restricted supply of $\mathrm{Pi}$. The lower concentrations of foliar $\mathrm{P}$, $\mathrm{K}, \mathrm{Mn}$ and Fe observed for mycorrhizal plants at low Pi availability are consistent with growth dilution effects resulting from increased $\mathrm{Cu}$ acquisition.

Sodium concentrations of shoots in non-mycorrhizal plants were elevated when Pi became limited, and decreased as P status was improved with increased Pi availability (Table 1.2, Figure 1.3). This may reflect a loss of membrane selectivity under Pi-limitation and the subsequent loss of Na exclusion. Cumming and Weinstein (1990) also noted $\mathrm{Na}$ accumulation in non-mycorrhizal pine under $\mathrm{Pi}$ limitation. Furthermore, mycorrhizal broomsedge plants maintained relatively constant foliar $\mathrm{K}, \mathrm{Fe}, \mathrm{Mn}$, and $\mathrm{Na}$ concentrations across Pi treatments, which would be important to support the normal metabolism and optimal growth of broomsedge plants under varying Pi environments (Mooney and Winner 1991). These patterns all indicate that AM fungi are important in balancing the nutritional status of plants under Pi stress.

One possible factor leading to the observed convergence in biomass of mycorrhizal and non-mycorrhizal plants at $100 \mu \mathrm{M} \mathrm{Pi}$ is the constraint resulting from limited root volume (Thomas and Strain 1991). If mycorrhizal plants at high Pi no longer could add biomass due to such limitation, non-mycorrhizal plant biomass would approach that of mycorrhizal plants. However, I feel this may not be the case due to the significantly different slopes exhibited by mycorrhizal and non-mycorrhizal plants between 60 and $100 \mu \mathrm{M} \mathrm{Pi}$. 
The association of mycorrhizal fungi with the roots of broomsedge plants influences the nutrition of this species in several ways, all of which increase plant growth. Enhanced capture of Pi through greater biomass allocation to root systems and effective Pi drawdown leads to better plant growth under Pi limiting conditions. Higher PUE of mycorrhizal plants at low Pi availability increases biomass production when Pi limits growth of non-mycorrhizal plants. The strategies of resource allocation, lower $\mathrm{C}_{\text {min }}$, and higher PUE in mycorrhizal plants under low Pi availability undoubtedly facilitate the acquisition of other nutrient resources. Enhanced acquisition of $\mathrm{Cu}$ may play a role in the observed growth dilution by increasing PUE when Pi is not optimal. In viewing broad patterns of nutrition in this experiment, one striking feature is the more stable elemental concentrations, but less constant $\mathrm{P}$ concentrations, of tissues of mycorrhizal than non-mycorrhizal plants grown over the range of Pi studied. These patterns reflect a well-regulated nutrient homeostasis in mycorrhizal broomsedge under varying Pi availability that is not evident in non-mycorrhizal plants. 


\section{CHAPTER II}

\section{Mycorrhizal Roles in Al Resistance of Broomsedge}

\section{Introduction}

Aluminum (Al) present in acidic soils can be toxic to plants (Haug 1984; Ritchie 1995). In addition to reducing root growth, $\mathrm{Al}$ affects nutrient availability in soils and the uptake and translocation of nutrients by plants (Roy et al. 1988; Taylor 1988; Rengel and Robinson 1989; Nichol et al. 1993). For example, Al reduces inorganic phosphorus (Pi) availability by forming Al-Pi precipitates in the rhizosphere and restricts $\mathrm{P}$ translocation within a plant (Randall and Vose 1963; Clarkson 1966; de Miranda and Rowell 1989; Macklon et al. 1994), and Al additionally interferes with $\mathrm{Ca}$ and $\mathrm{Mg}$ uptake and translocation in plants (Haug and Caldwell 1985; Keltjens and Tan 1993; Ryan and Kochian 1993; Delhaize and Ryan 1995; Rengel et al. 1995). These effects undoubtedly result in the imbalance of nutrients in plants, consequently reducing plant growth.

Some plant species/cultivars exhibit persistent growth under $\mathrm{Al}$ exposure. The $\mathrm{Al}$ resistance in plants may be associated with alteration in rhizosphere $\mathrm{pH}$, release of organic acids, and $\mathrm{Al}$ efflux from the roots (Delhaize and Ryan 1995; Kochian 1995; Marschner 1995), which affects Al availability in soil solutions, consequently leading to lower tissue Al concentrations. Some plants develop specific mechanisms to detoxify $\mathrm{Al}$ internally by increasing production of compounds to chelate $\mathrm{Al}$ (Ma et al. 1998). Moreover, a mycorrhizal role is emphasized in protection of roots from Al toxicity in plants where $\mathrm{Pi}$ deficiency-induced root responses are impaired by Al (Marschner 1995).

Arbuscular mycorrhizal (AM) fungi are widely established in acidic soils (Clark 1997). AM fungal colonization improves seedling survival and enhances plant growth (Danielson 1985). One of the best described roles of AM fungi is the facilitation of acquisition of mineral nutrients by the host plants as a result of extensive external fungal hyphae exploiting a larger volume of soil and mining scarce resources that are otherwise unavailable for roots (Smith and Read 1997). Phosphorus is the most documented nutrient improved by AM symbiosis (Bolan 1991; Smith and Read 1997; Chapter I). Moreover, AM fungal colonization enhances the uptake 
of copper (Cu) and zinc (Zn) (Ross 1971; Pacovsky 1986; Smith and Read 1997; Chapter I). In addition, AM fungi may reduce the accumulation of some other elements, such as $\mathrm{Mn}$ and Fe (Pacovsky 1986; Kothari et al. 1991; Chapter I).

Given these roles of AM fungi in mycorrhizal symbioses, AM fungal colonization may confer $\mathrm{Al}$ resistance to the host plants by facilitating nutrient acquisition for the host plants under Al exposure. A limited number of experiments have demonstrated that AM fungal colonization ameliorates Al effects on plant growth and nutrition (Koslowsky and Boerner 1989; Medeiros et al. 1994; Mendoza and Borie 1998; Lux and Cumming 1999). However, it is not clear how this amelioration is achieved. Furthermore, AM fungi differentially affect plant nutrition in different developmental stages (Pacovsky 1986), and plant growth, nutrition, and root enzymes differentially respond to $\mathrm{Al}$ at different stages (Rengel and Robinson 1989; Widell et al. 1994). Thus, it may be important to elucidate different times in the process of plant development where there are differential effects of mycorrhizal presence as a function of $\mathrm{Al}$ treatments.

The present study aimed to investigate the response of broomsedge (Andropogon virginicus) plants to different levels of $\mathrm{Al}$, to examine $\mathrm{AM}$ fungal roles in the nutrition and growth of plants exposed to $\mathrm{Al}$, and to determine how mycorrhizal plants differ from nonmycorrhizal plants in Al resistance. I hypothesized that 1) mycorrhizal and non-mycorrhizal plants would differ in their response patterns to varying $\mathrm{Al}$ concentrations in root zones at different stages of plant development; 2) mycorrhizal plants and non-mycorrhizal plants also would differ in the ways of achieving $\mathrm{Al}$ resistance. I used broomsedge (Andropogon virginicus L.), a dominant grass species in many adverse edaphic habitats, and native AM fungi isolated from an abandoned acidic coal mining soil to test these hypotheses in two experiments.

\section{Materials and Methods}

Preparation of AM Fungal Inoculum

AM fungal inoculum was generated from broomsedge plants collected from the Field Crest abandoned coal mine in Morgantown, West Virginia, USA, in which Glomus clarum is the main fungus with Gigaspora gigantea also present. Although the site has been abandoned for about 50 years, much surface soil remains devoid of vegetation. The vegetated surface consists of a broomsedge sward surrounding stunted red maple (Acer rubrum) and big-toothed aspen 
(Populus grandidentata) trees. Soil from the site has a $\mathrm{pH}$ from 3.0 to 3.3 (soil-water paste) and contains Melich-extractable Pi of $3.76 \mathrm{mg} \mathrm{kg}^{-1}$ and Al of $363.1 \mathrm{mg} \mathrm{kg}^{-1}$ soil.

To produce the inoculum of AM fungi, broomsedge plants with intact mycorrhizal roots and adhering soil from the mine site were transplanted into $15 \mathrm{~cm}$ diameter pots containing a mixture of autoclaved mine-soil and sand $(1: 3 \mathrm{v} / \mathrm{v})$. After a month, the pot contents became the source of infective inoculum for the experiment.

Preparation of Plants

Broomsedge seeds were sown around the transplants in nursery pots (15 cm diameter). Broomsedge seeds also were sown in pots containing sterile-germinated broomsedge and the mixture of autoclaved mine-soil and sand $(1: 3 \mathrm{v} / \mathrm{v})$ with the bacteria extracted from the minesoil. Seedlings from these pots served as a non-mycorrhizal control. After four weeks growth, roots of a small subset of seedlings ( $c a$. 10) were examined to determine mycorrhizal status. Tissue P status was analyzed after wet digestion (Parkinson and Allen 1975) by the molybdate blue method (Olsen and Sommers 1982). Tissue phosphorus concentrations and tissue dry weights between mycorrhizal and non-mycorrhizal plants did not differ significantly.

Sand Culture and Growth Conditions

Mycorrhizal and non-mycorrhizal broomsedge seedlings were transplanted and grown in D16 Deepots (5 cm diameter x $18 \mathrm{~cm}$ height) (Stuewe and Sons, Inc., Corvallis, Oregon, USA) pre-filled with $220 \mathrm{~cm}^{3}$ of a 3:1 (v/v) mixture of coarse:fine acid-washed sand. Deepots were placed into a growth chamber with 14 hours of light at $28^{\circ} \mathrm{C}, 60 \% \mathrm{RH}$, and 10 hours of darkness at $21^{\circ} \mathrm{C}, 50 \% \mathrm{RH}$. Average light intensity at pot height in the chamber was $260 \mu \mathrm{mol} \mathrm{m} \mathrm{s}^{-1}$ from mixed fluorescent and incandescent sources. Plants received a baseline nutrient solution containing $\mathrm{Pi}(40 \mu \mathrm{M})$ of $\mathrm{NaH}_{2} \mathrm{PO}_{4}, \mathrm{Ca}(0.675 \mathrm{mM}), \mathrm{K}(0.79 \mathrm{mM}), \mathrm{Mg}(0.25 \mathrm{mM}), \mathrm{NO}_{3}(1.5$ $\mathrm{mM}), \mathrm{NH}_{4}(0.5 \mathrm{mM}), \mathrm{SO}_{4}(0.25 \mathrm{mM}), \mathrm{B}(23.14 \mu \mathrm{M}), \mathrm{Fe}(25 \mu \mathrm{M}), \mathrm{Mn}(4.57 \mu \mathrm{M}), \mathrm{Zn}(0.38 \mu \mathrm{M})$, $\mathrm{Cu}(0.16 \mu \mathrm{M})$, and $\mathrm{Mo}(0.06 \mu \mathrm{M})$. All solutions were adjusted to $\mathrm{pH} 4.0$ after $\mathrm{Al}$ treatment was added and before application. Solutions (approximately $15 \mathrm{ml}$ ) were automatically delivered to the plants three times each day for eight weeks. 


\section{Multiple Harvest Dose Response}

Treatments were $0,10,50,100$, and $200 \mu \mathrm{M} \mathrm{Al}$ in a form of $\mathrm{AlCl}_{3}$. Simulation analysis of these solution by the program GEOCHEM (Parker et al. 1993) indicated that $\mathrm{Al}^{3+}$ concentrations were $0,5.72,29.91,62.75$, and $133.90 \mu \mathrm{M}$ in the solutions, respectively. For data analysis hereafter, delivered $\mathrm{Al}$ concentrations were used. A mycorrhizal-by-Al factorial design was employed with 10 replicates for each treatment combination. The influence of plants on solution $\mathrm{pH}$ was monitored every week by collecting excess solution flowing the Deepots (leachate) for an hour after delivery of solution. The first harvest was conducted after week 4, the second after week 6, and the final harvest after week 8. Three, three, and four plants from each combination were randomly chosen for the first, second, and third harvest, respectively.

Plants were gently removed from Deepots and roots were rinsed free of sand with running deionized $\mathrm{H}_{2} \mathrm{O}$. Roots were excised. To determine acid phosphatase (APase) activity, 5-8 cm root tips were cut off, washed in de-ionized water, chopped into $1 \mathrm{~cm}$ pieces, and transferred into centrifuge tubes containing $4.5 \mathrm{ml}$ of the appropriate treatment solution. Then, $0.5 \mathrm{ml}$ of $1 \mathrm{mM}$ nitrophenylphosphate (NPP) was added to each tube and tubes were incubated for 1 hour at room temperature. After the incubation period, $1 \mathrm{ml}$ of $0.5 \mathrm{~N} \mathrm{NaOH}$ was added to each tube. Acid phosphatase activity (nitrophenol produced) was spectrophotometrically determined at $410 \mathrm{~nm}$ wavelength (Tabatabai and Bremner 1969).

The remainder of the root system as well as the shoot were rinsed in running de-ionized $\mathrm{H}_{2} \mathrm{O}$ and dried. After they were dried at $60^{\circ} \mathrm{C}$ for at least 24 hours, roots and shoots were weighed and ground in a Wiley mill. Ground roots and shoots were digested in concentrated $\mathrm{H}_{2} \mathrm{SO}_{4} / 30 \%$ hydrogen peroxide (Parkinson and Allen 1975). Phosphorus and Al concentrations of the digests were determined spectrophotometrically using the molybdate blue method (Olsen and Sommers 1982) and the eriochrome cyanine method (Anonymous 1985), respectively.

Extended Dose Response

Treatments were 0, 200, 400, and $1000 \mu \mathrm{M} \mathrm{Al}$ in a form of $\mathrm{AlCl}_{3}$. Simulation analysis of these solutions by the program GEOCHEM (Parker et al. 1993) indicated that $\mathrm{Al}^{3+}$ concentrations were $0,133.9,379.4$, and $945.8 \mu \mathrm{M}$ in the solutions, respectively. The treatments were arranged in a mycorrhizal-by-Al factorial design in the growth chamber with 10 replicates for each treatment combination. At the termination of the experiment following eight weeks of treatment, tiller number of each plant was counted and cumulative length of all these tillers was recorded. 
Sand was removed from roots under running de-ionized water, and shoots were rinsed in deionized water. Roots then were excised. Percentage mycorrhizal colonization of roots was assessed on a 5\% root sub-sample by the gridline intersect method (Giovannetti and Mosse 1980). Shoots and roots were dried at $60^{\circ} \mathrm{C}$, weighed, and ground. Tissue samples were digested as noted above. The concentration of $\mathrm{P}$ in the digests was determined according to Taussky and Shoor (1953). All other mineral elements (Al, Fe, Mn, Mg, Ca, Zn, Cu, Na, and K) of the digests were analyzed by inductively coupled plasma (ICP) emission spectrophotometry (Leeman PS 950) by the National Research Center for Coal and Energy Analytical Laboratory at West Virginia University.

Data Calculation and Analysis

Percentage inhibition of nutrient uptake and plant resistance index were separately calculated as follow (Rengel and Robinson 1989):

$$
\begin{aligned}
& \text { inhibition }=\frac{M_{0}-M_{j}}{M_{0}} \times 100 \\
& \text { resistance index }=\mathbf{W}_{\mathrm{Al}} / \mathbf{W}_{\text {control }}
\end{aligned}
$$

where $\mathbf{M}_{\mathbf{0}}$ and $\mathbf{M}_{\mathrm{j}}$ are separately total content of a nutrient in a plant at 0 and Al level $\boldsymbol{j}$ and $\mathbf{W}_{\mathrm{Al}}$ and $\mathbf{W}_{\text {control }}$ are plant dry weights with $\mathrm{Al}$ treatment and without $\mathrm{Al}$ treatment, respectively.

Data were analyzed by analysis of covariance with solution Al concentrations treated as a covariate, and regression analysis using the statistical package JMP (SAS Institute, Cary, North Carolina, USA).

\section{Results}

Multiple Harvest Dose Response

Differential effects of mycorrhizal fungal colonization as a function of $\mathrm{Al}$ concentrations were observed on leachate $\mathrm{pH}$ in the early period of the experiment (Table 2.1). Mycorrhizal plants were more sensitive in the leachate $\mathrm{pH}$ to changes of the solution $\mathrm{Al}$ concentrations than 
Table 2.1. $P$ values from ANCOVA for leachate $\mathrm{pH}$ in broomsedge (A. virginicus) plants as influenced by mycorrhizal (Myc) and Al treatments at different time (week).

\begin{tabular}{lllllll}
\hline Source & Week 3 & Week 4 & Week 5 & Week 6 & Week 7 & Week 8 \\
\hline Myc & $<0.001$ & 0.035 & $\mathrm{~ns}^{\dagger}$ & 0.001 & $\mathrm{~ns}$ & $\mathrm{~ns}$ \\
Al & 0.034 & 0.044 & $\mathrm{~ns}$ & $\mathrm{~ns}$ & $\mathrm{~ns}$ & 0.032 \\
Myc $*$ Al & $<0.001$ & 0.050 & $\mathrm{~ns}$ & 0.020 & $\mathrm{~ns}$ & $\mathrm{~ns}$ \\
\hline
\end{tabular}

$\alpha=0.05$, the same hereafter. 
Figure 2.1. Influence of $\mathrm{Al}$ treatment on leachate $\mathrm{pH}$ of mycorrhizal (solid) and nonmycorrhizal (open) broomsedge (A. virginicus) plants.

Slopes and $P$ values from the regression:

A. Week 3

Mycorrhizal:

Slope: -0.00247 , and $P$ value: $<0.001$;

Non-mycorrhizal:

Slope: 0.00422 (linear) and -0.00002 (quadratic), and $P$ value: 0.028 (linear) and 0.059 (quadratic).

B. Week 4

Mycorrhizal:

Slope: -0.00224 , and $P$ value: 0.004 ;

Non-mycorrhizal:

Slope: -0.00003 , and $P$ value: ns.

C. Week 6

Mycorrhizal:

Slope: 0.00592 (linear) and -0.00003 (quadratic), and $P$ value: 0.006 (linear) and < 0.001 (quadratic);

Non-mycorrhizal:

Slope: 0.00037 , and $P$ value: ns; 

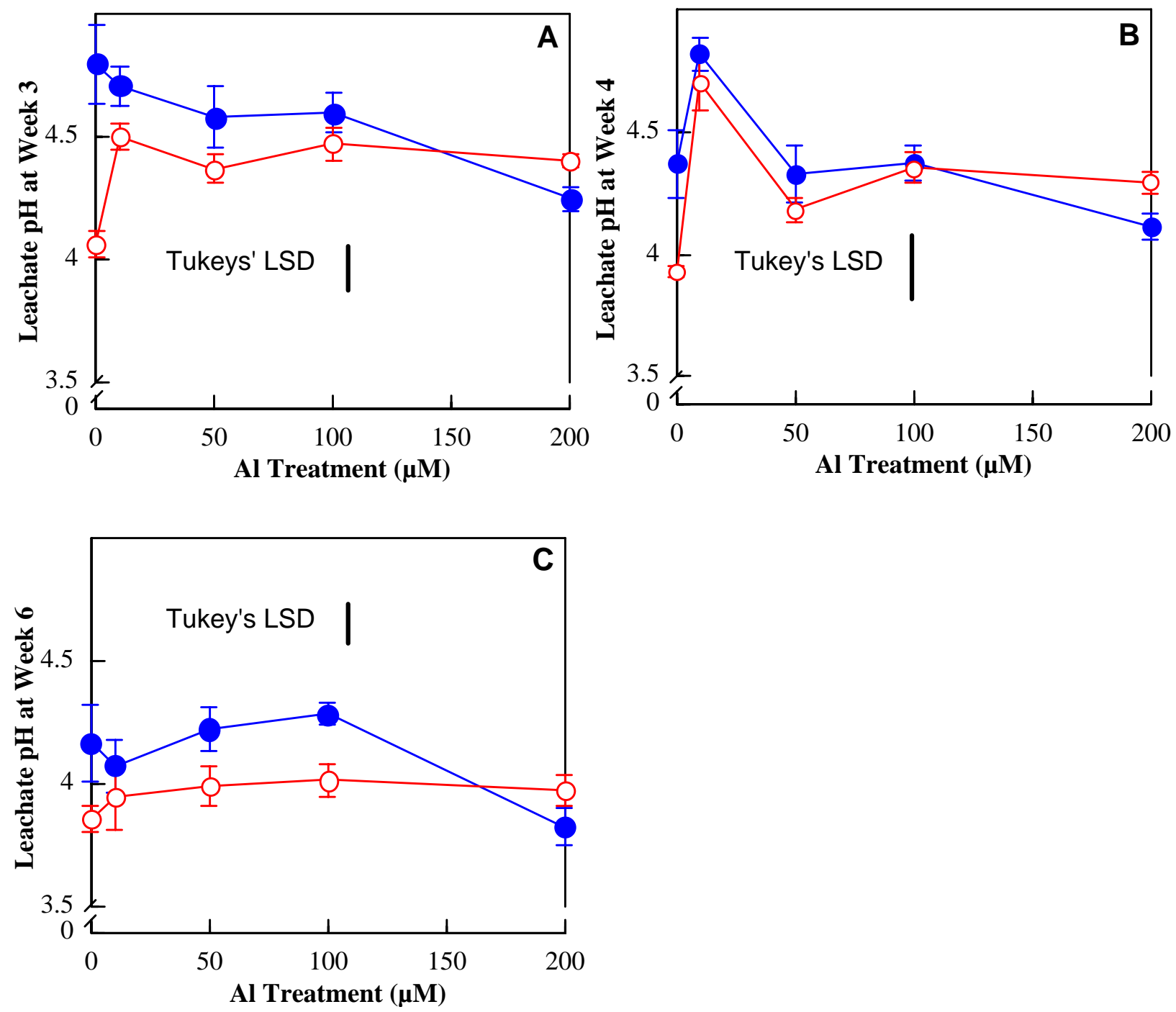
Figure 2.2. Influence of Al treatment on plant mass of mycorrhizal (solid) and non-mycorrhizal (open) broomsedge (A virginicus).

$P$ values from ANCOVA:

A. The first harvest:

Myc: ns, Al: 0.040, and Myc*Al: 0.028 .

B. The second harvest:

Myc: ns, Al: ns, and Myc*Al: ns.

C. The third harvest:

Myc: < 0.001, Al: 0.008, and Myc*Al: ns. 

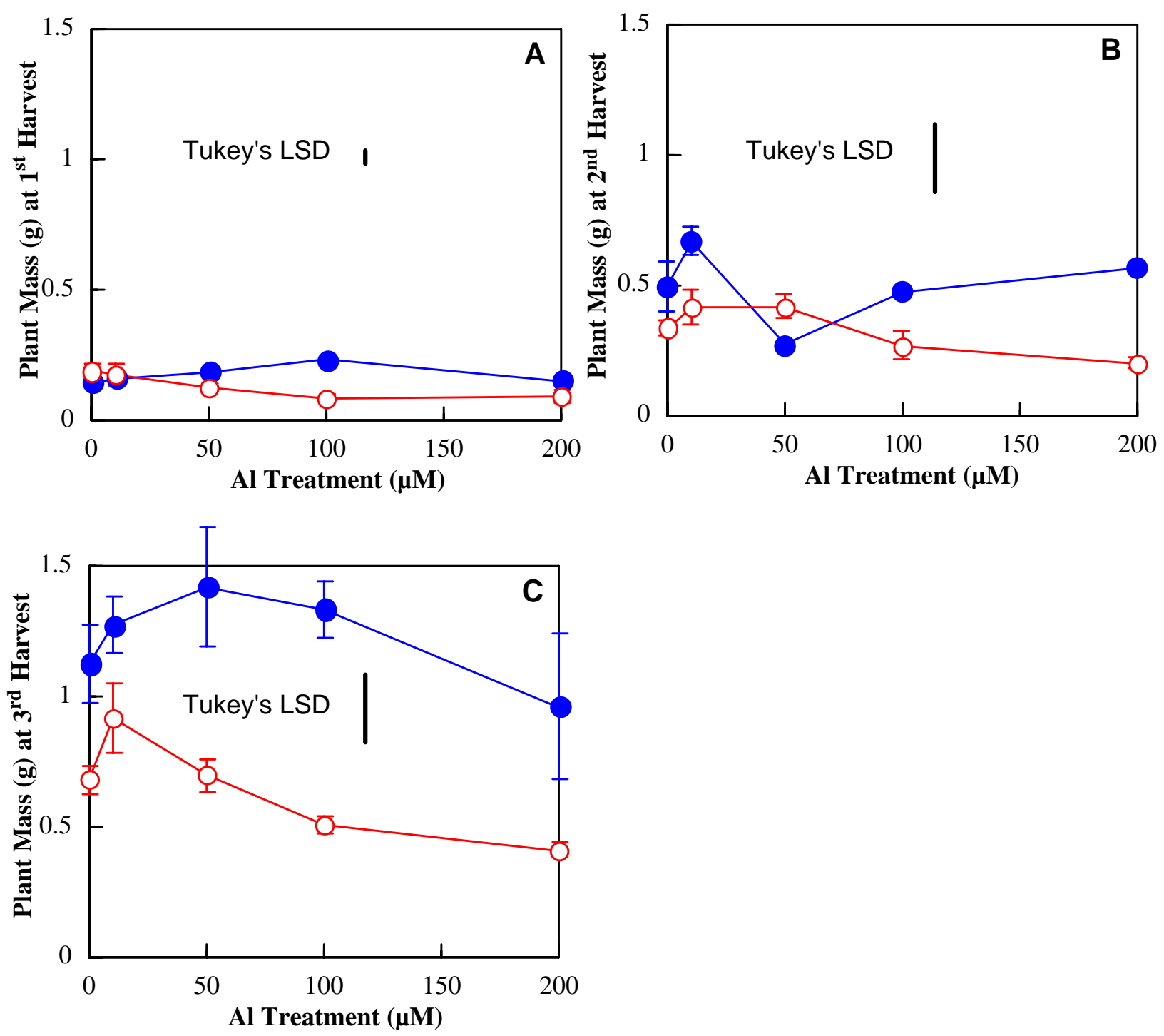
Figure 2.3. Influence of Al treatment on root acid phosphatase (APase) activity of mycorrhizal (solid) and non-mycorrhizal (open) broomsedge (A. virginicus) plants.

$P$ values from ANCOVA:

A. The first harvest:

Myc: < 0.001, Al: 0.054, and Myc* Al: ns.

B. The second harvest:

Myc: 0.027, Al: ns, and Myc* Al: ns.

C. The third harvest:

Myc: < 0.001, Al: ns, and Myc* Al: ns. 

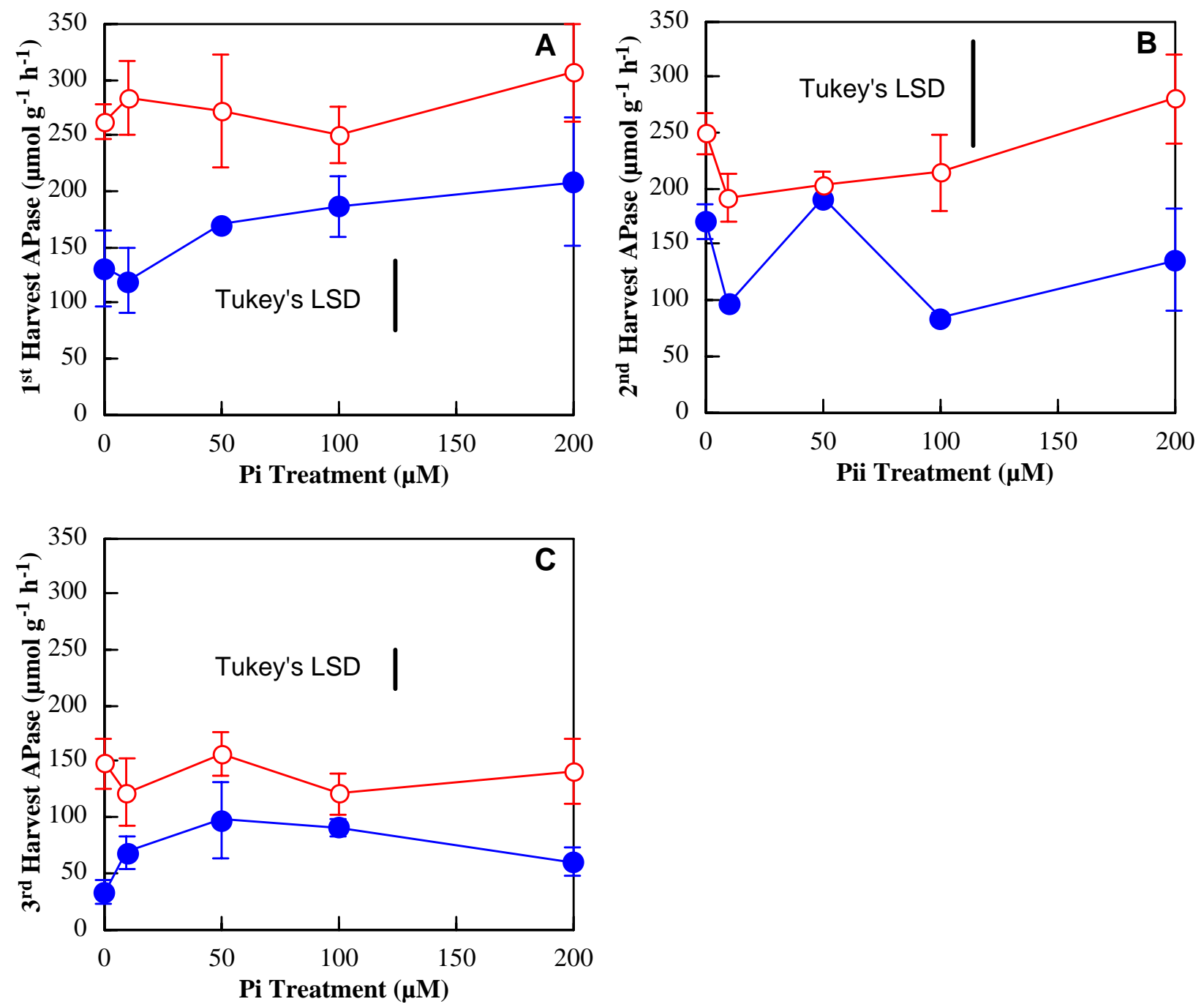
non-mycorrhizal plants (Figure 2.1). The leachate $\mathrm{pH}$ of all other plants, except ones exposed to $10 \mu \mathrm{M} \mathrm{Al}$, which had leachate $\mathrm{pH}$ higher than 4.8, was below 4.5 (data not presented), suggesting that $\mathrm{Al}$ existed primarily as $\mathrm{Al}^{3+}$ in the root zones of these plants.

There were differential effects of mycorrhizal fungal colonization on plant mass only in the first harvest under different $\mathrm{Al}$ solution concentrations (Figure 2.2). As the $\mathrm{Al}$ concentrations increased, dry weights of non-mycorrhizal plants decreased, whereas Al below $100 \mu \mathrm{M}$ stimulated mycorrhizal plant growth and even $200 \mu \mathrm{M}$ Al had no effect on mycorrhizal plants (Figure 2.2) compared to the control plants. When plants were exposed to $\mathrm{Al}$ for longer periods of time ( 8 weeks), mycorrhizal benefit became more pronounced (Figure 2.2) (mycorrhizal plants with mean dry weight of $1.268 \mathrm{~g}$ over all the Al treatments and $0.690 \mathrm{~g}$ for nonmycorrhizal plants).

Acid phosphatase (APase) activity is a marker for Pi limitation (e.g. Fries et al. 1998) and was used as an indicator of $\mathrm{Al}$ effects on Pi acquisition by broomsedge. The APase activity of mycorrhizal plants was consistently lower than that of non-mycorrhizal plants across all Al treatments and at all harvests, and the APase of both mycorrhizal and non-mycorrhizal plants decreased over time (Figure 2.3). The exception was for mycorrhizal plants exposed to $50 \mu \mathrm{M}$ $\mathrm{Al}$ at the second harvest. Taken together with growth data (Figure 2.2), it appears as if this treatment was anomalous.

Mycorrhizal fungal colonization significantly reduced $\mathrm{Al}$ influx into host plants and limited Al translocation within host plants at 100 and $200 \mu \mathrm{M} \mathrm{Al}$ during the first six weeks (Table 2.2). During the last two weeks of this experiment, mycorrhizal plants had marginally higher shoot and root $\mathrm{Al}$ concentrations than non-mycorrhizal plants under $200 \mu \mathrm{M} \mathrm{Al}$ exposure. When plants were exposed to $50 \mu \mathrm{M} \mathrm{Al}$ and below in the first and second harvests or even 100 $\mu \mathrm{M} \mathrm{Al}$ in the third harvest, there was no significant difference in shoot and root $\mathrm{Al}$ concentrations between mycorrhizal and non-mycorrhizal plants (Table 2.2).

Mycorrhizal and non-mycorrhizal plants significantly differed in shoot and root $\mathrm{P}$ in the first four weeks as $\mathrm{Al}$ concentrations changed (Table 2.3). Shoot and root $\mathrm{P}$ concentrations of mycorrhizal plants were significantly higher than those of non-mycorrhizal plants in the first harvest at $50 \mu \mathrm{M} \mathrm{Al}$ and above, but there was no significant difference in tissue $\mathrm{P}$ concentration between them at 0 and $10 \mu \mathrm{M} \mathrm{Al}$ treatment. For the second harvest, mycorrhizal plants generally had higher shoot and root $\mathrm{P}$ concentrations than non-mycorrhizal plants. But shoot $\mathrm{P}$ 
Table 2.2. Shoot and root $\mathrm{Al}$ concentrations $\left(\mathrm{mg} \mathrm{g}^{-1}\right)$ of mycorrhizal and non-mycorrhizal broomsedge (A. virginicus) plants as influenced by Al treatments.

\begin{tabular}{|c|c|c|c|c|c|c|c|}
\hline \multirow{2}{*}{$\begin{array}{l}\mathbf{A l} \\
(\mu \mathrm{M})\end{array}$} & \multirow{2}{*}{ Myc } & \multicolumn{2}{|c|}{$\mathbf{1}^{\text {st }}$ Harvest } & \multicolumn{2}{|c|}{$2^{\text {nd }}$ Harvest } & \multicolumn{2}{|c|}{$3^{\text {rd }}$ Harvest } \\
\hline & & Shoot & Root & Shoot & Root & Shoot & Root \\
\hline \multirow{2}{*}{ 0 } & + & 0.231 & 0.507 & 0.159 & 0.229 & 0.048 & 0.076 \\
\hline & - & 0.251 & 0.261 & 0.247 & 0.459 & 0.156 & 0.055 \\
\hline \multirow{2}{*}{10} & + & 0.274 & 0.395 & 0.111 & 0.198 & 0.147 & 0.060 \\
\hline & - & 0.220 & 0.398 & 0.191 & 0.136 & 0.198 & 0.074 \\
\hline \multirow{2}{*}{50} & + & 0.256 & 0.495 & 0.254 & 0.35 & 0.162 & 0.053 \\
\hline & - & 0.286 & 0.556 & 0.147 & 0.349 & 0.118 & 0.070 \\
\hline \multirow{2}{*}{100} & + & 0.294 & 0.509 & 0.188 & 0.171 & 0.412 & 0.502 \\
\hline & - & 1.109 & 1.695 & 0.602 & 1.213 & 0.408 & 0.430 \\
\hline \multirow{2}{*}{200} & + & 0.699 & 1.675 & 0.381 & 0.506 & 0.926 & 1.004 \\
\hline & - & 1.143 & 1.610 & 1.304 & 1.678 & 0.788 & 0.874 \\
\hline \multicolumn{2}{|c|}{ Tukey's LSD } & 0.512 & 0.693 & 0.289 & 0.493 & 0.176 & 0.212 \\
\hline$P$ & Myc & ns & $\mathrm{ns}$ & $\mathrm{ns}$ & ns & $\mathrm{ns}$ & $\mathrm{ns}$ \\
\hline \multirow{2}{*}{ values } & Al & $<0.001$ & $<0.001$ & $<0.001$ & $<0.001$ & $<0.001$ & $<0.001$ \\
\hline & Myc*Al & 0.058 & ns & $<0.001$ & $<0.001$ & 0.060 & ns \\
\hline
\end{tabular}

${ }^{\dagger}$ Least significant difference at $\alpha=0.05$ with $\mathrm{n}=3$. 
Table 2.3. Shoot and root $\mathrm{P}$ concentrations $\left(\mathrm{mg} \mathrm{g}^{-1}\right)$ of mycorrhizal and non-mycorrhizal broomsedge (A. virginicus) plants as influenced by Al treatments.

\begin{tabular}{|c|c|c|c|c|c|c|c|}
\hline \multirow{2}{*}{$\begin{array}{l}\mathbf{A l} \\
(\mu \mathrm{M})\end{array}$} & \multirow{2}{*}{ Myc } & \multicolumn{2}{|c|}{$1^{\text {st }}$ Harvest } & \multicolumn{2}{|c|}{$2^{\text {nd }}$ Harvest } & \multicolumn{2}{|c|}{$3^{\text {rd }}$ Harvest } \\
\hline & & Shoot & Root & Shoot & Root & Shoot & Root \\
\hline \multirow{2}{*}{$\mathbf{0}$} & + & 1.544 & 0.910 & 1.778 & 0.836 & 0.859 & 0.962 \\
\hline & - & 1.074 & 0.622 & 1.468 & 0.801 & 1.357 & 0.635 \\
\hline \multirow{2}{*}{10} & + & 1.204 & 1.004 & 1.677 & 1.168 & 1.165 & 0.841 \\
\hline & - & 1.282 & 0.828 & 1.587 & 0.751 & 1.273 & 0.834 \\
\hline \multirow{2}{*}{50} & + & 2.183 & 1.361 & 2.004 & 1.263 & 1.213 & 0.701 \\
\hline & - & 1.305 & 0.488 & 1.232 & 0.630 & 1.379 & 0.572 \\
\hline \multirow{2}{*}{100} & + & 1.922 & 1.272 & 1.855 & 0.982 & 1.164 & 0.737 \\
\hline & - & 1.201 & 0.286 & 1.412 & 0.558 & 1.691 & 0.891 \\
\hline \multirow{2}{*}{200} & + & 2.256 & 1.503 & 1.702 & 1.252 & 1.613 & 1.385 \\
\hline & - & 0.998 & 0.518 & 1.860 & 0.716 & 1.763 & 0.806 \\
\hline \multicolumn{2}{|c|}{ Tukey's LSD } & 0.603 & 0.418 & 0.695 & 0.333 & 0.476 & 0.532 \\
\hline $\mathbf{P}$ & Myc & ns & 0.011 & 0.052 & 0.007 & 0.042 & $\mathrm{~ns}$ \\
\hline \multirow{2}{*}{ values } & Al & ns & $\mathrm{ns}$ & ns & ns & 0.001 & ns \\
\hline & Myc*Al & 0.012 & 0.006 & ns & ns & ns & ns \\
\hline
\end{tabular}

${ }^{\dagger}$ Least significant difference at $\alpha=0.05$ with $\mathrm{n}=3$. 
concentrations of mycorrhizal plants from the third harvest were generally higher than those of non-mycorrhizal plants (Table 2.3).

Extended Dose Response

To gain insight into the extent to which the observed mycorrhizal benefit could function at higher $\mathrm{Al}$ levels, mycorrhizal and non-mycorrhizal broomsedge plants were exposed to $\mathrm{Al}$ concentrations up to $1000 \mu \mathrm{M}$. The patterns of growth responses to $\mathrm{Al}$ concentrations in the solutions significantly differed between mycorrhizal and non-mycorrhizal plants (Figure 2.4). Mycorrhizal plants had no significant reduction in shoot mass and cumulative height under exposure to Al up to $400 \mu \mathrm{M}$ (Figure 2.4). However, non-mycorrhizal plants even at $200 \mu \mathrm{M} \mathrm{Al}$ exhibited Al toxicity symptoms, such as brown root tips (data not presented), and showed significant reduction in shoot and root mass (Figure 2.4). At $1000 \mu \mathrm{M} \mathrm{Al}$, shoot and root of mycorrhizal plants were 22 and 18 fold larger than those of non-mycorrhizal plants, and mycorrhizal plants were 15 fold higher and 4.5 fold more tillers than non-mycorrhizal plants (Figure 2.4). In addition, mycorrhizal plant allocated more biomass to roots than nonmycorrhizal plants (Figure 2.4).

Mycorrhizal colonization was significantly affected by solution Al concentrations (Figure 2.5). Below $400 \mu \mathrm{M} \mathrm{Al}$, mycorrhizal colonization of broomsedge plants increased as $\mathrm{Al}$ concentrations increased. When solution Al concentration reached $1000 \mu \mathrm{M}$, mycorrhizal colonization percentage decreased (Figure 2.5).

Effects of mycorrhizal fungal colonization on shoot and root Al concentrations depended on the solution Al concentrations (Figure 2.6). Mycorrhizal plants maintained significantly lower shoot and root Al concentrations than non-mycorrhizal plants at 400 and $1000 \mu \mathrm{M} \mathrm{Al}$ levels, where non-mycorrhizal plants had 1.8 and 5.6 fold higher shoot $\mathrm{Al}$ concentrations and 4.2 and 7.2 fold higher root $\mathrm{Al}$ concentrations, respectively. At 0 and $200 \mu \mathrm{M} \mathrm{Al}$ concentrations, there was no significant difference in shoot and root Al concentrations between mycorrhizal and nonmycorrhizal plants (Figure 2.6).

Different patterns of growth and shoot and root Al concentrations indicated that mycorrhizal fungal colonization may have altered other nutrient composition of shoots and roots. Differential effects of mycorrhizal fungal colonization as a function of the solution Al 
Figure 2.4. Influence of $\mathrm{Al}$ treatment on shoot (circle) and root (triangle) dry weights (A), cumulative height (circle) and number of tillers (triangle) (B) of mycorrhizal (solid) and nonmycorrhizal (open) broomsedge (A. virginicus) plants.

$P$ values from ANCOVA:

A. Shoot mass:

Myc: <0.001, Al: <0.001, and $\mathrm{Myc} * \mathrm{Al}: 0.013 ;$

Root mass:

Myc: <0.001, Al: <0.001, and Myc* Al: 0.029.

B. Cumulative height:

Myc: < 0.001, Al: < 0.001, and Myc * Al: < 0.001;

Number of tillers:

Myc: ns, $\mathrm{Al}:<0.001$, and $\mathrm{Myc} * \mathrm{Al}:<0.001$. 

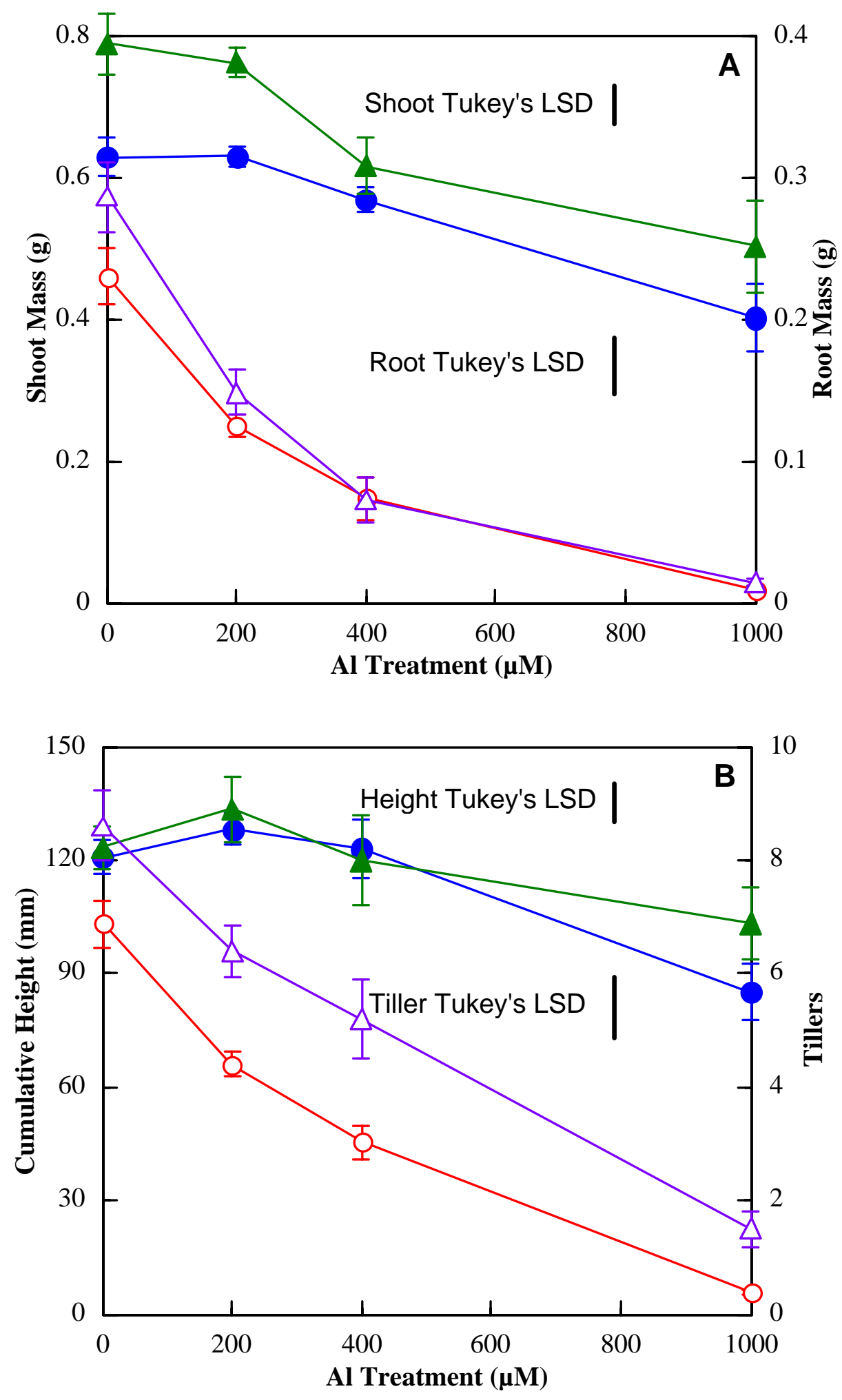
Figure 2.5. Mycorrhizal colonization of broomsedge (A. virginicus) plants as influenced by Al treatment.

Slope: 0.086 (linear) and -0.000066 (quadratic), and $P$ value: $<0.001$ (linear) and 0.003 (quadratic). 


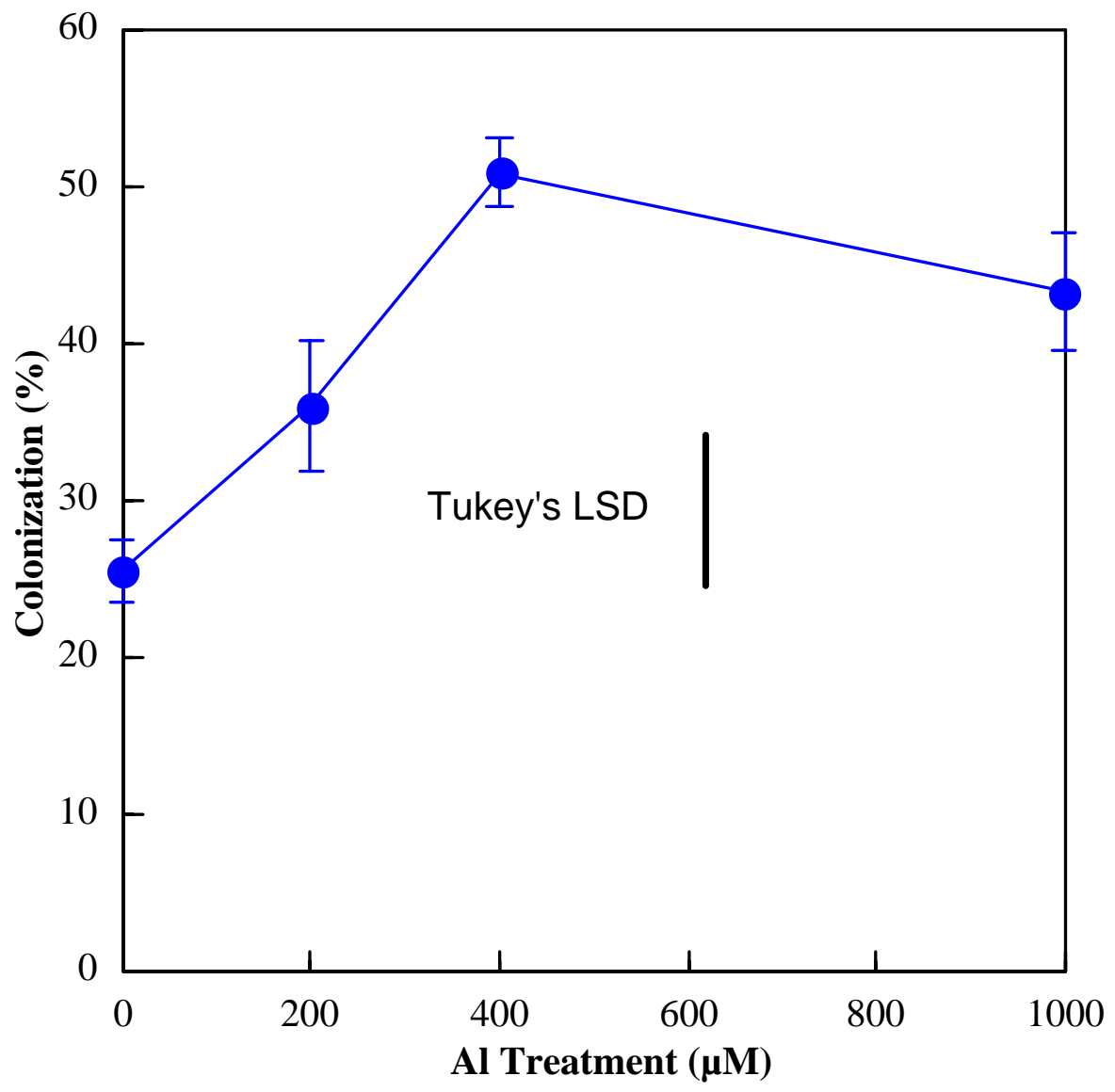


Figure 2.6. Influence of $\mathrm{Al}$ treatment on shoot (circle) and root (triangle) $\mathrm{Al}$ concentrations of mycorrhizal (solid) and non-mycorrhizal (open) broomsedge (A. virginicus) plants.

$P$ values from ANCOVA:

Shoot $\mathrm{Al}$ concentration:

Myc: ns, $\mathrm{Al}:<0.001$, and Myc* $\mathrm{Al}:<0.001$;

Root $\mathrm{Al}$ concentration:

Myc: 0.020, Al: $<0.001$, and Myc * Al: $<0.001$. 


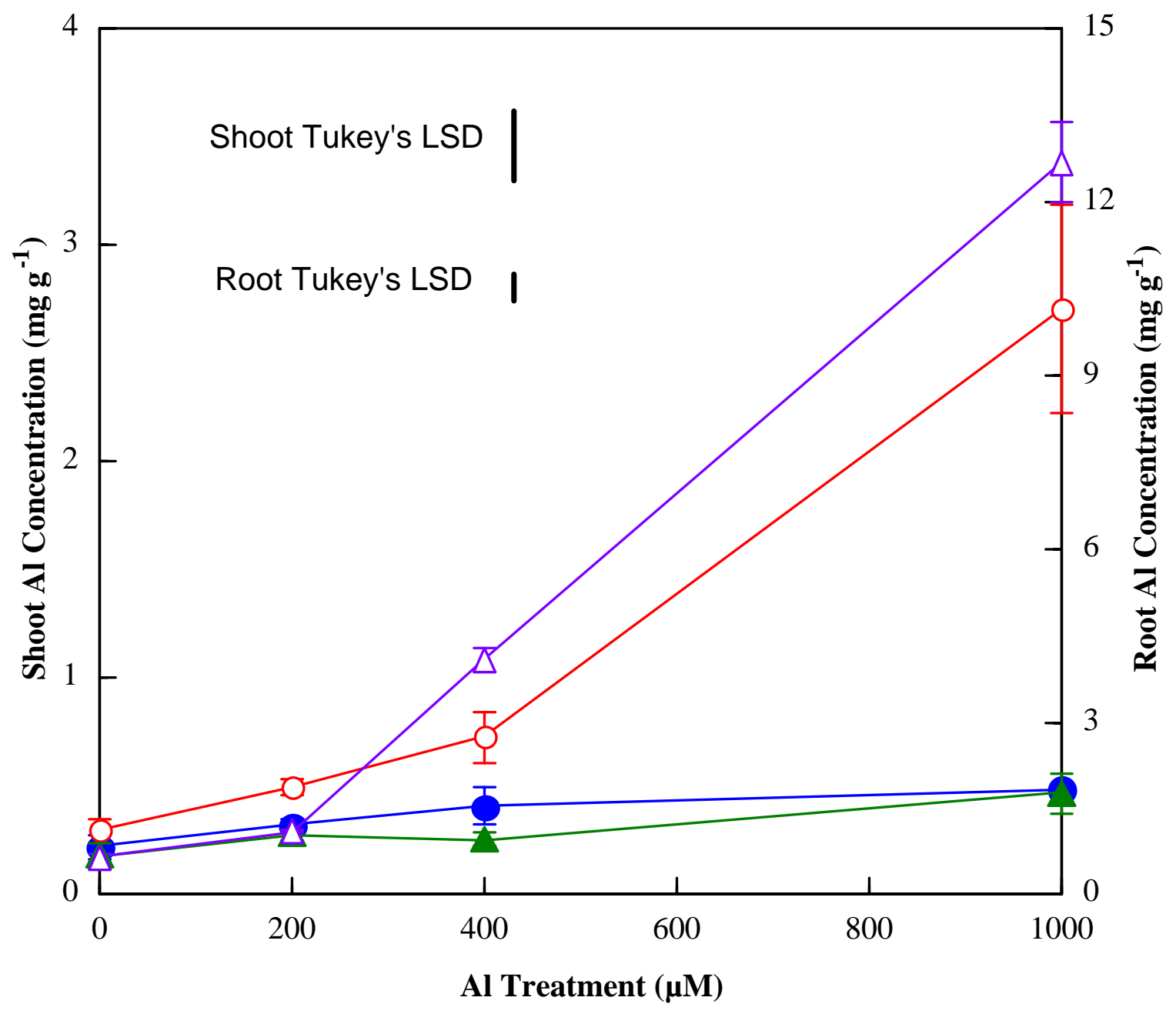


Table 2.4. $P$ values from ANCOVA for shoot and root nutrients of broomsedge (A. virginicus) plants as influenced by mycorrhizal (Myc) and Al treatments.

\begin{tabular}{|c|c|c|c|c|c|c|c|c|c|c|}
\hline & Source & $\mathbf{P}$ & $\mathbf{K}$ & $\mathrm{Ca}$ & Mg & $\mathbf{F e}$ & Mn & $\mathbf{C u}$ & $\mathbf{Z n}$ & $\mathbf{N a}$ \\
\hline \multirow{3}{*}{$\frac{\overrightarrow{8}}{\ddot{g}}$} & Мyc & $<0.001$ & 0.012 & ns & ns & ns & 0.001 & ns & ns & ns \\
\hline & Al & $<0.001$ & ns & $<0.001$ & $<0.001$ & 0.030 & ns & 0.028 & 0.001 & 0.039 \\
\hline & $\mathbf{M y c} * \mathbf{A l}$ & $<0.001$ & 0.004 & $\mathrm{~ns}$ & 0.015 & 0.002 & ns & 0.002 & 0.008 & ns \\
\hline \multirow{3}{*}{$\underset{\mathscr{\theta}}{\overrightarrow{0}}$} & Myc & $\mathrm{ns}$ & 0.027 & 0.034 & 0.006 & ns & ns & $<0.001$ & $\mathrm{~ns}$ & ns \\
\hline & Al & 0.001 & ns & $<0.001$ & $<0.001$ & $<0.001$ & ns & ns & ns & $<0.001$ \\
\hline & Myc * Al & $<0.001$ & ns & ns & ns & $<0.001$ & 0.017 & $<0.001$ & $<0.001$ & ns \\
\hline
\end{tabular}


Figure 2.7. Influence of $\mathrm{Al}$ treatment on shoot nutrient concentrations of mycorrhizal (solid) and non-mycorrhizal (open) broomsedge (A. virginicus) plants.

Slopes and $P$ values from the regression:

A. Shoot $\mathrm{P}$ concentrations:

Mycorrhizal:

N/A;

Non-mycorrhizal:

Slope: 0.00242 (linear) and -0.000003 (quadratic), and $P$ value: $<0.001$ (linear and quadratic).

B. Shoot K concentrations:

Mycorrhizal:

Slope: 0.00248 , and $P$ value: 0.039 ;

Non-mycorrhizal:

Slope: 0.01941 (linear) and -0.00002 (quadratic), and $P$ value: 0.003 (linear) and < 0.001 (quadratic).

C. Shoot Mg concentrations:

Mycorrhizal:

Slope: -0.00161 , and $P$ value: $<0.001$;

Non-mycorrhizal:

Slope: -0.00296 , and $P$ value: $<0.001$.

D. Shoot Fe concentrations:

Mycorrhizal:

Slope: -0.65437 (linear) and 0.00054 (quadratic), and $P$ value: 0.019 (linear) and 0.030 (quadratic);

Non-mycorrhizal:

Slope: 0.35987 , and $P$ value: 0.005 .

E. Shoot $\mathrm{Cu}$ concentrations:

Mycorrhizal:

N/A;

Non-mycorrhizal:

Slope: 0.02277 , and $P$ value: 0.010 .

F. Shoot $\mathrm{Zn}$ concentrations;

Mycorrhizal:

N/A;

Non-mycorrhizal:

Slope: 0.10410 , and $P$ value: $<0.001$. 

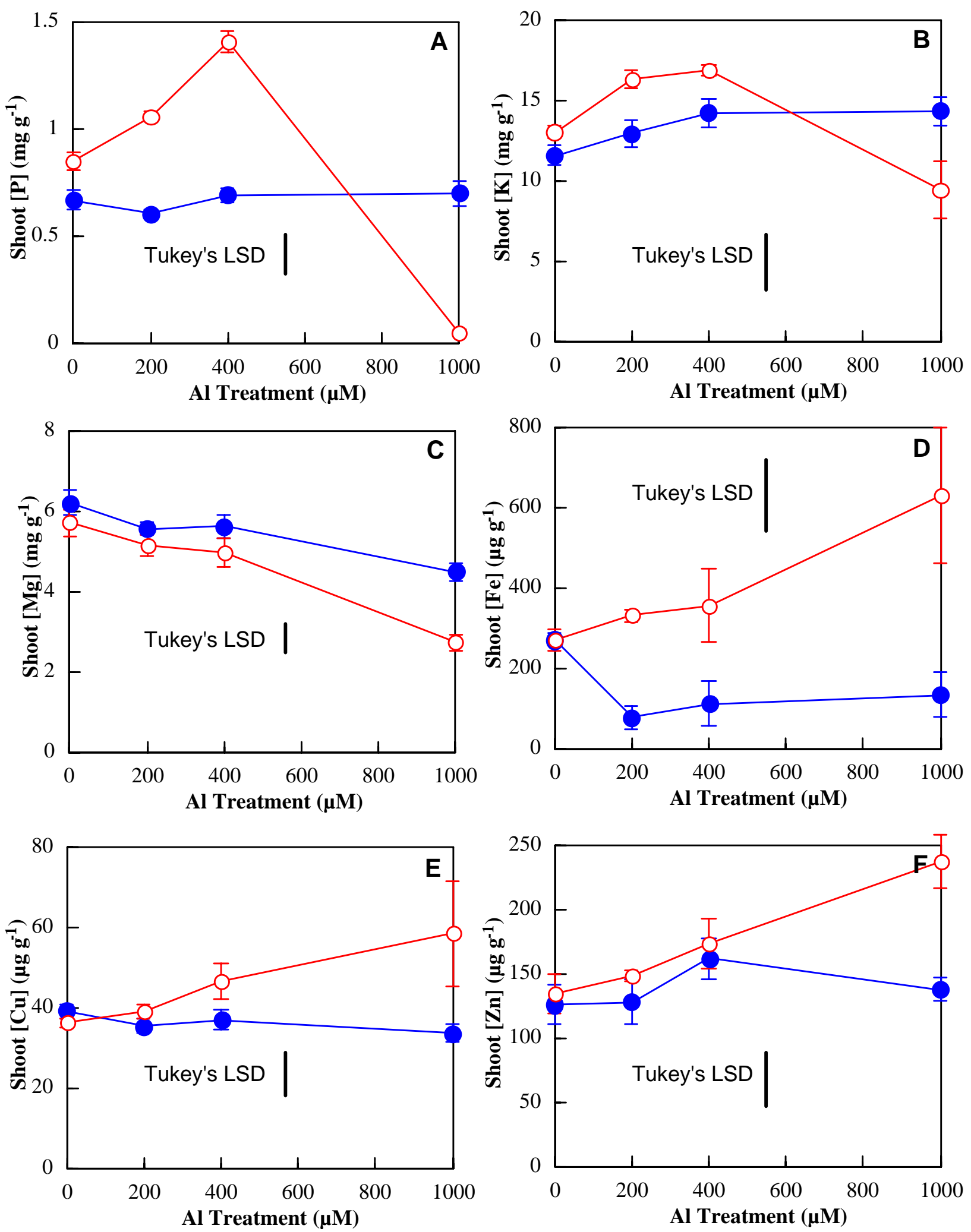
Figure 2.8. Influence of $\mathrm{Al}$ treatment on root nutrient concentrations of mycorrhizal (solid) and non-mycorrhizal (open) broomsedge (A. virginicus) plants.

Slopes and $P$ values from the regression:

A. Root P concentrations:

Mycorrhizal:

Slope: 0.00054 (linear) and -0.000005 (quadratic), and $P$ value: $<0.001$ (linear and quadratic);

Non-mycorrhizal:

Slope: 0.00074 (linear) and -0.000001 (quadratic), and $P$ value: 0.016 (linear) and < 0.001 (quadratic).

B. Root Fe concentrations:

Mycorrhizal:

N/A;

Non-mycorrhizal:

Slope: 2.30579 , and $P$ value: 0.002 .

C. Root Mn concentrations:

Mycorrhizal:

Slope: 1.83537 (linear) and -0.00189 (quadratic), and $P$ value: $<0.001$ (linear and quadratic);

Non-mycorrhizal:

Slope: -0.41900 , and $P$ value: 0.004 .

D. Root $\mathrm{Cu}$ concentrations:

Mycorrhizal:

Slope: -0.03638, and $P$ value: 0.005;

Non-mycorrhizal:

N/A.

E. Root Zn concentrations;

Mycorrhizal:

Slope: -0.10398 , and $P$ value: 0.002;

Non-mycorrhizal:

Slope: 0.12970 , and $P$ value: $<0.001$. 

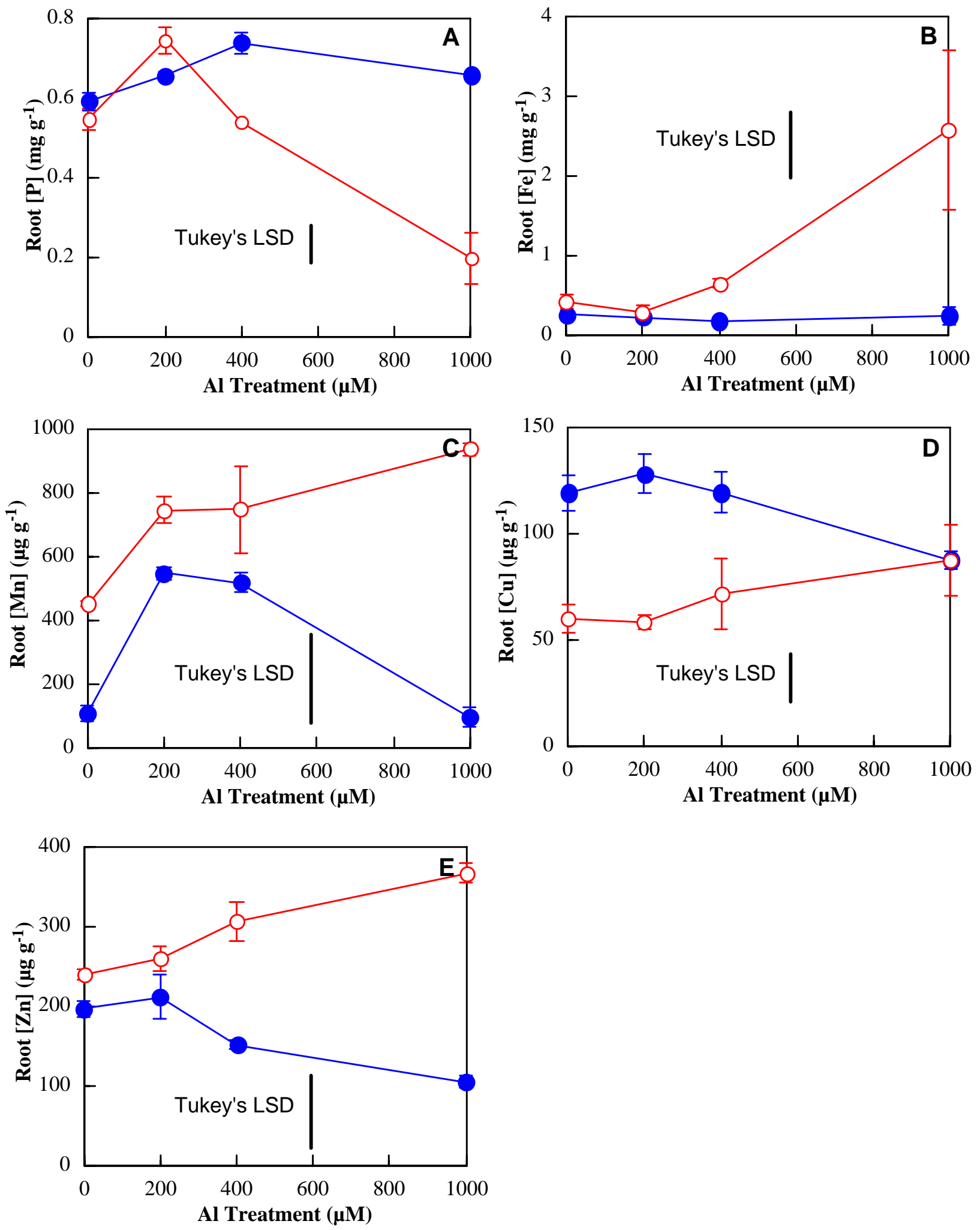
Figure 2.9. Relationships between resistance index and percentage inhibition of nutrient uptake in mycorrhizal (solid) and non-mycorrhizal (open) broomsedge (A. virginicus) plants.

Slopes and $\mathrm{R}^{2}$ from the regression:

A. Phosphorus

Mycorrhizal:

Slope: -0.0056 , and $\mathrm{R}^{2}: 0.50$;

Non-mycorrhizal:

Slope: -0.0091 , and $\mathrm{R}^{2}: 0.89$.

B. Potassium

Mycorrhizal:

Slope: -0.0038 , and $\mathrm{R}^{2}$ : 0.30;

Non-mycorrhizal:

Slope: -0.0089 , and $\mathrm{R}^{2}: 0.85$.

C. Calcium

Mycorrhizal:

Slope: -0.0040 , and $\mathrm{R}^{2}$ : 0.77;

Non-mycorrhizal:

Slope: -0.0089 , and $\mathrm{R}^{2}$ : 0.92 .

D. Magnesium

Mycorrhizal:

Slope: -0.0048, and $\mathrm{R}^{2}$ : 0.81;

Non-mycorrhizal:

Slope: -0.0092 , and $\mathrm{R}^{2}$ : 0.94 .

E. Iron

Mycorrhizal:

Slope: -0.0026 , and $\mathrm{R}^{2}$ : 0.39;

Non-mycorrhizal:

Slope: -0.0099 , and $\mathrm{R}^{2}$ : 0.80 .

F. Manganese

Mycorrhizal:

Non-mycorrhizal:

Slope: -0.00215 , and $\mathrm{R}^{2}$ : 0.31;

Slope: -0.0094 , and $\mathrm{R}^{2}$ : 0.86 .

G. Copper

Mycorrhizal:

Slope: -0.0034 , and $\mathrm{R}^{2}$ : 0.66;

Non-mycorrhizal:

Slope: -0.0100 , and $\mathrm{R}^{2}: 0.95$.

H. Zinc

Mycorrhizal:

Slope: -0.0044 , and $\mathrm{R}^{2}$ : 0.69;

Non-mycorrhizal:

Slope: -0.0089 , and $\mathrm{R}^{2}$ : 0.85 .

I. Sodium

Mycorrhizal:

Slope: 0.0001, and $\mathrm{R}^{2}$ : $<0.01$;

Non-mycorrhizal:

Slope: -0.0096 , and $\mathrm{R}^{2}$ : 0.85 . 

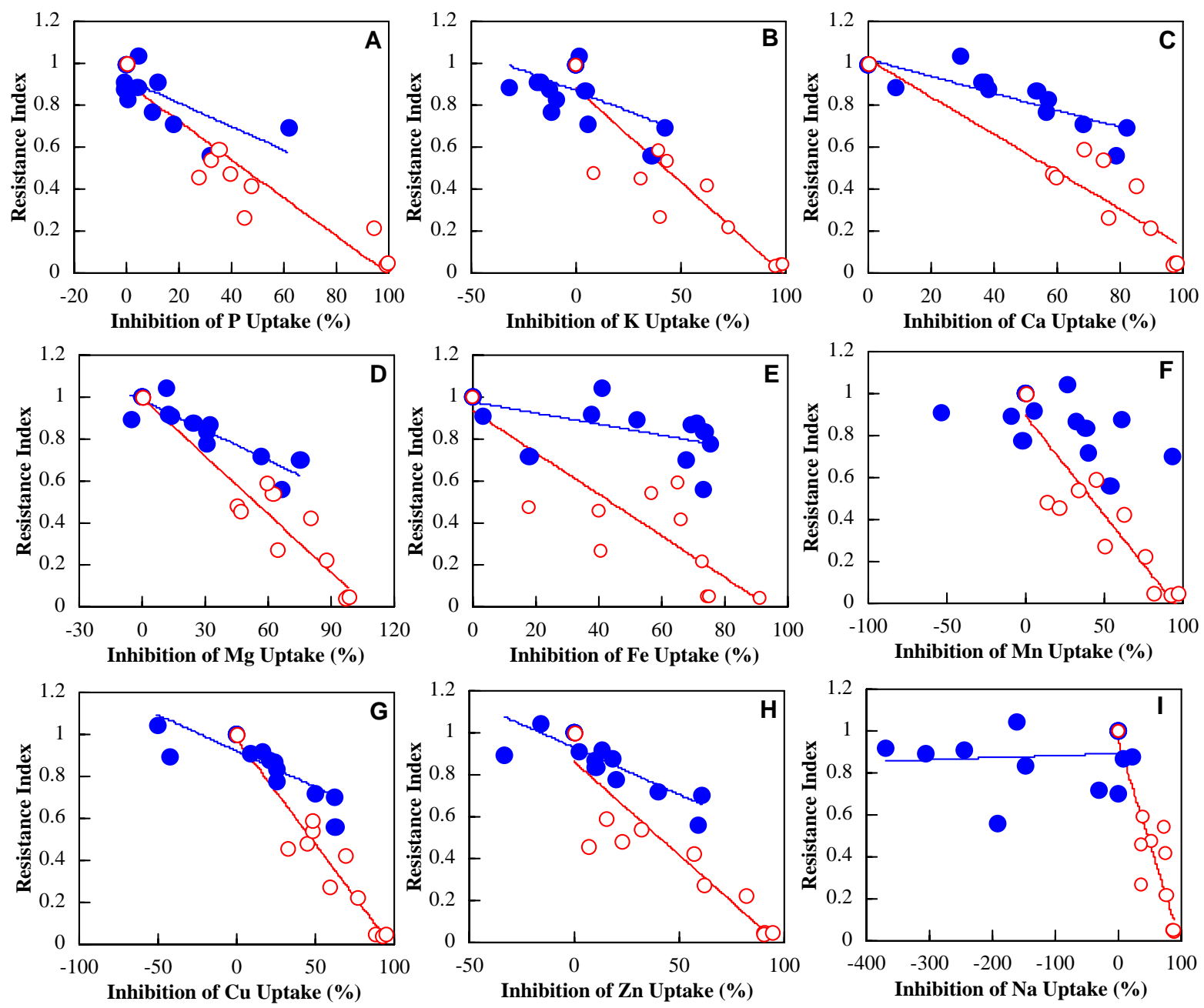
concentrations were pronounced for shoot $\mathrm{P}, \mathrm{K}, \mathrm{Mg}, \mathrm{Fe}, \mathrm{Cu}$, and $\mathrm{Zn}$ concentrations, and root $\mathrm{P}$, $\mathrm{Fe}, \mathrm{Mn}, \mathrm{Cu}$, and $\mathrm{Zn}$ concentrations (Table 2.4). Under $\mathrm{Al}$ exposure (200, 400, and $1000 \mu \mathrm{M} \mathrm{Al})$, mycorrhizal plants maintained narrow boundaries of shoot $\mathrm{P}, \mathrm{K}, \mathrm{Fe}$, and $\mathrm{Cu}$ concentrations across the $\mathrm{Al}$ concentrations (Figure 2.7), reflecting that mycorrhizal plants maintained uptake of these nutrients under $\mathrm{Al}$ exposure. In non-mycorrhizal plants, however, shoot $\mathrm{P}, \mathrm{K}, \mathrm{Mg}, \mathrm{Fe}, \mathrm{Cu}$, and $\mathrm{Zn}$ concentrations were pronouncedly interfered by $1000 \mu \mathrm{M} \mathrm{Al}$ concentration (Figure 2.7). Of interesting was shoot $\mathrm{P}$ concentration reduction in non-mycorrhizal plants by $1000 \mu \mathrm{M} \mathrm{Al}$, which was 13.7 fold lower than that of mycorrhizal plants, reflecting a general effect of $\mathrm{Al}$ on $\mathrm{P}$ acquisition by plants.

Effect of high $\mathrm{Al}$ concentrations on $\mathrm{P}$ concentrations in non-mycorrhizal plants was also observed for root $\mathrm{P}$ concentrations (Figure 2.8). Variations of root $\mathrm{P}, \mathrm{Cu}$, and $\mathrm{Zn}$ concentrations in mycorrhizal plants may be associated with prior balancing these nutrient concentrations in shoots (Figure 2.7 and 2.8). Mycorrhizal plants also had stable root Fe concentrations across Al levels, but root Fe concentrations of non-mycorrhizal plants increased at 400 and $1000 \mu \mathrm{M} \mathrm{Al}$ levels (Figure 2.8). At $1000 \mu \mathrm{M} \mathrm{Al}$, there was significant difference in root $\mathrm{Mn}$ concentrations between mycorrhizal and non-mycorrhizal plants (Figure 2.8).

Different patterns of shoot and root mass and nutrient concentrations in response to $\mathrm{Al}$ concentrations suggested that mycorrhizal fungal colonization may have ameliorated Al detrimental effects on nutrient acquisition. Balanced accumulation of nutrients in mycorrhizal plants exhibited less $\mathrm{Al}$ inhibition of nutrient uptake, consequently resulting in a loose relationship between resistance index and $\mathrm{Al}$ inhibition of $\mathrm{P}, \mathrm{K}, \mathrm{Ca}, \mathrm{Mg}, \mathrm{Fe}, \mathrm{Mn}, \mathrm{Cu}, \mathrm{Zn}$ and $\mathrm{Na}$ uptake (Figure 2.9). On the other hand, adverse effects of $\mathrm{Al}$ on nutrient acquisition observed in higher plants were operative in non-mycorrhizal broomsedge plants as well (Table 2.2, Figure 2.7 and 2.8), so, $\mathrm{Al}$ resistance index decreased as $\mathrm{Al}$ inhibited worse uptake of $\mathrm{P}, \mathrm{K}, \mathrm{Ca}, \mathrm{Mg}, \mathrm{Fe}$, $\mathrm{Cu}, \mathrm{Zn}$, and $\mathrm{Na}$ (Figure 2.9).

\section{Discussion}

Broomsedge is found colonizing acidic soils in the mid-Atlantic United States (Campbell 1983) and is the dominant herbaceous species colonizing extremely edaphic sites (Chapman and Jones 1975; Gibson and Risser 1982), such as abandoned coal mines (Nellssen and Ungar 1993). The chemistry of such soils is dominated by phytotoxic Al. The present study indicates that 
broomsedge is not inherently an Al tolerant, with significant reductions in growth occurring at and above $100 \mu \mathrm{M} \mathrm{Al}$ (Figure 2.2 and 2.4).

The present study shows that AM fungi provide a great benefit to broomsedge plants in terms of plant growth (Figure 2.2 and 2.4) as demonstrated previously (Medeiros et al. 1994, Mendoza and Borie 1998). Furthermore, mycorrhizal plants did not exhibit Al toxic symptoms of growth at $200 \mu \mathrm{M} \mathrm{Al}$ and below, even showed stimulated growth under lower than $100 \mu \mathrm{M} \mathrm{Al}$ concentrations (Figure 2.2 and 2.4). When the $\mathrm{Al}$ treatment was over $400 \mu \mathrm{M}$, which is approximately the $\mathrm{Al}$ concentration of the soil solution in the coal-mining site from where the inoculum originated, mycorrhizal broomsedge plants exhibited some growth reduction, but were still much larger than non-mycorrhizal plants. This indicates that this native AM fungal consortium has adapted to acidic soils and Al stress. In addition, mycorrhizal broomsedge plants allocated more biomass to roots, which would enhance acquisition of limited resources imposed by $\mathrm{Al}$ presence, such as phosphorus.

Under low Al levels, such as $10 \mu \mathrm{M}$, the leachate $\mathrm{pH}$ of both mycorrhizal and nonmycorrhizal plants initially rose up to 5.0 after they established, which would significantly affect Al speciation in the solution (Figure 2.1). But the high $\mathrm{Al}$ concentrations (over $50 \mu \mathrm{M}$ ) in the nutrient solutions limited the capability of plants to alter leachate $\mathrm{pH}$ (Figure 2.1), which may be related to high $\mathrm{Al}$ buffering capacity under high $\mathrm{Al}$ concentrations. These results are consistent with the previous reports (Rengel and Robinson 1989), suggesting that the rhizosphere $\mathrm{pH}$ change under $50 \mu \mathrm{M}$ and higher concentrations plays a minor role in Al resistance of plants (Miyasaka et al. 1989, Rengel and Robinson 1989).

Shoot and root $\mathrm{Al}$ and $\mathrm{P}$ concentrations (Table 2.2 and 2.3) indicated that in the early stage of the development, AM fungi facilitated $\mathrm{P}$ acquisition in broomsedge plants exposed to 50 $\mu \mathrm{M} \mathrm{Al}$ and above, which undoubtedly supports long-term growth of host plants under $\mathrm{Al}$ exposure. The capability of mycorrhizal fungi mining $\mathrm{P}$ from limited $\mathrm{P}$ sources under conditions of Al existence was observed in other fungi and plants (Cumming and Weinstein 1990). Meanwhile, AM fungi limited Al influx into host plants, further improving the growth of host broomsedge plants. These two roles of AM fungi in broomsedge plants under Al toxicity are important for this plant species to establish in acidic soils, where phosphorus limitation and $\mathrm{Al}$ toxicity are the primary factors limiting plant growth. For a long-term Al exposure, mycorrhizal plants maintained lower shoot and root $\mathrm{Al}$ concentration than non-mycorrhizal plants when $\mathrm{Al}$ concentrations in root zones were higher than $400 \mu \mathrm{M}$ (Figure 2.6). The reduction of shoot and 
root $\mathrm{Al}$ concentrations in host plants by $\mathrm{AM}$ fungi were also found in other plant species (Koslowsky and Boerner 1989; Medeiros et al. 1994; Mendoza and Borie 1998). Disruption of P availability and acquisition by $\mathrm{Al}$ is believed to be one of $\mathrm{Al}$ toxic mechanisms in plants (Randall and Vose 1963; Clarkson 1966; Foy 1983; Roy et al. 1988; Andersson 1988; de Miranda and Rowell 1989; Taylor 1988; Tan and Keltjens 1990; Macklon and Sim 1992). The present study showed that $\mathrm{Al}$ exposure adversely affected $\mathrm{P}$ uptake by non-mycorrhizal broomsedge plants, especially in the early stages of plant development (Table 2.3). Data of acid phosphatase activity (Figure 2.3) also suggest that mycorrhizal plants were under less $\mathrm{P}$ stress than non-mycorrhizal plants. For a long-term $\mathrm{Al}$ exposure, high $(1000 \mu \mathrm{M}) \mathrm{Al}$ extremely reduced shoot and root $\mathrm{P}$ concentrations of non-mycorrhizal plants (Figure 2.7 and 2.8). However, mycorrhizal plants maintained stable foliar P concentrations across the Al levels (Figure 2.7).

Numerous experiments have demonstrated that Al interferes with the acquisition of cations in plants (Rengel and Robinson 1989, Huang et al. 1992, Nichol et al. 1993, Wheeler and Dodd 1995, Lindberg and Strid 1997), although there are reports that root growth cessation and Al-induced alterations in divalent cation flux are not correlated (Ryan and Kochian 1993, Ryan et al. 1993, Jones et al. 1998). These all are short-term experiments and suggest that Al toxicity and resistance in plants may or may not be related to uptake and translocation of divalent cations from the rhizosphere. In long-term $\mathrm{Al}$ studies, the disruption of $\mathrm{Ca}$ and $\mathrm{Mg}$ nutrition is frequently observed (Rengel and Robinson 1989, Tan et al. 1993). The similar detrimental effects of $\mathrm{Al}$ on shoot and root $\mathrm{Ca}$ and $\mathrm{Mg}$ concentrations were noted for both mycorrhizal and non-mycorrhizal broomsedge plants in the present study (Table 2.4, Figure 2.7 and 2.8), suggesting that AM fungi have no direct effect on acquisition of these two cations (Smith and Read 1997).

Differences in shoot and root nutrient concentrations between mycorrhizal and nonmycorrhizal plants exposed to $\mathrm{Al}$ can be related to differential effects of $\mathrm{Al}$ on nutrient availability to and acquisition by plants (Foy 1983; Roy et al. 1988; Marschner 1995). Aluminum inhibits root elongation, which reduces root zones, and affects membrane permeability of root cells, consequently changing elemental influx into roots (Foy 1983; Andersson 1988; Taylor 1988; Kochian 1995). Therefore, non-mycorrhizal broomsedge plants exhibited disrupted status of shoot and root nutrition (Figure 2.7 and 2.8). Arbuscular mycorrhizal fungi greatly enhanced root growth (Figure 2.4), mined scarce resources (Table 2.2 and 2.3, Figure 2.7 and 2.8), and reduced Al impacts (Figure 2.2, 2.4, and 2.9). All these 
benefits of AM fungi to host plants fostered the balanced accumulation of shoot $\mathrm{K}, \mathrm{Fe}, \mathrm{Cu}$, and $\mathrm{Zn}$, concentrations and root Fe concentrations in broomsedge plants (Table 2.4, Figure 2.7 and 2.8).

The differences in relationships of $\mathrm{Al}$ resistance index and $\mathrm{Al}$ inhibition of nutrient uptake between mycorrhizal and non-mycorrhizal plants suggest that detrimental effects of $\mathrm{Al}$ on nutrient acquisition in non-mycorrhizal plants may be one of primary Al toxic mechanisms (Foy 1983; Taylor 1988; Kochian 1995). In mycorrhizal broomsedge plants, AM fungi limited Al influence (Table 2.2, Figure 2.6) and improved nutrition of host plants (Table 2.4, Figure 2.7 and 2.8), so that the host plants were no longer under nutrient stress as much as non-mycorrhizal plants were. Given these conditions, Al resistance in mycorrhizal plants is less dependent on reduction of $\mathrm{Al}$ inhibition of nutrient uptake as indicated by Figure 2.9. This relationship between $\mathrm{Al}$ resistance and $\mathrm{Al}$ inhibition of nutrient uptake also implies that balanced accumulation of nutrients maybe become more important than facilitation and/or reduction of nutrient uptake in mycorrhizal plants exposed to Al.

In conclusion, broomsedge appears not to have an inherent mechanism to block $\mathrm{Al}$ influx and resist $\mathrm{Al}$ in the rhizosphere. Although broomsedge plants are capable of adjusting the rhizosphere $\mathrm{pH}$, this capability is very limited, especially at high $\mathrm{Al}$ concentrations. Aluminum significantly reduced broomsedge plant growth possibly by mainly interfering availability, acquisition, and translocation of nutrients in non-mycorrhizal plants, as evidenced by close relationships between $\mathrm{Al}$ resistance and $\mathrm{Al}$ inhibition of nutrient uptake in non-mycorrhizal plants. The acid ecotypic AM fungi used in this experiment conferred Al resistance to broomsedge. Arbuscular mycorrhizal fungi enhanced $\mathrm{P}$ acquisition by and reduced $\mathrm{Al}$ influx to host plants in the early stage of development. For a long-term high Al exposure, reduction of Al influx into host plants, consequently leading to less Al impacts on the host plants, and regulation of $\mathrm{P}$ uptake by AM fungi may be an important mechanism for plants to survive and establish in acidic soils. The impacts of $\mathrm{Al}$ on nutrient acquisition in mycorrhizal plants were less pronounced than in non-mycorrhizal plants. The balanced accumulation of nutrients in mycorrhizal plants exposed to $\mathrm{Al}$ may be another important mechanism involved in the $\mathrm{Al}$ resistance. Thus, the symbiosis between AM fungi and broomsedge plants plays critical roles in Al resistance of this plant species, which allows this plant species establish and grow in acidic soils. 


\section{CHAPTER III}

\section{Differential Responses of Different Mycorrhizal and Non- Mycorrhizal Broomsedge Plants to Aluminum}

\section{Introduction}

Plant roots release organic acids into the rhizosphere in response to some adverse environmental factors (Curl and Truelove 1986; Kochian 1995; Marschner 1995; Strom 1997). Aluminum is one of the primary edaphic factors limiting plant growth on acidic soils. However, there is a wide range of Al sensitivity among and within plant species (Andersson 1988; Blamey et al. 1992; Bona et al. 1994; Wheeler and Dodd 1995). For example, there is differential Al sensitivity of two co-existing woodland plant species that may be associated with Al disruption of macronutrients in plants (Andersson 1992; Andersson and Brunet 1993). Different responses of 10 selected crops to $\mathrm{Al}$ were observed, which is not related to root cation-excahnge capacity (Blamey et al. 1992). With 34 species and 143 genotypes of temperate legume exposed to Al, large different responses were observed in terms of growth and tissue nutrients (Wheeler and Dodd 1995). One proposed mechanism for $\mathrm{Al}$ resistance in plants is the chelation of $\mathrm{Al}$ in the rhizosphere by organic acids exuded from root systems (Delhaize and Ryan 1995; Kochian 1995; Ma 2000). Different plant species excrete different organic acids in response to Al treatments. Quantity of organic acids is also different with different plant species and cultivars and Al levels. For example, snapbean (Phaseolus vulgaris) produces citrate, but the tolerant cultivar (Dade) exudes 50 times more citric acid with $\mathrm{Al}$ exposure compared to without $\mathrm{Al}$ exposure, and 10 times more than the sensitive cultivar (Romano) (Miyasaka et al. 1991). The Al-tolerant cultivar ET3 of wheat (Triticum aestivum) releases 5- to 10-fold more malic acid than Al-sensitive cultivar ES3 and the effect is more pronounced with longer Al exposure (Delhaize et al. 1993). More oxalic acid is secreted by buckwheat (Fagopyrum esculentum) roots in response to increased $\mathrm{Al}$ concentrations in the bathing solution and longer Al exposure (Ma et al. 1997). Different organic acids differentially ameliorate Al toxicity in plants. Citrate, oxalate, malate, tartrate, succinate, lactate, formate, and acetate, in order of importance, detoxify Al (Taylor 1988; Miyasaka et al. 1991; Strom 1997). 
A role of mycorrhizal fungi in $\mathrm{Al}$ resistance of plants has been recognized (Koslowsky and Boerner 1989; Shaw and Read 1989; Cumming and Weinstein 1990; Medeiros et al. 1994; Yang and Goulart 1997; Mendoza and Borie 1998; Chapter II). One of the important benefits provided by mycorrhizas to plants exposed to $\mathrm{Al}$ is the facilitation of nutrient acquisition, especially $\mathrm{Pi}$, and reduction of Al uptake (Koslowsky and Boerner 1989; Medeiros et al. 1994; Smith and Read 1997; Mendoza and Borie 1998; Chapter II). In the previous study with broomsedge (Andropogon virginicus) (Chapter II), arbuscular mycorrhizal (AM) fungi collected from an acidic minesoil significantly reduced the impacts of $\mathrm{Al}$ on growth and nutrient relations.

Furthermore, different mycorrhizal fungi, even strains of the same fungal species, differentially contribute to acidic resistance and metal resistance in host plants (Goldon and Tinker 1981; Koslowsky and Boerner 1989; Medeiros et al. 1994; Clark 1997). These differential effects of different mycorrhizal fungi may be associated with their roles in the original habitats. For example, switchgrass plants colonized by an AM fungal isolate from a high $\mathrm{Al}$ site had significantly lower tissue $\mathrm{Al}$ concentrations, but higher shoot mass, and more tillers than plants colonized by an isolate from a low Al site (Koslowksy and Boerner 1989).

Because root exudation of organic acids plays an important role in Al detoxification, I hypothesized that $\mathrm{AM}$ fungi may confer $\mathrm{Al}$ resistance by altering the profile of root exudates which may protect roots from the detrimental effects of $\mathrm{Al}$ on growth of host plants. An early review by Curl and Truelove (1986) highlighted the influence of microorganisms present in the rhizosphere on root exudation. A study of cucumber (Cucumis sativus) by Pinior et al. (1999) suggest that mycorrhizal fungal colonization alters the profile of the root exudates. Furthermore, there are no investigations of how this alteration of root exudation affects $\mathrm{Al}$ resistance in plants.

The present study examined the profiles of organic acids from the rhizosphere of broomsedge plants exposed to different $\mathrm{Al}$ levels, investigated mycorrhizal effects on rhizosphere organic acids and its relationship with $\mathrm{Al}$ resistance in the plants, and assessed the effects of different AM fungal isolates on plant nutritional status and their relationships with the root exudation of organic acids. I hypothesize that 1) different AM fungi differentially affect exudation of organic acids from root systems; 2) the differences in the exudation of organic acids may be involved in differential Al resistance among different mycorrhizal and non-mycorrhizal plants. 


\section{Materials and Methods}

Preparation of AM Fungal Inocula

AM fungal inocula were used in this study, separately originated from two abandoned coal mining sites in West Virginia. One site is in Mingo County, having soil $\mathrm{pH}$ of 6.6 and containing $\mathrm{NaHCO}_{3}$-extractable $\mathrm{Pi}$ of $19 \mathrm{mg}$ per $\mathrm{kg}$ of soil. At this $\mathrm{pH}, \mathrm{Al}$ is not toxic to plants. Soil from the other site in Monongalia County has a pH from 3.0 to 3.3, containing Melichextractable Pi of $3.76 \mathrm{mg}$ per $\mathrm{kg}$ of soil and $\mathrm{Al}$ of $363.12 \mathrm{mg}$ per $\mathrm{kg}$ of soil.

To produce the inocula of Glomus clarum, inocula (WV233-1 and WV219A-5) from the INVAM collection at West Virginia University, which originated separately from the Monongalia site and the Mingo site, were used to inoculated sterilely germinated broomsedge plants, respectively. These inoculated broomsedge plants were planted into $15 \mathrm{~cm}$ diameter pots containing a mixture of autoclaved mine-soil from the Monongalia site and sand (1:3 v/v). After a month, the pot contents became the sources of infective LM and HM inoculum for the experiment, respectively, where LM and HM separately represent mycorrhizal fungi from low $\mathrm{pH}$ site at Monongalia abandoned coal mine and high pH site at Mingo abandoned coal mine.

Preparation of Plants

Broomsedge seeds were sown around the transplants in nursery pots $(15 \mathrm{~cm}$ diameter). Broomsedge seeds also were sown in pots containing sterile-germinated broomsedge and the mixture of autoclaved mine-soil and sand $(1: 3 \mathrm{v} / \mathrm{v})$. Seedlings from these pots served as a nonmycorrhizal control. After four weeks growth, roots of a small subset of seedlings ( $c a .10$ from each pot) were examined to determine mycorrhizal status. Tissue P status was analyzed after wet digestion (Parkinson and Allen 1975) by the molybdate blue method (Olsen and Sommers 1982). Tissue phosphorus concentrations and tissue dry weights between mycorrhizal and nonmycorrhizal plants did not differ significantly at the time of transplanting.

Nutrient Solution and Growth Conditions

Mycorrhizal and non-mycorrhizal broomsedge seedlings were transplanted and grown in D16 Deepots (5 cm diameter x $18 \mathrm{~cm}$ height) (Stuewe and Sons, Inc., Corvallis, Oregon, USA) pre-filled with $220 \mathrm{~cm}^{3}$ of a 3:1 (v/v) mixture of coarse:fine acid-washed sand. Deepots were placed into a growth chamber with 14 hours of light at $28^{\circ} \mathrm{C}, 60 \% \mathrm{RH}$, and 10 hours of darkness 
at $21^{\circ} \mathrm{C}, 50 \% \mathrm{RH}$. Average light intensity at pot height in the chamber was $260 \mu \mathrm{mol} \mathrm{m} \mathrm{s}^{-1}$ from mixed fluorescent and incandescent sources. Plants received a baseline nutrient solution containing $\mathrm{PO}_{4}(40 \mu \mathrm{M}), \mathrm{Ca}(0.675 \mathrm{mM}), \mathrm{K}(0.79 \mathrm{mM}), \mathrm{Mg}(0.25 \mathrm{mM}), \mathrm{NO}_{3}(1.5 \mathrm{mM}), \mathrm{NH}_{4}(0.5$ $\mathrm{mM}), \mathrm{SO}_{4}(0.25 \mathrm{mM}), \mathrm{B}(23.14 \mu \mathrm{M}), \mathrm{Fe}(25 \mu \mathrm{M}), \mathrm{Mn}(4.57 \mu \mathrm{M}), \mathrm{Zn}(0.38 \mu \mathrm{M}), \mathrm{Cu}(0.16 \mu \mathrm{M})$, and Mo $(0.06 \mu \mathrm{M})$. All solutions were adjusted to $\mathrm{pH} 4.0$ after $\mathrm{Al}$ treatment was added and before application. Solutions (approximately $15 \mathrm{ml}$ ) were automatically delivered to the plants three times each day for eight weeks.

\section{Plant Growth}

Following establishment (a week), seedlings were exposed to 0, 200, 400, or $1000 \mu \mathrm{M} \mathrm{Al}$ in a form of $\mathrm{AlCl}_{3}$. Simulation analysis of these solutions by the program GEOCHEM (Parker et al. 1993) indicated that $\mathrm{Al}^{3+}$ concentrations were $0,133.9,379.4$, and $945.8 \mu \mathrm{M}$ in the solutions, respectively. For data analysis, delivered Al concentrations were used. The treatments were arranged in a Al-by-mycorrhizal factorial design in a growth chamber with 10 replicates for each treatment combination. Solution draining (leachate) from four Deepots per treatment was collected for an hour following one solution delivery weekly. The leachate $\mathrm{pH}$ was measured.

Plants were harvested following eight weeks of treatment. Plants were gently removed from the pots. After extraction of organic acids, roots were excised. Shoots and roots were rinsed in running de-ionized water, dried at $60^{\circ} \mathrm{C}$, weighed, and ground. Tissue digestion and determination of tissue elements were the same as in previous experiments (Chapter II).

\section{Extraction and Analysis of Rhizosphere Organic Acids}

Extraction The root system with intact sand was dipped into de-ionized water in a volumetric container. The water volume used $\left(\mathbf{V}_{\text {water }}\right)$ depended on the root system size. The change in the volume was recorded and represented the total rhizosphere volume plus the root system and adhering sand volumes $\left(\mathbf{V}_{\text {total }}\right)$. The root system was shaken gently for 5 minutes, removed, dried by folding it in tissue paper, and submerged into another volumetric container containing a known volume of water. The change in the volume was the root volume $\left(\mathbf{V}_{\text {root }}\right)$. The extraction solution in the first container was transferred into $15 \mathrm{ml}$ centrifuge tubes. The sand remaining in the first container was dried in an oven and its volume was measured $\left(\mathbf{V}_{\text {sand }}\right)$.

Preparation for the Ion Chromatography Analysis Ten $\mathrm{mM}$ of $\mathrm{Na}_{2}$-EDTA was added into each of the centrifuge tubes containing the extraction solution to a final concentration of 
$10 \%(\mathrm{v} / \mathrm{v})$. The $\mathrm{pH}$ was adjusted to neutral and samples were concentrated using a SpeedVac (Savant corp., NY). The residual salt in each tube was dissolved in $1 \mathrm{ml}$ of de-ionized water, which was passed through a C18 column (Dionex Corp, Sunnyside, CA).

Ion chromatography Analysis The ion chromatography analysis was performed using a Dionex DX-300 Ion Chromatograph, an IonPac ICE-AS6 column, with detection by conductivity (Dionex Corp., Sunnyvale, CA). The operating conditions were after the suggestion by the company with a little of modifications: $1.6 \mu \mathrm{M}$ heptafuorobutyric acid as the eluent at $1 \mathrm{ml} \mathrm{min}^{-1}$ flow rate and $0.4 \mu \mathrm{M}$ tetrabutyl-ammonium hydroxide as the suppressant. A mixture of $20 \mu \mathrm{M}$, $50 \mu \mathrm{M}$, or $100 \mu \mathrm{M}$ standard organic acids (acetate, citrate, formate, fumarate, glycolate, malate, succinate, tartrate), which was prepared following the same procedure as the samples, was analyzed with the samples in the same run. Data were acquired and calibrated with the standard organic acids using Dionex AI-450 Chromatography Software Program (release 3.33). The final amount ( $\mu \mathrm{mol})$ of organic acid was calculated as:

\section{$\mathbf{C} \cdot \mathbf{V}_{\text {water }}$}

where $\mathbf{C}$ was concentration of an organic acid from Dionex, and concentration of an organic acid $(\mu \mathrm{M})$ was calculated using following equation:

$$
\left(\mathbf{C} \cdot \mathbf{V}_{\text {water }}\right) /\left(\mathbf{V}_{\text {total }}-\mathbf{V}_{\text {root }}-\mathbf{V}_{\text {sand }}\right)
$$

\section{Data Analysis}

Data were analyzed by analyses of covariance with Al concentrations treated as a covariate and regression analysis using the statistical package JMP (SAS Institute, Cary, North Carolina, USA).

\section{Results}

Through the experiment, leachate $\mathrm{pH}$ with $\mathrm{Al}$ treatments was never higher than 4.20 (data not presented), indicating that the $\mathrm{Al}$ primarily existed as $\mathrm{Al}^{3+}$ in the solutions (Snoeyink and Jenkins 1980). 
Non-mycorrhizal plants exhibited Al toxicity symptoms even at $200 \mu \mathrm{M} \mathrm{Al} \mathrm{level,} \mathrm{such} \mathrm{as}$ stunted roots (data not presented). At higher Al levels, non-mycorrhizal plants grew little (Figure 3.1). Colonization by both AM fungal isolates significantly enhanced shoot and root dry weights at $400 \mu \mathrm{M} \mathrm{Al}$ level and below, at which Al levels there was no significant difference in shoot and root mass between LM and HM mycorrhizal plants (Figure 3.1). At $1000 \mu \mathrm{M} \mathrm{Al}$ level, HM mycorrhizal plants were still significantly larger than non-mycorrhizal plants, but LM mycorrhizal and non-mycorrhizal plants did not significantly differ in shoot and root mass (Figure 3.1), reflecting that different AM fungal isolates differentially affected growth of the same host plant species under Al exposure.

Al treatment did not significantly affect on mycorrhizal colonization (Myc $P=0.951$, Al $P=0.307$, and $\mathrm{Myc} * \mathrm{Al} P=0.603)$. LM and HM colonization over all the Al treatments was $36.16 \%$ and $33.93 \%$, respectively.

Shoot and root $\mathrm{Al}$ concentrations of mycorrhizal and non-mycorrhizal plants depended on the solution Al concentrations (Figure 3.2). Shoot Al concentrations of both mycorrhizal plants colonized by LM and HM isolates were significantly lower than those of non-mycorrhizal plants at all $\mathrm{Al}$ levels except at $200 \mu \mathrm{M} \mathrm{Al}$, where LM mycorrhizal and non-mycorrhizal plants did not significantly differ (Figure 3.2). For root Al concentrations, non-mycorrhizal plants had significantly higher values at all Al levels than LM mycorrhizal plants, but did not significantly differ from HM mycorrhizal plants except at $200 \mu \mathrm{M}$ Al level, where root Al concentration of HM mycorrhizal plants was significantly lower than that of non-mycorrhizal plants (Figure 3.2). 
Figure 3.1. Influence of $\mathrm{Al}$ treatment on shoot $(\mathbf{A})$ and root $(\mathbf{B})$ mass of LM mycorrhizal (solid circle), HM mycorrhizal (solid triangle), and non-mycorrhizal (open circle) broomsedge ( $A$. virginicus) plants.

$P$ values from ANCOVA:

A. Shoot mass

Myc: $<0.001, \mathrm{Al}:<0.001$, and Myc * Al: $\mathrm{ns}^{\dagger}$;

B. Root mass

Myc: $<0.001, \mathrm{Al}:<0.001$, and Myc* Al: 0.032 .

$\alpha=0.05$, the same hereafter. 

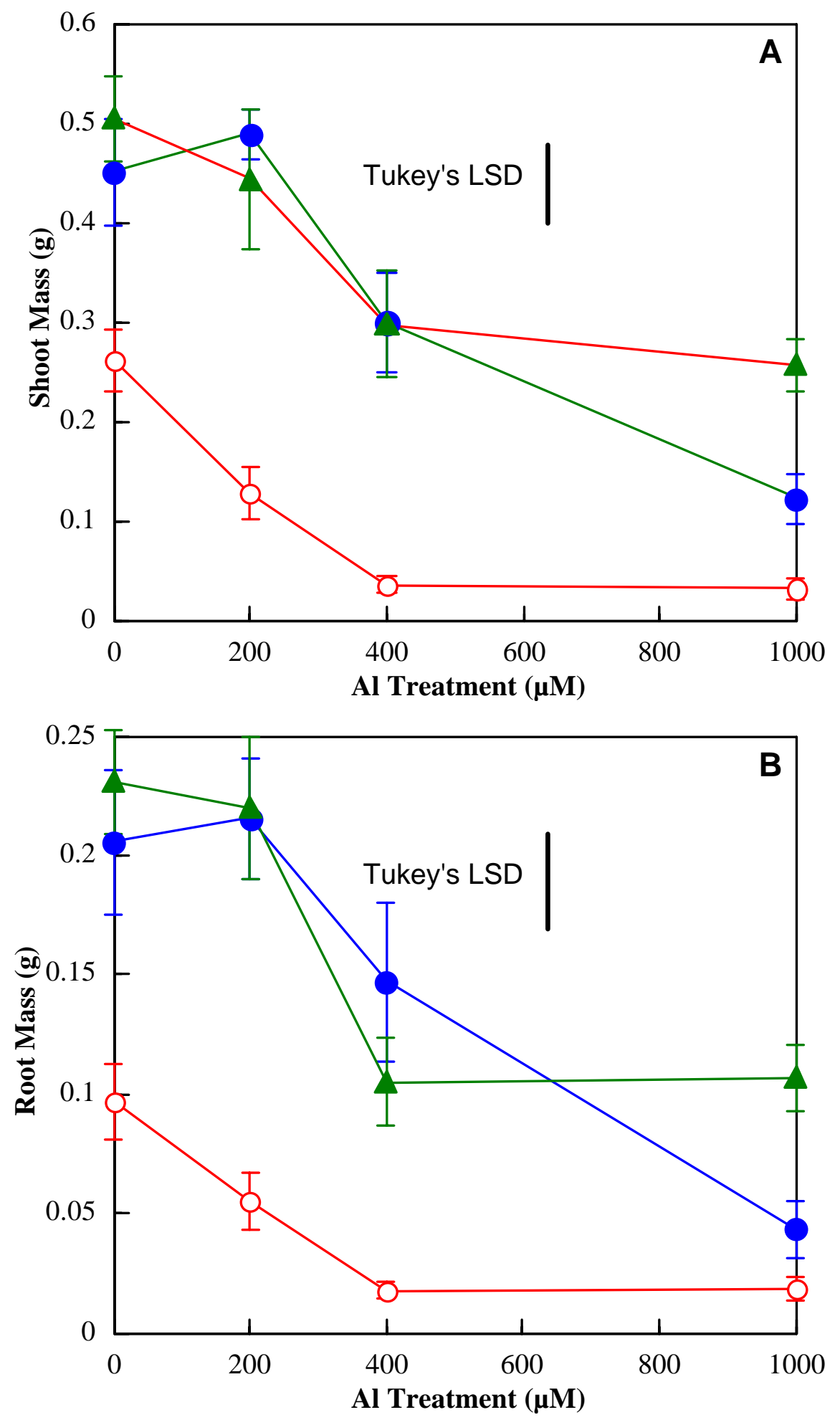
Figure 3.2. Influence of $\mathrm{Al}$ treatment on shoot $(\mathbf{A})$ and root $(\mathbf{B}) \mathrm{Al}$ concentrations of LM mycorrhizal (solid circle), HM mycorrhizal (solid triangle), and non-mycorrhizal (open circle) broomsedge (A. virginicus) plants.

$P$ values from ANCOVA:

A. Shoot $\mathrm{Al}$ concentrations

Myc: 0.035, Al: $<0001$, and Myc * Al: $<0.001$.

B. Root Al concentrations

Myc: 0.054, Al: < 0.001, and Myc* Al: 0.043 . 

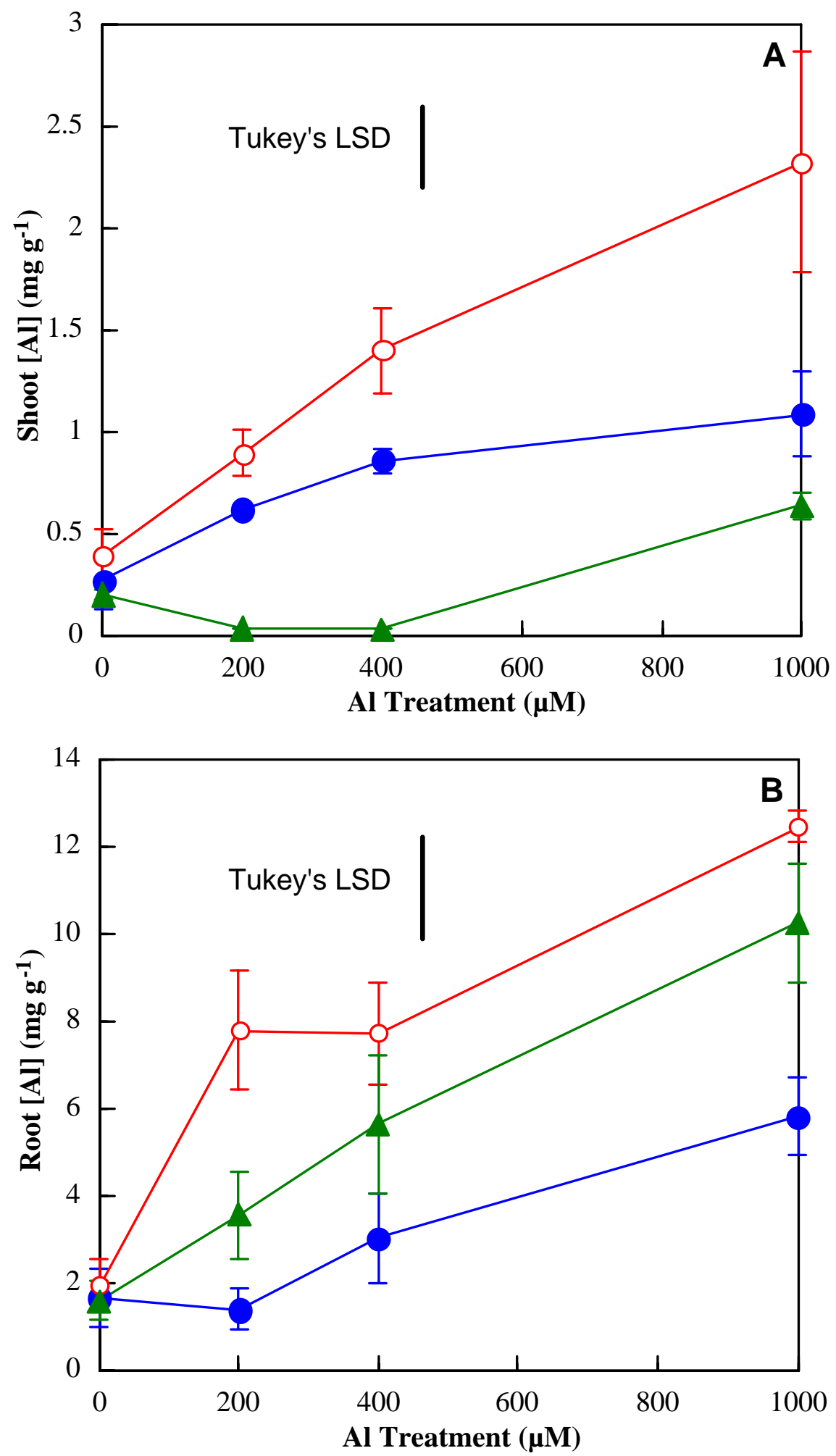
Table 3.1. Influence of $\mathrm{Al}$ treatment on productions of organic acids ( $\mu \mathrm{mol} \mathrm{g}^{-1}$ of root mass) extracted from the rhizosphere of LM mycorrhizal, HM mycorrhizal, and non-mycorrhizal broomsedge (A. virginicus) plants.

\begin{tabular}{|c|c|c|c|c|c|c|c|c|c|}
\hline $\mathbf{A l}(\mu \mathrm{M})$ & Мyc & Formate & Acetate & Glycolate & Lactate & Malate & Tartrate & Citrate & unknown \\
\hline \multirow[t]{3}{*}{ 0 } & LM & 2.734 & 1.721 & 2.301 & 6.524 & 2.116 & 0.274 & 1.427 & 15.110 \\
\hline & HM & 4.133 & 1.625 & 7.578 & 4.418 & 3.966 & 0.276 & 1.791 & 27.860 \\
\hline & NM & 3.452 & 3.896 & 0 & 5.063 & 1.523 & 0 & 0.707 & 0 \\
\hline \multirow[t]{3}{*}{200} & LM & 1.854 & 3.259 & 0 & 7.010 & 0.972 & 0.244 & 1.511 & 11.502 \\
\hline & HM & 3.618 & 1.636 & 0 & 4.509 & 3.319 & 0.179 & 2.495 & 20.543 \\
\hline & NM & 1.974 & 1.683 & 0 & 8.398 & 3.579 & 0 & 1.532 & 0 \\
\hline \multirow[t]{3}{*}{400} & LM & 2.110 & 3.418 & 0 & 7.166 & 0 & 0 & 2.291 & 0 \\
\hline & HM & 7.475 & 6.301 & 0 & 7.838 & 3.954 & 0 & 2.718 & 0 \\
\hline & NM & 11.935 & 4.127 & 0 & 19.590 & 3.041 & 0 & 2.361 & 0 \\
\hline \multirow[t]{4}{*}{1000} & $\mathbf{L M}$ & 6.402 & 5.038 & 0 & 21.032 & 0 & 0 & 2.665 & 0 \\
\hline & HM & 3.336 & 4.128 & 0 & 4.724 & 0 & 0 & 1.977 & 0 \\
\hline & NM & 6.573 & 7.104 & 0 & 8.438 & 2.366 & 0 & 5.218 & 0 \\
\hline & $\mathbf{L S D}^{f}$ & 3.732 & 2.063 & 2.071 & 3.767 & 1.899 & 0.022 & 0.730 & 5.333 \\
\hline$P$ & $\mathbf{M}$ & $\mathrm{ns}^{*}$ & ns & $<0.001$ & ns & 0.003 & $<0.001$ & 0.002 & $<0.001$ \\
\hline \multirow[t]{2}{*}{ values } & Al & 0.041 & $<0.001$ & 0.005 & $<0.001$ & 0.021 & $<0.001$ & $<0.001$ & $<0.001$ \\
\hline & $\mathbf{M} * \mathbf{A l}$ & ns & ns & 0.010 & 0.002 & ns & $<0.001$ & $<0.001$ & $<0.001$ \\
\hline
\end{tabular}

${ }^{\dagger}$ Unidentified organic acid at ca 26.0 minute of retention time, and its unit is area per gram of root mass.

${ }^{f}$ Tukey's Least Significant Difference at 0.05 level with $\mathrm{N}$ of from 5 to 12.

$\alpha=0.05$, the same hereafter. 
Figure 3.3. Influence of $\mathrm{Al}$ treatment on citrate $(\mathbf{A})$ and lactate $(\mathbf{B})$ production of LM mycorrhizal (solid circle), HM mycorrhizal (solid triangle), and non-mycorrhizal (open circle) broomsedge (A. virginicus) plants.

Slopes and $P$ values from the regression:

A. Citrate

LM mycorrhizal: slope $=0.00129$ and $P$ value $=0.015$;

HM mycorrhizal: slope $=-0.00036$ and $P$ value: ns;

Non-mycorrhizal: slope $=0.00457$ and $P$ value $<0.001$.

B. Lactate

LM mycorrhizal: slope $=0.01358$ and $P$ value $<0.001$;

HM mycorrhizal: slope $=0.00040$ and $P$ value: ns;

Non-mycorrhizal: slope $=0.04190$ (linear) and -0.00004 (quadratic), and $P$ value $=0.003$ (linear) and 0.006 (quadratic). 

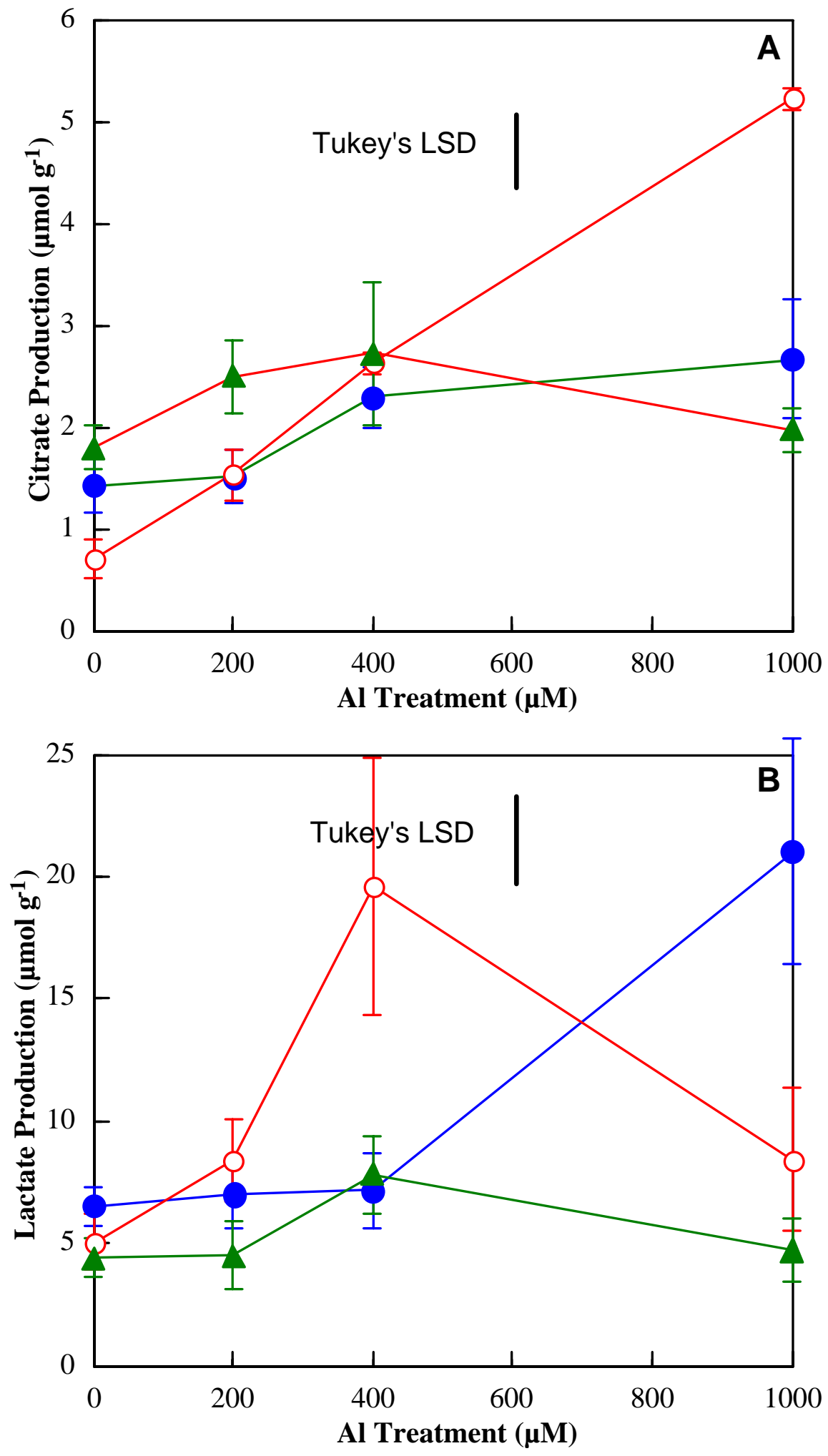
Figure 3.4. Influence of $\mathrm{Al}$ treatment on total amount ( $\mu \mathrm{mol})$, total production $\left(\mu \mathrm{mol} \mathrm{g}^{-1}\right)$, and total concentration $(\mathrm{mM})$ of organic acids (R-COOH) in rhizosphere of LM mycorrhizal (solid circle), HM mycorrhizal (solid triangle), and non-mycorrhizal (open circle) broomsedge ( $A$. virginicus) plants.

$P$ values from ANCOVA:

A. Total amount of organic acids $(\mu \mathrm{mol})$ :

Myc: $<0.001$;

$\mathrm{Al}:<0.001$;

Myc* Al: ns.

B. Total production of organic acids $\left(\mu \mathrm{mol} \mathrm{g} \mathrm{g}^{-1}\right)$ :

Myc: $<0.001$;

Al: 0.008;

Myc * Al: $<0.001$.

C. Total concentration of organic acids $(\mathrm{mM})$ :

Myc: $<0.001$;

Al: 0.026;

$\mathrm{Myc} * \mathrm{Al}: \mathrm{ns}$. 

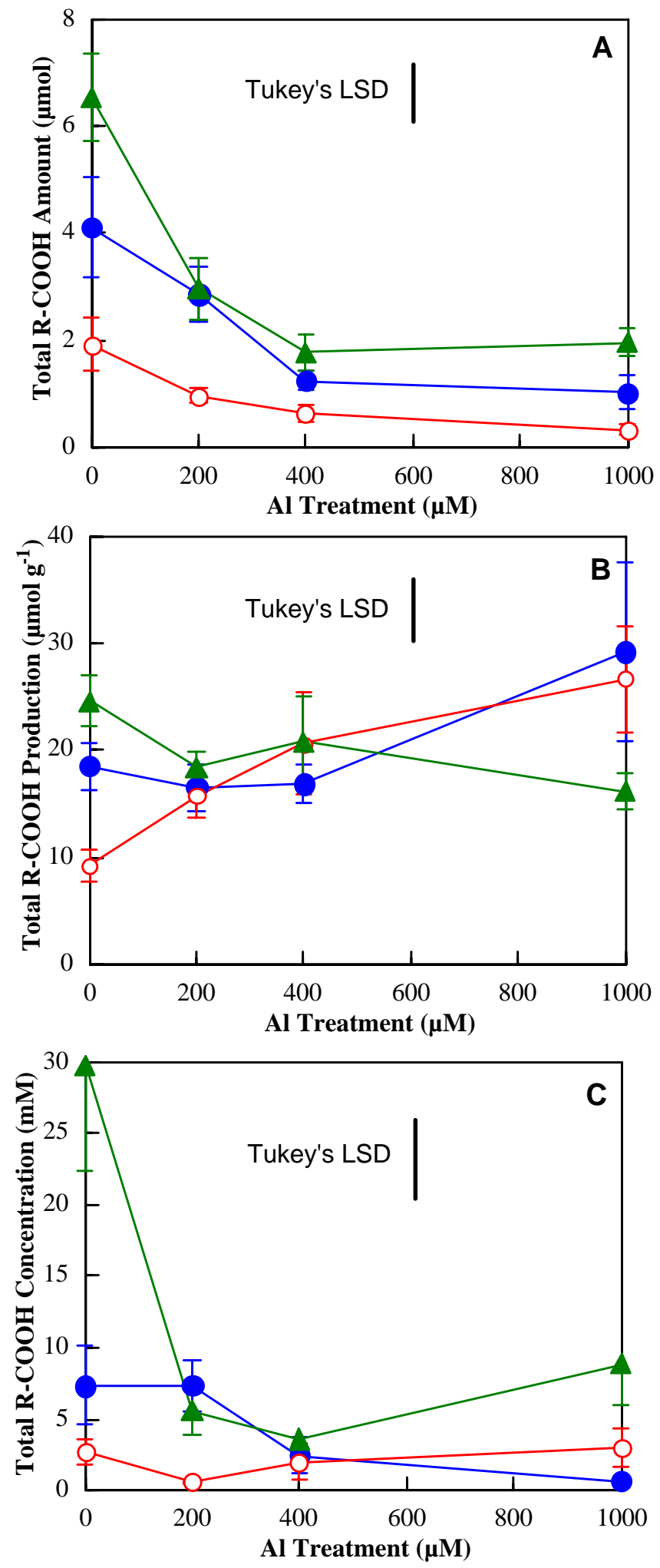
Patterns of exudation of organic acids depended on both Al and mycorrhizal treatments (Table 3.1). Glycolate was released only by LM and HM mycorrhizal plants under a condition of no Al exposure. Tartrate and an unidentified organic acid were also exuded only by both mycorrhizal plants at 0 and $200 \mu \mathrm{M} \mathrm{Al}$. Exudation of lactate and citrate by LM mycorrhizal, HM mycorrhizal, and non-mycorrhizal plants depended on the solution Al concentrations (Table 3.1). Release of citrate from non-mycorrhizal roots was extremely stimulated by increased Al concentrations (Figure 3.3). For both mycorrhizal plants, low Al concentrations enhanced exudation of citrate, but $1000 \mu \mathrm{M}$ Al did no stimulated excretion of citrate, even reduced its production in HM mycorrhizal plants (Figure 3.3). Lactate exudation from non-mycorrhizal roots was stimulated by 200 and $400 \mu \mathrm{M}$ Al concentrations, but $1000 \mu \mathrm{M}$ Al remarkably reduced lactate production in non-mycorrhizal plants (Figure 3.3). Al exposure had no significant effect on lactate exudation in both LM and HM mycorrhizal plants except at $1000 \mu \mathrm{M}$ Al, where LM mycorrhizal plants exuded a large amount of lactate. Mycorrhizal fungal colonization had no significant effect on formate and acetate production (Table 3.1).

When all organic acids released from root systems were taken into consideration together, exudation of organic acids from root systems of either mycorrhizal or non-mycorrhizal plants was significantly reduced by $\mathrm{Al}$ exposure (Figure 3.4A). However, mycorrhizal plants exuded more organic acids than non-mycorrhizal plants, especially HM mycorrhizal plants released significantly a greater amount of organic acids than non-mycorrhizal plants (Figure 3.4A). Production of organic acids based on root mass reflects capability of plants to exude organic acids in response to Al treatments. LM mycorrhizal, HM mycorrhizal, and nonmycorrhizal plants differed in production of total organic acids as Al concentrations changed (Figure 3.4B). Both LM and HM mycorrhizal plants produced significantly higher organic acids than non-mycorrhizal plants when no Al was applied. At $1000 \mu \mathrm{M}$ Al, HM mycorrhizal plants released less organic acids per gram of root mass than LM mycorrhizal and non-mycorrhizal plants. Total concentration of organic acids in rhizosphere indirectly reflects $\mathrm{Al}$ accumulation and availability in rhizosphere. Mycorrhizal plants had higher concentrations of organic acids in rhizosphere than non-mycorrhizal plants at $200 \mu \mathrm{M} \mathrm{Al}$ or when no $\mathrm{Al}$ was applied (Figure 3.4C). At $1000 \mu \mathrm{M}$ Al, organic acid concentration in rhizosphere of HM mycorrhizal plants was higher than that of LM mycorrhizal and non-mycorrhizal plants. 
Table 3.2. $P$ values from ANCOVA for the shoot and root nutrient concentrations of LM mycorrhizal, HM mycorrhizal, and non-mycorrhizal broomsedge (A. virginicus) plants.

\begin{tabular}{lllllllllll}
\hline & Source & $\mathbf{P}$ & $\mathbf{K}$ & $\mathbf{C a}$ & $\mathbf{M g}$ & $\mathbf{F e}$ & $\mathbf{M n}$ & $\mathbf{C u}$ & $\mathbf{Z n}$ & $\mathbf{N a}$ \\
\hline \multirow{2}{*}{ Shoot } & $\mathbf{M y c}$ & 0.014 & $\mathrm{~ns}$ & $\mathrm{~ns}$ & $\mathrm{~ns}$ & $\mathrm{~ns}$ & 0.020 & 0.001 & 0.031 & $\mathrm{~ns}$ \\
& $\mathbf{A l}$ & $<0.001$ & $\mathrm{~ns}$ & $<0.001$ & $<0.001$ & $\mathrm{~ns}$ & $\mathrm{~ns}$ & $\mathrm{~ns}$ & $\mathrm{~ns}$ & 0.050 \\
& $\mathbf{M y c} * \mathbf{A l}$ & $<0.001$ & 0.004 & $\mathrm{~ns}$ & 0.004 & 0.025 & $\mathrm{~ns}$ & $\mathrm{~ns}$ & $\mathrm{~ns}$ & $\mathrm{~ns}$ \\
\hline \multirow{2}{*}{ Root } & $\mathbf{M y c}$ & $\mathrm{ns}$ & $<0.001$ & $\mathrm{~ns}$ & $\mathrm{~ns}$ & $\mathrm{~ns}$ & $<0.001$ & $<0.001$ & $<0.001$ & $\mathrm{~ns}$ \\
& $\mathbf{A l}$ & $<0.001$ & $\mathrm{Ns}$ & $\mathrm{ns}$ & $<0.001$ & $<0.001$ & $\mathrm{~ns}$ & $\mathrm{Ns}$ & $\mathrm{ns}$ & 0.004 \\
& $\mathbf{M y c * A l}$ & $\mathrm{ns}$ & $<0.001$ & $\mathrm{~ns}$ & $\mathrm{~ns}$ & $<0.001$ & $\mathrm{~ns}$ & $\mathrm{~ns}$ & $\mathrm{~ns}$ & $\mathrm{~ns}$ \\
\hline
\end{tabular}


Figure 3.5. Influence of $\mathrm{Al}$ treatment on shoot and root nutrient concentrations of LM mycorrhizal (solid circle), HM mycorrhizal (solid triangle), and non-mycorrhizal (open circle) broomsedge (A. virginicus) plants.

Slopes and $P$ values from the regression:

A. Shoot $\mathrm{P}$ concentrations

LM mycorrhizal: slope $=-0.00094$ and $P$ value $=0.001$;

HM mycorrhizal: slope $=0.00029$ and $P$ value: $n s$;

Non-mycorrhizal: slope $=-0.00136$ and $P$ value $<0.001$.

B. Shoot K concentrations

LM mycorrhizal: slope $=0.00181$ and $P$ value: ns;

HM mycorrhizal: slope $=0.00188$ and $P$ value: $\mathrm{ns}$;

Non-mycorrhizal: slope $=-0.00873$ and $P$ value $=0.011$.

C. Root K concentrations

LM mycorrhizal: slope $=0.00708$ and $P$ value $=0.008$;

HM mycorrhizal: slope $=0.02561$ (linear) and -0.00002 (quadratic), and $P$ value $=0.003$

(linear) and 0.025 (quadratic);

Non-mycorrhizal: slope $=-0.01368$ and $P$ value $=0.007$.

D. Shoot Mg concentrations

LM mycorrhizal: -0.000091 and $P$ value: ns;

HM mycorrhizal: slope $=-0.00520$ (linear) and 0.000004 (quadratic), and $P$ value $=$ 0.041 (linear) and 0.083 (quadratic);

Non-mycorrhizal: slope $=-0.00364$ and $P$ value $<0.001$.

E. Shoot Fe concentrations

LM mycorrhizal: slope $=0.11763$ and $P$ value: ns;

HM mycorrhizal: slope $=-2.11247$ (linear) and 0.00182 (quadratic), and $P$ value $=0.003$ (linear) and 0.005 (quadratic);

Non-mycorrhizal: slope $=0.56728$ and $P$ value $=0.003$.

F. Root Fe concentrations

LM mycorrhizal: slope $=-2.48287$ (linear) and 0.00277 (quadratic), $P$ values $=$ ns (linear) and 0.039 (quadratic);

HM mycorrhizal: N/A;

Non-mycorrhizal: slope $=3.47617$ and $P$ value $=0.002$. 

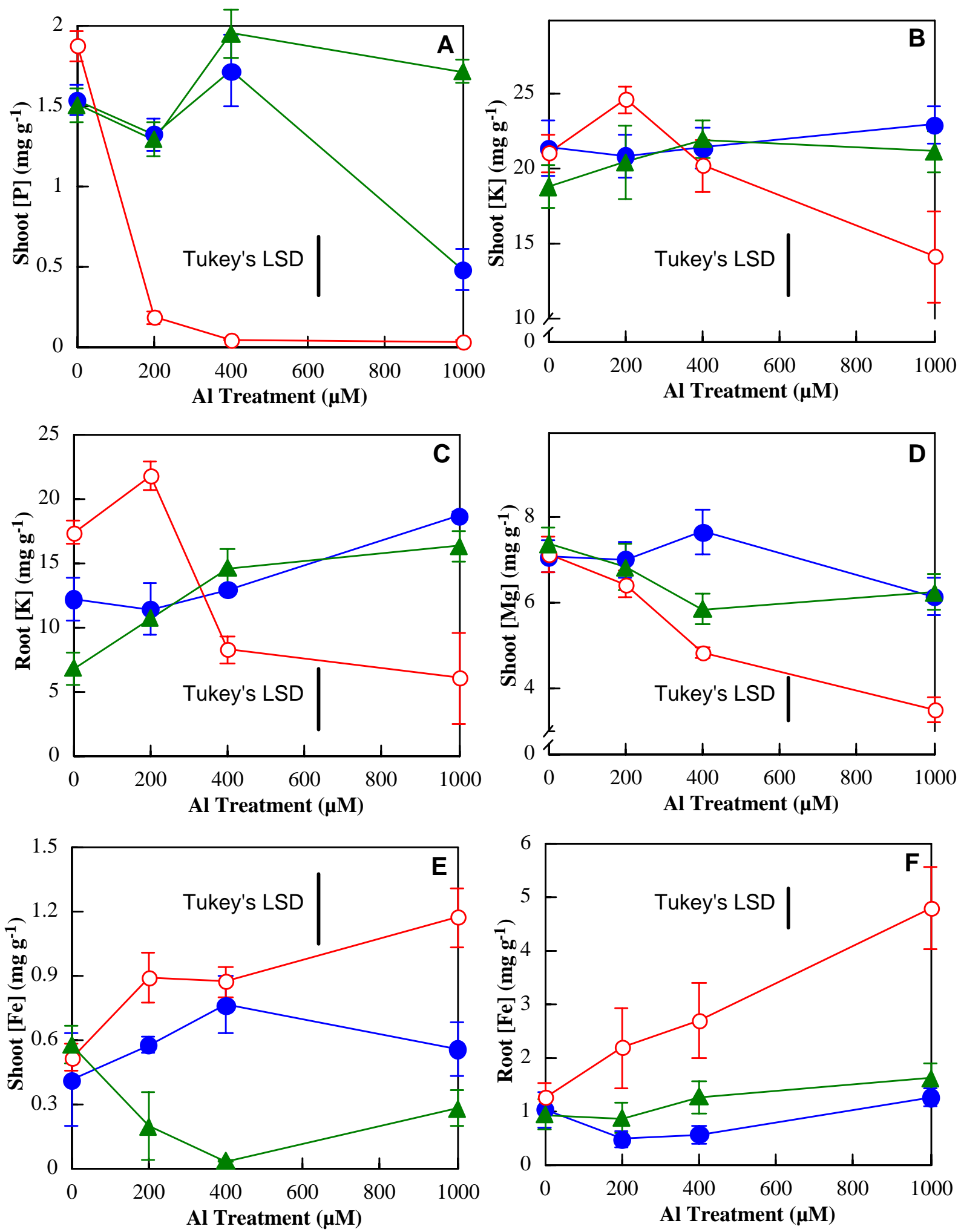
Different patterns of growth, shoot and root Al concentrations, and excreted organic acids indicated that mycorrhizal fungal colonization may have altered other nutrient composition of shoots and roots. Colonization of both AM fungal isolates significantly reduced shoot and root $\mathrm{Mn}$ and $\mathrm{Zn}$ concentrations across all $\mathrm{Al}$ levels, but enhanced shoot and root $\mathrm{Cu}$ concentrations under $\mathrm{Al}$ exposure (Table 3.2). Shoot $\mathrm{P}, \mathrm{K}, \mathrm{Mg}$, and $\mathrm{Fe}$ concentrations and root $\mathrm{K}$ and $\mathrm{Fe}$ concentrations of LM mycorrhizal, HM mycorrhizal, and non-mycorrhizal plants depended on the solution $\mathrm{Al}$ concentrations (Table 3.2). Shoot $\mathrm{P}$ concentrations of non-mycorrhizal plants were extremely disrupted by $\mathrm{Al}$ presence (Figure 3.5). Both mycorrhizal plants under Al exposure had much higher shoot $\mathrm{P}$ concentrations relative to that of non-mycorrhizal plants except at $1000 \mu \mathrm{M} \mathrm{Al}$, where shoot $\mathrm{P}$ concentration of LM mycorrhizal plants was greatly reduced (Figure 3.5).

Shoot $\mathrm{K}$ and $\mathrm{Mg}$ concentrations and root $\mathrm{K}$ concentrations of non-mycorrhizal plants were significantly reduced by 400 and $1000 \mu \mathrm{M} \mathrm{Al}$ concentrations, where, however, both LM and HM mycorrhizal plants still remained high concentrations of these nutrients (Figure 3.5). Non-mycorrhizal plants increased shoot and root $\mathrm{Fe}$ concentrations as the solution $\mathrm{Al}$ concentrations increased, but LM and HM mycorrhizal plants in shoot Fe concentrations divergently responded to increased $\mathrm{Al}$ concentrations (Figure 3.5). Root Fe concentrations of both mycorrhizal plants were low and relatively stable across the Al levels (Figure 3.5).

\section{Discussion}

In the previous Al study (Chapter II), multiple AM fungi functioning together, provided a great benefit to broomsedge plants, and protected host plants from $\mathrm{Al}$ toxicity through reduction of $\mathrm{Al}$ influx and translocation and amelioration of $\mathrm{Al}$ effects on nutrient acquisition and translocation. These results suggested that AM fungi were important to this plant species establishing in acidic soils with elevated Al. However, different fungal species, even different strains of the same fungal species, differentially enhance growth of host plants (Medeiros et al. 1994; Clark 1997). The present study shows that two fungal isolates differentially benefited broomsedge plants under severe $\mathrm{Al}$ toxicity, but there was no significant difference in this aspect between these two fungal isolates when they were exposed to $\mathrm{Al}$ at $400 \mu \mathrm{M}$ and below (Figure 3.1). LM plant growth was extremely reduced by $1000 \mu \mathrm{M} \mathrm{Al}$ treatment as were nonmycorrhizal plants (Figure 3.1). This pattern might imply that the symbiotic LM plants are only 
adapted to mild $\mathrm{Al}$ toxicity present in their original habitats (about $360 \mathrm{mg} \mathrm{Al}$ per $\mathrm{kg}$ of soil), and very high $\mathrm{Al}$ would be toxic to LM plants as well as non-mycorrhizal plants. Superiority of HM fungus to host plants exposed to $1000 \mu \mathrm{M} \mathrm{Al}$ may be associated with its capability to mining scarce phosphorus, as evidenced that $\mathrm{P}$ concentrations of $\mathrm{HM}$ mycorrhizal plants were not significantly affected by $\mathrm{Al}$ (Figure 3.5). This role of HM fungus may be originated from its original habitats where phosphorus limitation is the primary factor for plants to establish. These results indicate that local adaptation of AM fungi to edaphic stress is important to host plants to establish in such habitats.

Reduction of Al influx into shoot and root by AM fungi may be one of the important mechanisms in Al resistance of higher plants (Medeiros et al. 1994; Mendoza and Borie 1998; Chapter II). The present study revealed that both LM and HM fungi significantly reduced Al influx into host plants (Figure 3.2). But different fungal isolates took different ways to limit Al influx. LM fungus limited $\mathrm{Al}$ influx into both shoots and roots of host plants, whereas HM fungus primarily reduced $\mathrm{Al}$ translocation into shoots of broomsedge plants (Figure 3.2). This observation is contrary to the previous report on Panicum virgatum (Koslowsky and Boerner 1989).

In response to deficient $\mathrm{Pi}$ and excess $\mathrm{Al}$, plant roots release organic acids (Curl and Truelove 1986; Kochian 1995; Strom 1997). The roles of these organic acids in overcoming Pi limitation and Al toxicity have been experimentally demonstrated (Miyasaka et al. 1991; Delhaize et al. 1993; Jones and Darrah 1994; Delhaize and Ryan 1995; Ma et al. 1997; Zhang et al. 1997). Organic acids chelate metals, reducing their precipitation reaction with $\mathrm{Pi}$ and reducing the activity of toxic free metal ions in the rhizosphere. The present study showed that release of citrate by non-mycorrhizal root systems was stimulated by Al exposure, and nonmycorrhizal plants exuded more citrate as the solution Al concentrations increased (Table 3.1, Figure 3.3). This pattern of citrate responses in non-mycorrhizal broomsedge plants to increased Al concentration is consistent with reports on Al-resistant plants (Miyasaka et al. 1991; Delhaize et al. 1993; Ryan et al. 1995; Pellet et al. 1996; Ma et al. 1997), which reflects the general response of Al-tolerant plants to increasing $\mathrm{Al}$.

In both LM and HM mycorrhizal plants, however, there were no such responsive patterns of organic acids to increasing $\mathrm{Al}$ concentrations that was observed in non-mycorrhizal plants (Table 3.1, Figure 3.3 and 3.4), which suggests a difference in root characters between mycorrhizal and non-mycorrhizal plants (Berta et al. 1993; Miller et al. 1997) and mycorrhizal 
fungal colonization may pose carbon constraints on host plants under stressful conditions (Po and Cumming 1997; Smith and Read 1997). Because mycorrhizal roots were bigger than nonmycorrhizal roots (Figure 3.1), mycorrhizal plants exuded a greater amount of organic acids than non-mycorrhizal plants (Figure 3.4A). However, chelation of $\mathrm{Al}$ in rhizosphere and releasing phosphorus from bound complexes are not determined by the production of organic acids from the root systems, but by concentrations of organic acids presented in rhizospheres. Mycorrhizal plants had higher concentrations of organic acids in rhizosphere than no-mycorrhizal plants at $200 \mu \mathrm{m} \mathrm{Al}$ or no Al applied. Especially HM mycorrhizal plants had higher organic acids in rhizosphere than non-mycorrhizal plants (Figure 3.4C). So that more Al was chelated and more $\mathrm{P}$ was released from bound complexes by organic acids in the rhizosphere of mycorrhizal plants under these conditions than that of non-mycorrhizal plants, which undoubtedly contributes Al resistance observed in mycorrhizal plants (Figure 3.1). Furthermore, mycorrhizal plants reduced $\mathrm{Al}$ influx into shoots and roots (Figure 3.2), and balanced accumulation of nutrients (Table 3.2, Figure 3.5), which all would contribute to Al resistance in host plants. However, different mycorrhizal plants were not completely the same in amelioration of $\mathrm{Al}$ detrimental effects on host plants. The difference in plant mass between LM and HM mycorrhizal plants may be at least partially related to the difference in the concentrations of organic acids in their rhizosphere, particularly at $1000 \mu \mathrm{M} \mathrm{Al}$ (Figure 3.1 and 3.4C). LM and HM mycorrhizal plants considerably differed in the extents of limiting $\mathrm{Al}$ influx into shoots and roots (Figure 3.2), and improvement of $\mathrm{P}$ nutrition (Figure 3.5), which also contribute to the difference in $\mathrm{Al}$ resistance between LM and HM mycorrhizal plants.

Differences in nutrient concentrations among different mycorrhizal and non-mycorrhizal plants exposed to $\mathrm{Al}$ can be related to colonization of different mycorrhizal fungal strains, $\mathrm{Al}$ influence, and exudation of organic acids (Rengel and Robinson 1989; Nichol et al. 1993; Jones and Darrah 1994; Delhaize and Ryan 1995; Marschner 1995; Smith and Read 1997; Strom 1997). Mycorrhizal fungal colonization reduced Al concentrations (Figure 3.2), and altered profiles and concentrations of organic acids in rhizosphere (Table 3.1, Figure 3.3 and 3.4), which undoubtedly affects plant nutrition. Nutrition of non-mycorrhizal broomsedge plants was disrupted by $\mathrm{Al}$ (Figure 3.5). Phosphorus was the most sensitive to $\mathrm{Al}$ exposure (Figure 3.5). At $200 \mu \mathrm{M} \mathrm{Al}$, shoot P concentration of non-mycorrhizal plants was reduced 10 times compared to the control (Figure 3.5). Moreover, $\mathrm{Al}$ reduced shoot $\mathrm{K}$ and $\mathrm{Mg}$ and root $\mathrm{K}$ concentrations, but increased shoot and root Fe concentrations of non-mycorrhizal plants (Figure 3.5). Calcium 
concentrations of all plants, no matter whether they were mycorrhizal or non-mycorrhizal, were significantly reduced by $\mathrm{Al}$, which reflects the general detrimental effect of $\mathrm{Al}$ on $\mathrm{Ca}$ uptake by plants (Huang et al. 1992), and AM fungi have no effect on Ca uptake (Smith and Read 1997). Results from previous experiments (Koslowsky and Boerner 1989, Medeiros et al. 1994) demonstrated that different fungal isolates differentially affect nutrient concentrations of shoots and roots of host plants. The present study similarly revealed differential influences on nutrient concentrations by different AM fungal isolates, especially on shoot $\mathrm{P}, \mathrm{Fe}$, and $\mathrm{Mn}$ concentrations (Table 3.2, Figure 3.5), which suggests differential roles of different AM fungi in plant nutrition (Medeiros et al. 1994; Clark 1997; Smith and Read 1997).

Release of organic acids by root systems may affect mineral nutrient availability to and acquisition by plants (Jones and Darrah 1994; Strom 1997). Mycorrhizal and non-mycorrhizal plants significantly differed in tissue $\mathrm{Mn}, \mathrm{Cu}$, and $\mathrm{Zn}$, independent of $\mathrm{Al}$ concentrations in the root zones (Table 3.2). In addition, the differences in tissue $\mathrm{P}, \mathrm{K}, \mathrm{Mg}$, and $\mathrm{Fe}$ between mycorrhizal and non-mycorrhizal plants changed as $\mathrm{Al}$ concentrations in the root zones changed (Table 3.2, Figure 3.5). These differences in tissue nutrients between mycorrhizal and nonmycorrhizal plants exposed to varying $\mathrm{Al}$ concentrations may be associated with the differences in the rhizosphere organic acids (Figure 3.4). Organic acids have a high affinity with Al so that nutrients could be freed from Al-bound complexes by organic acids (Taylor 1988; Miyasaka et al. 1991; Jones and Darrah 1994; Strom 1997). The differences in tissue nutrients between mycorrhizal and non-mycorrhizal plants brought about by organic acids might be related to anion channels, co-transport, and/or anti-transport processes suggested in other studies (Schwenke and Wagner 1992; Ryan et al. 1997; Strom 1997; Parker and Pedler 1998). Additionally, the higher shoot $\mathrm{P}$ concentration of HM mycorrhizal than LM mycorrhizal plants exposed to $1000 \mu \mathrm{M} \mathrm{Al}$ (Figure 3.5) may be ascribed to the higher concentration of organic acids in their rhizosphere than that of LM mycorrhizal plants (Figure 3.4).

Mycorrhizal fungal colonization not only quantitatively but also qualitatively altered profiles and concentrations of organic acids exuded from root systems (Table 3.1, Figure 3.3 and 3.5), which implies that the physiology of host broomsedge plants was altered by colonization of either AM fungal isolate, as has been previously reported (McArthur and Knowles 1992, 1993; Benabdellah et al. 2000), but different fungal isolates differentially affected the profiles and concentrations. The differences in the exudation of organic acids observed among LM 
mycorrhizal, HM mycorrhizal, and non-mycorrhizal plants in the present study might be associated with the changes in physiology.

From this study, I would have expected that broomsedge plants colonized by the LM isolate of Glomus clarum would have been higher $\mathrm{Al}$ resistance than the plants colonized by the $\mathrm{HM}$ isolate under $\mathrm{Al}$ exposure. In contrast, both isolates were equally effective at fostering growth of host plant exposed to up to $400 \mu \mathrm{M} \mathrm{Al}$, and also root colonization by these fungi was not affected by $\mathrm{Al}$ exposure. One reason for this lack of difference in $\mathrm{Al}$ resistance between isolates from divergent habitats may be the cultural history of these isolates. Both isolates were obtained from the INVAM collection at West Virginia University (Morton et al. 1993), in which isolates were maintained in a common soil ( $\mathrm{pH}$ 6.2) for numerous generations ( 5 generations for HM and one generation for LM isolate). Due to the multinucleate nature of AM fungi, selection pressure in the INVAM collection may be different from those present in the fields, consequently leading to differential roles from the ones in the fields and exhibiting similar responses under common conditions (Morton 1990; Stutz and Morton 1996).

The present study demonstrated that LM mycorrhizal, HM mycorrhizal, and nonmycorrhizal broomsedge plants differentially responded in tissue Al concentrations, tissue nutrient concentrations, and profiles and concentrations of organic acids exuded from root systems to the solution $\mathrm{Al}$ concentrations, consequently resulting in differential patterns of growth in response to Al treatments. Mycorrhizal fungal colonization increased the amount of organic acids released into rhizosphere by root systems, pronouncedly reduced Al influx into roots and translocation into shoots, which undoubtedly reduces adverse effects of $\mathrm{Al}$ on host plants, and facilitated P uptake by host plants. But LM and HM mycorrhizal plants differed in the amount and concentrations of organic acids in the rhizosphere, the extents of limiting $\mathrm{Al}$ into shoots and roots, and tissue $\mathrm{P}$ concentrations. Citrate exuded from non-mycorrhizal root systems increased as $\mathrm{Al}$ concentrations increased, reflecting a general response of Al-tolerant plants to increasing $\mathrm{Al}$ concentrations in root zones. In both LM and HM mycorrhizal plants, no such pattern was observed, but there were a greater amount and concentrations of organic acids in their rhizosphere, which would contribute to $\mathrm{Al}$ resistance in mycorrhizal broomsedge plants. Mycorrhizal fungal colonization ameliorated detrimental effects of $\mathrm{Al}$ on nutrition of host plants. The difference in $\mathrm{Al}$ resistance between LM and HM mycorrhizal plants under severe Al toxicity $(1000 \mu \mathrm{M})$ may be ascribed to the difference in the concentrations of organic acids in the rhizosphere and the improvement of $\mathrm{P}$ status of host plants. The differences in reduction of Al 
influx into shoots and roots and improvement of P nutrition of host plants between LM and HM fungal isolates may be originated from their original habitats, respectively. The changes in profiles and amount of organic acids released from root systems of host plants brought about by different AM fungal isolates suggest changes in the physiology of broomsedge plants as a result of colonization by AM fungi, which might be associated with other alterations in host plants, such as activation of anion channels, co-transport, and/or anti-transport processes between cations and anions. Therefore, different AM fungal isolates differentially ameliorate adverse influences of $\mathrm{Al}$ on host plants through different ways, which all enhances growth of host plants under Al toxicity and other environmental stresses. 


\section{CHAPTER IV}

\section{Phosphorus and Aluminum Interactive Effects on Different Mycorrhizal and Non-Mycorrhizal Broomsedge Plants}

\section{Introduction}

The mycorrhizal symbioses between arbuscular mycorrhizal (AM) fungi and higher plants have existed for millions of years and the benefits of this mutualism to host plants have long been recognized (Mosse 1973; Newsham et al. 1995; Allen 1996; Smith and Read 1997). One of the most documented benefits brought about by AM fungi to the host plant is the facilitation of phosphorus (Pi) uptake (Mosse 1973; Hayman 1983; Bolan 1991; Smith et al. 1994). The increased acquisition of $\mathrm{Pi}$ is closely related to extensive fungal hyphae exploration of a larger volume of soil and mining scarce resources that are otherwise unavailable for roots (Smith and Read 1997).

The benefits provided by AM fungi to host plants may also be associated with the changes in plant physiology. For example, mycorrhizal fungal colonization alters the distribution of $\mathrm{H}^{+}$-ATPase in the plasma membrane of the host root cells (Gianinazzi-Pearson et al. 1991). The increased activity of membrane $\mathrm{H}^{+}$-ATPase in root cells might be related to Pi transfer across the fungus-plant interface (Smith and Read 1997). In addition, the alteration of physiological parameters in host plants may play roles in plants overcoming environmental stress (Allen et al. 1981; Hayman 1983; McArthur and Knowles 1993). Furthermore, mycorrhizal fungal colonization induces morphological modifications in the root system of the host plants (Berta et al. 1993). It is therefore unlikely that a root system, which is densely colonized by mycorrhizal fungi, will not be changed physiologically and metabolically.

There are reports that physiological traits of plants are changed upon mycorrhizal fungal colonization. For example, mycorrhizal fungal colonization alters host plant phytohormones (Allen et al. 1980; McArthur and Knowles 1992), phosphatases (Dighton 1983; McArthur and Knowles 1993; Fries et al. 1998), ATPase and other proteins (Gianinazzi-Pearson et al. 1991; McArthur and Knowles 1992, 1993, Bago et al. 1997; Boucher et al. 1999; Benabdellah et al. 
1999, 2000), metabolic pathways (Clapperton and Reid 1992; McArthur and Knowles 1992; Harrison and Dixon 1994), gene transcription and expression (Harrison 1999), hydraulic conductance (Allen et al.. 1981; Smith and Read 1997), photosynthesis and respiration (Allen et al. 1981; Eissenstat et al. 1993; Peng et al. 1993; Aguilera-Gomez et al. 1998; Boucher et al. 1999), kinetics of nutrient absorption (Cress et al. 1979; Kuhn et al. 2000; Chapter I), and root exudates (Pinior et al. 1999; Chapter III). Allen et al. (1981) found that AM fungal colonization significantly increased photosynthetic rate as a consequence of increased leaf chlorophyll and stomatal conductance. Phosphatase and/or other proteins of mycorrhizal roots may be higher (McArthur and Knowles 1992; Fries et al. 1998; Benabdellah et al. 1999) or lower (Dighton 1983; Cumming 1996) than their non-mycorrhizal counterparts, depending on plant species, fungal species, and environmental conditions. Boucher et al. (1999) demonstrated that different arbuscular mycorrhizal (AM) fungi had differential influences on leaf chlorophyll, proteins, and sugars.

These reports indicate that changes in plant physiology brought about by mycorrhizal fungal colonization are not casual phenomena. However, it is not clear how physiological responses of plants to mycorrhizal fungal colonization change under various edaphic conditions.

Broomsedge (Andropogon virginicus) is a mycotrophic species dominating many poor soil habitats and it relies on AM fungi to overcome detrimental edaphic conditions (Chapters I, II and III). Differences in exudation profiles of organic acids between mycorrhizal and nonmycorrhizal plants suggest that the physiology of broomsedge plants is altered by colonization of AM fungi (Chapter III). Previous experiments demonstrated that acid phosphatase, chlorophyll, and photosynthesis of broomsedge plants from a mine site were higher than those from an old field, but there was no difference in transpiration between them (Chapman and Jones 1975; Nellessen and Ungar 1993). These patterns indicate that this plant species may adjust its physiology in response to the adverse edaphic stresses present in the mine soil. However, it is not clear whether the plants in the above experiments were already colonized by mycorrhizal fungi. If these plants were already colonized by AM fungi, are these differences due to plants themselves or interactions between plants and fungi?

Mycorrhizal symbiosis considerably reduced $\mathrm{Al}$ influx into host plants and translocation within host plants, and facilitated Pi uptake by host plants (Chapter I, II, and III). These changes might be associated with alterations in physiology of host plants brought about by mycorrhizal symbiosis. Different AM fungi differentially affect Al influx, Pi uptake, and exudation of 
organic acids in host broomsedge plants (Chapter III). So, differences in physiology between these different mycorrhizal plants would be also expected. In the present study, I examined interactive effects of $\mathrm{Pi}, \mathrm{Al}$, and $\mathrm{AM}$ symbioses on biomass, foliar nitrogen, leaf chlorophyll, photosynthesis, leaf respiration, root acid phosphatase, root proteins, and tissue nutrient concentrations of broomsedge (Andropogon virginicus L.) plants. Two fungal isolates of the same species, Glomus clarum Nicolson and Schenck, were used. They originated from abandoned coal mine soils differing in $\mathrm{pH}$. I hypothesized that there would be differences in physiology and growth among different mycorrhizal and non-mycorrhizal plants under different $\mathrm{Pi}$ and Al levels because different mycorrhizal and non-mycorrhizal plants differed in Pi-by-Al interactions as $\mathrm{Pi}$ and $\mathrm{Al}$ concentrations change as observed in previous studies.

\section{Materials and Methods}

\section{Preparation of AM Fungal Inocula}

AM fungal inocula were used in this study, separately originated from two abandoned coal mining sites in West Virginia. One site is in Mingo County, having soil $\mathrm{pH}$ of 6.6 and containing $\mathrm{NaHCO}_{3}$-extractable $\mathrm{Pi}$ of $19 \mathrm{mg}$ per $\mathrm{kg}$ of soil. At this $\mathrm{pH}, \mathrm{Al}$ is not toxic to plants. Soil from the other site in Monongalia County has a pH from 3.0 to 3.3, containing Melichextractable Pi of $3.76 \mathrm{mg}$ per $\mathrm{kg}$ of soil and $\mathrm{Al}$ of $363.12 \mathrm{mg}$ per $\mathrm{kg}$ of soil.

To produce the inoculum of Glomus clarum, inocula (WV233-1 and WV219A-5) from the INVAM collection at West Virginia University, which originated separately from the Monongalia site and the Mingo site, were used to inoculate setrilely germinated broomsedge plants, respectively. These inoculated broomsedge plants were planted into $15 \mathrm{~cm}$ diameter pots containing a mixture of autoclaved mine-soil from the Monongalia site and sand (1:3 v/v). After two months, the pot contents became the sources of infective LM and HM inoculum for the experiment, respectively, where LM and HM separately represent mycorrhizal fungi from low $\mathrm{pH}$ site at Monongalia abandoned coal mine and high $\mathrm{pH}$ site at Mingo abandoned coal mine.

Preparation of Plants

Broomsedge seeds were sown around the transplants in nursery pots $(15 \mathrm{~cm}$ diameter). Broomsedge seeds also were sown in pots containing sterile-germinated broomsedge and the 
mixture of autoclaved mine-soil and sand (1:3 v/v). Seedlings from these pots served as a nonmycorrhizal control. After four weeks growth, roots of a small subset of seedlings ( $\mathrm{ca}$. 10 from each pot) were examined to determine mycorrhizal status. Tissue P status was analyzed after wet digestion (Parkinson and Allen 1975) by the molybdate blue method (Olsen and Sommers 1982). Tissue phosphorus concentrations and tissue dry weights between mycorrhizal and nonmycorrhizal plants did not differ significantly at the time of transplanting.

Nutrient Solution and Growth Conditions

Mycorrhizal and non-mycorrhizal broomsedge seedlings were transplanted and grown in D16 Deepots (5 cm diameter x $18 \mathrm{~cm}$ height) (Stuewe and Sons, Inc., Corvallis, Oregon, USA) pre-filled with $220 \mathrm{~cm}^{3}$ of a $3: 1(\mathrm{v} / \mathrm{v})$ mixture of coarse:fine acid-washed sand. Deepots were placed into a growth chamber with 14 hours of light at $28^{\circ} \mathrm{C}, 60 \% \mathrm{RH}$, and 10 hours of darkness at $21^{\circ} \mathrm{C}, 50 \% \mathrm{RH}$. Average light intensity at pot height in the chamber was $260 \mu \mathrm{mol} \mathrm{m} \mathrm{s}^{-1}$ from mixed fluorescent and incandescent sources. Plants received a baseline nutrient solution containing $\mathrm{Ca}(0.675 \mathrm{mM}), \mathrm{K}(0.79 \mathrm{mM}), \mathrm{Mg}(0.25 \mathrm{mM}), \mathrm{NO}_{3}(1.5 \mathrm{mM}), \mathrm{NH}_{4}(0.5 \mathrm{mM}), \mathrm{SO}_{4}$ (0.25 mM), B (23.14 $\mu \mathrm{M}), \mathrm{Fe}(25 \mu \mathrm{M}), \mathrm{Mn}(4.57 \mu \mathrm{M}), \mathrm{Zn}(0.38 \mu \mathrm{M}), \mathrm{Cu}(0.16 \mu \mathrm{M})$, and Mo $(0.06 \mu \mathrm{M})$. All solutions were adjusted to $\mathrm{pH} 4.0$ before application. Solutions (approximately $15 \mathrm{ml}$ ) were automatically delivered to the plants three times each day for eight weeks.

Measurements

Photosynthesis, stomatal conductance, and respiration of leaves were determined on day 50 with a LI-6200 Photosynthesis System (LICOR Inc., Lincoln, NE, USA). Photosynthesis and stomatal conductance were measured on the third fully developed leaf of each plant from 10 to 11 a.m. under the daytime growth conditions, and measurement of respiration was conducted on the same leaf of each plant from 9 to 10 p.m. in the dark. The leaf dimensions within the cuvette were recorded.

Determination of chlorophyll followed a modified method of Porra et al. (1989). On day 51 , approximately $5 \mathrm{~cm}$ of the same leaves for the measurement of photosynthesis and respiration above were exercised, weighed, and cut into $2 \mathrm{~mm}$ long sections. These pieces of leaves were instantly transferred into test tubes on ice. Two-ml of methanol was added to each tube. The tubes were sealed with parafilm and placed in a refrigerator overnight. Chlorophyll 
was determined by measuring absorptance at 652 and $665.2 \mathrm{~nm}$ with a spectrometer. Chlorophyll concentrations were calculated using the equations of Porra et al. (1989):

\section{Chlorophyll $(\mathrm{a}+\mathrm{b})\left(\mu \mathrm{g} \mathrm{ml}^{-1}\right)=22.12 \mathrm{~A}^{652}+2.71 \mathrm{~A}^{665.2}$.}

On day 55, four plants from each treatment were harvested, roots were washed in running de-ionized water. Acid phosphatase was determined as follows. Root tips (5 to $8 \mathrm{~cm}$ ) were cut off, washed in de-ionized water, chopped into $1 \mathrm{~cm}$ pieces, and transferred to centrifuge tubes containing $4.5 \mathrm{ml}$ of the appropriate treatment nutrient solution. Then, $0.5 \mathrm{ml}$ of $1 \mathrm{mM}$ nitrophenylphosphate (NPP) was added to each tube and tubes were incubated for 1 hour at room temperature. After the incubation period, $1 \mathrm{ml}$ of $0.5 \mathrm{~N} \mathrm{NaOH}$ was added to each tube. Acid phosphatase activity (nitrophenol produced) was spectrophotometrically determined at $410 \mathrm{~nm}$ (Tabatabai and Bremner 1969).

The remaining roots of each plant above were ground with a mortar and pestle in $20 \mathrm{ml}$ ice-cold buffer $(5 \%(\mathrm{w} / \mathrm{v})$ polyvinypyrrolidone $(\mathrm{PVP})$ in $0.1 \mathrm{M}, \mathrm{pH} 7.9$ Tris- $\mathrm{HCl})$ on ice, and centrifuged at $12,000 \mathrm{~g}$ for 20 minutes at $4^{\circ} \mathrm{C}$. The supernatant was kept on ice for a protein assay. Proteins were determined following the Bradford (1976) method using SIGMA Protein Assay Kit (Product \# P 5656, Sigma Chemical Co. Ltd., St. Louis, MO, USA).

The aboveground tissues of the plants above were dried at $60^{\circ} \mathrm{C}$ for 48 hours and ground. Approximately $4.8 \mu \mathrm{g}$ aliquot of the sample was loaded to a nitrogen analyzer (model NA 1500 Series 2, Henry Schein, Inc, NY, USA) to obtain nitrogen and carbon concentrations.

On day 56, the experiment was terminated, sand was removed from the roots of remaining plants under running de-ionized water, and shoots were rinsed in de-ionized water. Root and shoot dry weights were determined after they dried at $60^{\circ} \mathrm{C}$ for at least 24 hours. After wet digestion (Parkinson and Allen 1975), phosphorus concentrations of the digest solutions were determined spectrophotometrically (Taussky and Shoor 1953), and other mineral elements of the digests were analyzed using an inductively coupled plasma (ICP) emission spectrophotometer (Leeman PS 950) by the National Research Center for Coal and Energy Analytical Laboratory at West Virginia University. 
Experimental Design and Data Analysis

Mycorrhizal treatments were LM, HM, and non-mycorrhizal, Pi treatments were $40 \mu \mathrm{M}$ and $100 \mu \mathrm{M} \mathrm{NaH}_{2} \mathrm{PO}_{4}$, and $\mathrm{Al}$ treatments were 0 and $200 \mu \mathrm{M} \mathrm{AlCl}_{3}$. Simulation analysis of these solutions by the program GEOCHEM (Parker et al. 1993) indicated that $\mathrm{Al}^{3+}$ concentrations were $0,0,133.9$, and $112.4 \mu \mathrm{M}$ in the solutions of $40 \mu \mathrm{M} \mathrm{Pi}, 100 \mu \mathrm{M} \mathrm{Pi}, 40 \mu \mathrm{M} \mathrm{Pi}+200 \mu \mathrm{M} \mathrm{Al}$, and $100 \mu \mathrm{M} \mathrm{Pi}+200 \mu \mathrm{M} \mathrm{Al}$, respectively. Within a growth chamber, treatments were randomly arranged in a $2 \times 2 \times 3$ factorial (Pi-by-Al-by-mycorrhizal treatments) design. Each treatment had 10 replicates. Data were analyzed by analysis of variance using the statistical package JMP (SAS Institute, Cary, North Carolina, USA).

\section{Results}

Effects of mycorrhizal fungal colonization on shoot and root mass depended on Pi and Al concentrations (Figure 4.1). Tissue biomass of non-mycorrhizal plants was enhanced by high $(100 \mu \mathrm{M}) \mathrm{Pi}$ relative to low $(40 \mu \mathrm{M}) \mathrm{Pi}$ without regard to $\mathrm{Al}$ exposure, but reduced by $\mathrm{Al}$ exposure without regard to Pi concentrations, reflecting the general beneficial effect of easily available Pi and toxicity of elevated Al to plants. Both LM and HM isolates increased shoot and root mass of host plants at $40 \mu \mathrm{M}$ Pi or exposed to $\mathrm{Al}$ without regard to $\mathrm{Pi}$ concentrations, indicating that AM fungi benefit host plants under adverse conditions. At $100 \mu \mathrm{M}$ Pi and no Al presence, both mycorrhizal plants were smaller than non-mycorrhizal plants, exhibiting mild parasitic effects on host plants by mycorrhizal symbioses. HM isolate was more effective in enhancing host plant growth than LM isolate under all conditions except at $100 \mu \mathrm{M}$ Pi and no Al presence, where there was no significant difference in tissue biomass between LM and HM mycorrhizal plants (Figure 4.1).

Leaf chlorophyll concentrations ware significantly affected by both $\mathrm{Pi}(P<0.001)$ and $\mathrm{Al}$ $(P=0.003)$, and foliar $\mathrm{N}$ concentrations were significantly affected only by $\mathrm{Al}(P=0.011)$, but there was no significant interaction on these two traits between any of the main effects. 
Figure 4.1. Influence of $\mathrm{Pi}$ and $\mathrm{Al}$ treatments on shoot $(\mathbf{A})$ and root $(\mathbf{B})$ mass of LM mycorrhizal (solid bar), HM mycorrhizal (hatched bar), and non-mycorrhizal (open bar) broomsedge ( $A$. virginicus) plants.

$P$ values from ANOVA:

\begin{tabular}{lcccc}
\hline Source & df & A. Shoot Mass & & B. Root Mass \\
\cline { 1 - 2 } \cline { 2 - 3 } & 2 & $<0.001$ & & $<0.001$ \\
$\mathbf{P i}$ & 1 & $<0.001$ & & $<0.001$ \\
$\mathbf{A l}$ & 1 & $<0.001$ & & $<0.001$ \\
$\mathbf{M y c} * \mathbf{P i}$ & 2 & 0.006 & & $<0.001$ \\
$\mathbf{M y c} * \mathbf{A l}$ & 2 & $<0.001$ & & $<0.001$ \\
$\mathbf{P i} * \mathbf{A l}$ & 1 & 0.002 & & 0.006 \\
$\mathbf{M y c} * \mathbf{P i} * \mathbf{A l}$ & 2 & 0.003 & & 0.002 \\
\hline
\end{tabular}



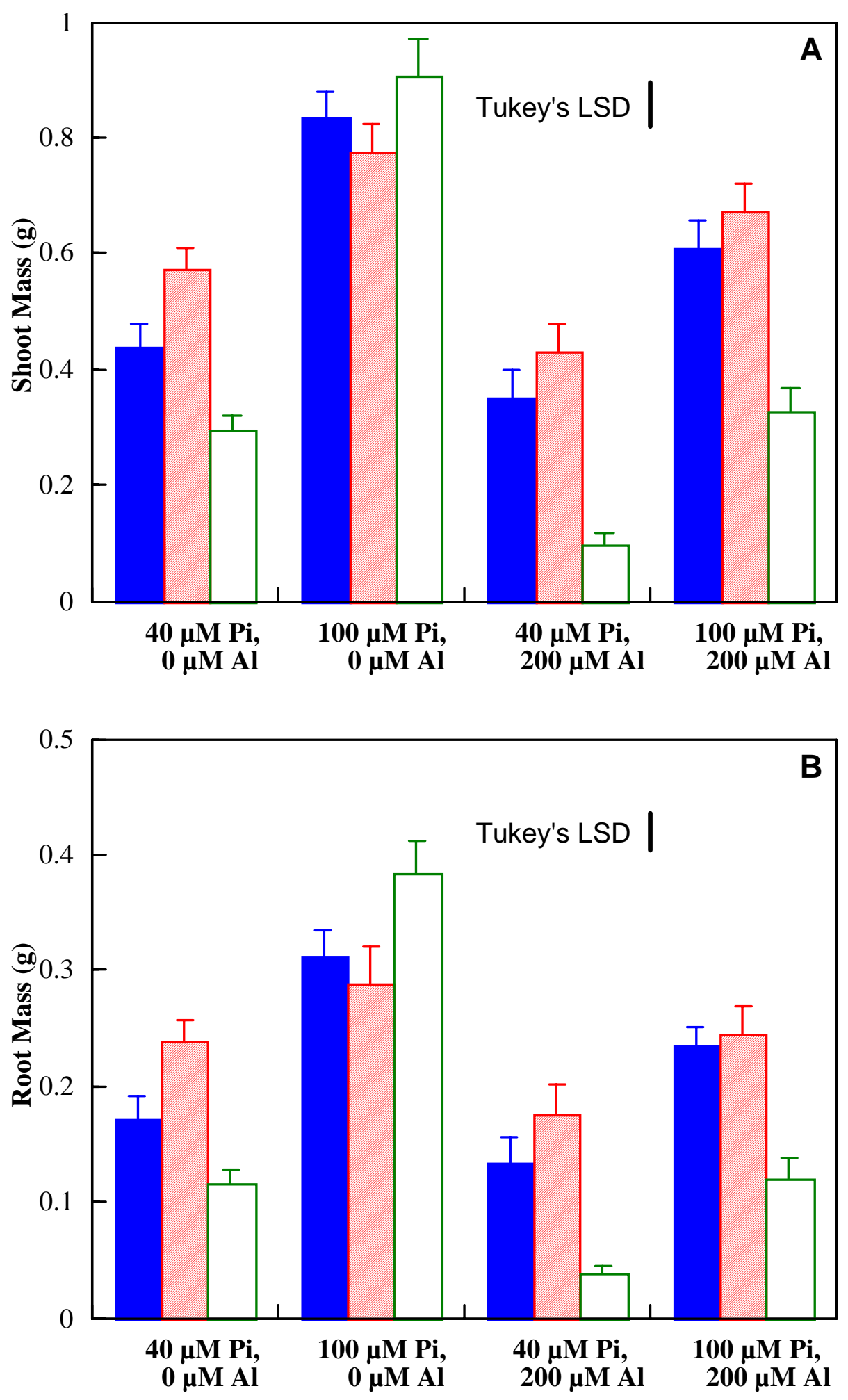
Stomatal conductance depended on $\mathrm{Pi}$ and $\mathrm{Al}$ concentration in root zones and mycorrhizal fungal isolates (Table 4.1). Stomatal conductance of non-mycorrhizal plants was reduced by high $\mathrm{Pi}$ when no Al was present, but enhanced by Al treatment when high Pi was applied at the same time (Table 4.2). LM isolate decreased stomatal conductance of host plants at $100 \mu \mathrm{M}$ when no Al was present, but increased stomatal conductance at $100 \mu \mathrm{M}$ Pi plus $200 \mu \mathrm{M}$ $\mathrm{Al}$, and had no effect on it under other conditions. HM isolate decreased stomatal conductance at $40 \mu \mathrm{M}$ Pi without regard to $\mathrm{Al}$ exposure, but increased stomatal conductance at $100 \mu \mathrm{M}$ Pi when $\mathrm{Al}$ was present, and had no effect on it at $100 \mu \mathrm{M}$ Pi and no $\mathrm{Al}$ (Table 4.2).

Leaf photosynthetic rate of mycorrhizal and non-mycorrhizal plants depended on $\mathrm{Pi}$ concentrations (Table 4.1). Photosynthetic rate of non-mycorrhizal plants was enhanced by Al treatment (Table 4.2). LH isolate had no significant effect on photosynthetic rate except under conditions of $40 \mu \mathrm{M}$ Pi plus $200 \mu \mathrm{M}$ Al, where photosynthetic rate of LM mycorrhizal plants was significantly higher than that of non-mycorrhizal plants. HM isolate increased photosynthetic rate of host plants only at $100 \mu \mathrm{M} \mathrm{Pi}$ and no Al presence, and under other conditions, did not significantly affect this trait of host plants.

Leaf respiratory rate of mycorrhizal and non-mycorrhizal plants depended on $\mathrm{Al}$ concentrations (Table 4.1). Leaf respiratory rate of non-mycorrhizal plants was enhanced by Al exposure and also by high Pi application when Al was present (Table 4.2). LM isolate increased leaf respiration of host plants at $40 \mu \mathrm{M}$ Pi and no $\mathrm{Al}$ presence, but reduced it under $\mathrm{Al}$ exposure without regard to Pi concentrations. HM isolate also reduced leaf respiration of host plants under $\mathrm{Al}$ exposure without regard to $\mathrm{Pi}$ concentrations. Under conditions of $40 \mu \mathrm{M} \mathrm{Pi}$ and no $\mathrm{Al}$ presence or $100 \mu \mathrm{M}$ Pi plus $200 \mu \mathrm{M}$ Al, respiration of LM mycorrhizal plants was significantly higher than that of HM mycorrhizal plants.

Root protein of mycorrhizal and non-mycorrhizal plants depended on Pi concentrations (Table 4.1). Root total soluble protein concentrations of non-mycorrhizal plants were reduced by high Pi when no $\mathrm{Al}$ was present, but enhanced by $\mathrm{Al}$ exposure under a condition of $100 \mu \mathrm{M} \mathrm{Pi}$ (Figure 4.2), which may be a reflection of the repressible Pi transport system and defense response to $\mathrm{Al}$ operated in higher plants, respectively. $\mathrm{LM}$ isolate significantly reduced the root protein of host plants without regard to Al exposure, but had no significant effect on it at $40 \mu \mathrm{M}$ Pi. HM isolate significantly increased the root protein of host plants at $40 \mu \mathrm{m} \mathrm{Pi}$ when no $\mathrm{Al}$ was present, but reduced the root protein at $100 \mu \mathrm{M}$ Pi plus $200 \mu \mathrm{M} \mathrm{Al}$, and had no pronounced 
Table 4.1. Probabilities from ANOVA for stomatal conductance $\left(\mathrm{mol} \mathrm{m}^{-2} \mathrm{~s}^{-1}\right)$, photosynthetic rate $\left(\mu \mathrm{mol} \mathrm{m} \mathrm{m}^{-2}\right)$, leaf respiratory rate $\left(\mu \mathrm{mol} \mathrm{m} \mathrm{m}^{-2}\right)$, root total soluble protein $\left(\mu \mathrm{g} \mathrm{g}^{-1}\right)$, and root acid phosphatase (APase) ( $\mu \mathrm{mol} \mathrm{g}^{-1} \mathrm{~h}^{-1}$ ) of LM mycorrhizal, HM mycorrhizal, and nonmycorrhizal broomsedge (A. virginicus) plants.

\begin{tabular}{lccccc}
\hline Source & $\begin{array}{c}\text { Stomatal } \\
\text { Conductance }\end{array}$ & $\begin{array}{c}\text { Photosynthetic } \\
\text { Rate }\end{array}$ & $\begin{array}{c}\text { Respiratory } \\
\text { Rate }\end{array}$ & $\begin{array}{c}\text { Root } \\
\text { Protein }\end{array}$ & APase \\
\hline $\mathbf{M y c}$ & $<0.001$ & 0.0199 & $\mathrm{~ns}$ & $\mathrm{~ns}$ & $\mathrm{~ns}$ \\
$\mathbf{P i}$ & 0.001 & $\mathrm{~ns}^{*}$ & $<0.001$ & 0.019 & $<0.001$ \\
$\mathbf{A l}$ & $<0.001$ & $<0.001$ & $<0.001$ & $<0.001$ & $\mathrm{~ns}$ \\
$\mathbf{M y c} * \mathbf{P i}$ & $<0.001$ & 0.002 & $\mathrm{~ns}$ & 0.016 & $\mathrm{~ns}$ \\
$\mathbf{M y c} * \mathbf{A l}$ & $<0.001$ & $\mathrm{~ns}$ & 0.018 & $\mathrm{~ns}$ & 0.021 \\
$\mathbf{P i} * \mathbf{A l}$ & $<0.001$ & 0.017 & 0.001 & $\mathrm{~ns}$ & $\mathrm{~ns}$ \\
$\mathbf{M y c} * \mathbf{P i} * \mathbf{A l}$ & $<0.001$ & $\mathrm{~ns}$ & $\mathrm{~ns}$ & $\mathrm{~ns}$ & $\mathrm{~ns}$ \\
\hline
\end{tabular}

$\alpha=0.05$, the same hereafter. 
Table 4.2. Stomatal conductance $\left(\mu \mathrm{mol} \mathrm{m} \mathrm{m}^{-2}\right)$, photosynthetic rate $\left(\mu \mathrm{mol} \mathrm{m} \mathrm{m}^{-2}\right)$, and leaf respiratory rates $\left(\mu \mathrm{mol} \mathrm{m} \mathrm{m}^{-2} \mathrm{~s}^{-1}\right)$ in LM mycorrhizal, HM mycorrhizal, and non-mycorrhizal broomsedge (A. virginicus) plants as influenced by $\mathrm{Al}$ exposure or Pi concentrations.

\begin{tabular}{|c|c|c|c|}
\hline & Stomatal Conductance & Photosynthetic Rate & Respiratory Rate \\
\hline \multicolumn{4}{|c|}{$0 \mu \mathrm{M} \mathrm{Al}, 40 \mu \mathrm{M}$ Pi } \\
\hline LM & 0.241 & 1.953 & 0.475 \\
\hline HM & 0.217 & 1.613 & 0.350 \\
\hline NM & 0.247 & 1.822 & 0.300 \\
\hline \multicolumn{4}{|c|}{$0 \mu \mathrm{M} A \mathrm{Al}, 100 \mu \mathrm{M}$ Pi } \\
\hline $\mathbf{L M}$ & 0.219 & 2.159 & 0.328 \\
\hline HM & 0.193 & 2.546 & 0.362 \\
\hline NM & 0.189 & 1.854 & 0.313 \\
\hline \multicolumn{4}{|c|}{$200 \mu \mathrm{M} A \mathrm{Al}, 40 \mu \mathrm{M}$ Pi } \\
\hline LM & 0.253 & 3.452 & 0.332 \\
\hline HM & 0.236 & 2.059 & 0.268 \\
\hline NM & 0.254 & 2.339 & 0.488 \\
\hline \multicolumn{4}{|c|}{$200 \mu \mathrm{M}$ Al, $100 \mu \mathrm{M}$ Pi } \\
\hline LM & 0.384 & 2.411 & 0.750 \\
\hline HM & 0.303 & 2.469 & 0.628 \\
\hline NM & 0.254 & 2.358 & 0.889 \\
\hline $\mathbf{L S D}^{\dagger}$ & 0.014 & 0.380 & 0.112 \\
\hline
\end{tabular}

† Tukey’s Least significant difference at $\alpha=0.05$ with $\mathrm{n}=12$. 
Figure 4.2. Influence of $\mathrm{Pi}$ and $\mathrm{Al}$ treatments on root total soluble protein concentration $(\mathbf{A})$ and root acid phosphatase activity (B) of LM mycorrhizal (solid bar), HM mycorrhizal (hatched bar), and non-mycorrhizal (open bar) broomsedge (A. virginicus) plants. 

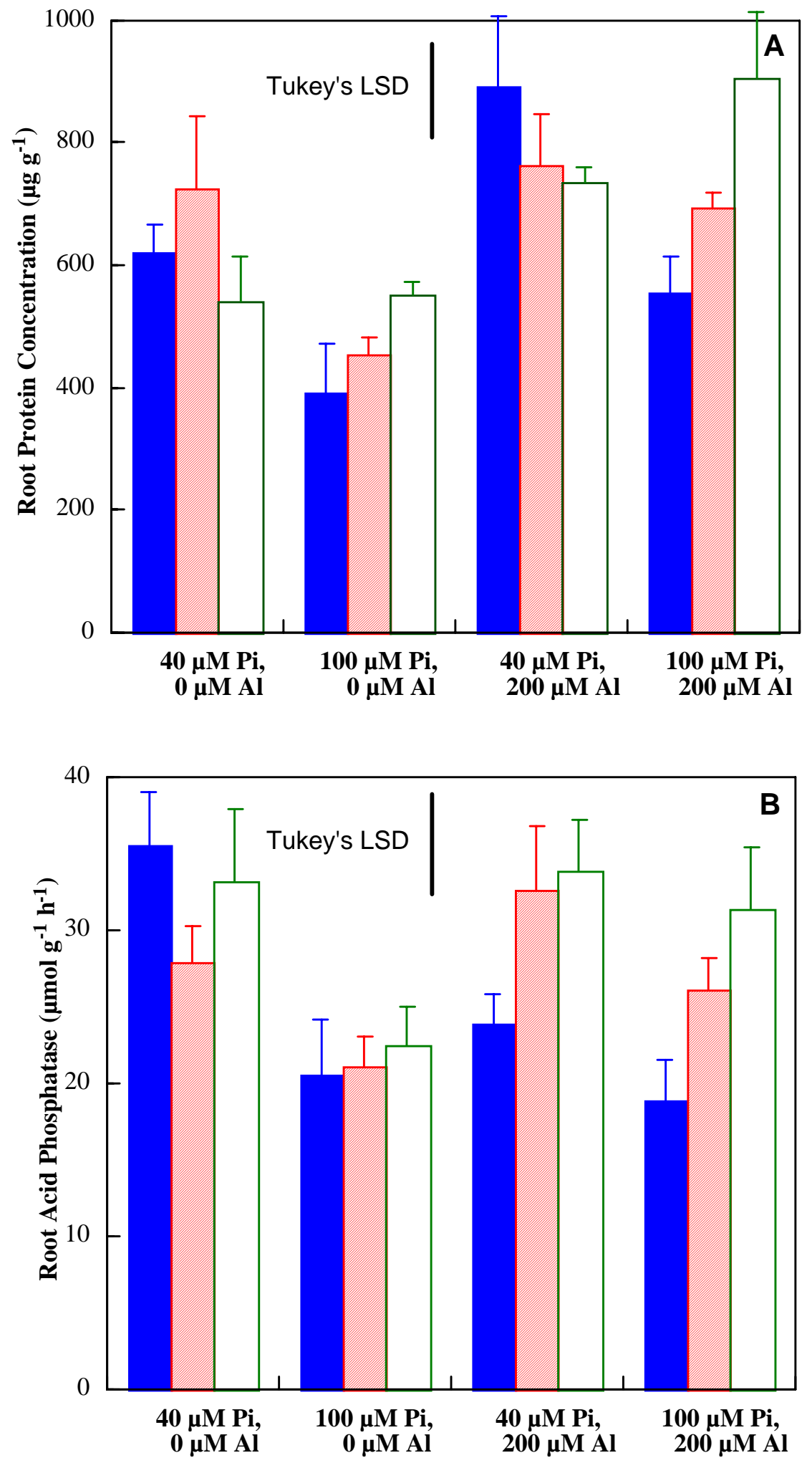
effect on this parameter under other two conditions examined in this experiment (Figure 4.2).

Root acid phosphatase (APase) of mycorrhizal and non-mycorrhizal plants depended on Al concentrations (Table 4.1). Root APase activity of non-mycorrhizal plants was reduced byhigh $\mathrm{Pi}$ without regard to $\mathrm{Al}$ exposure, and insensitive to $\mathrm{Al}$ exposure (Figure 4.2). LM isolate had no significant effect on the APase of host plants when no Al was present, but decreased it under $\mathrm{Al}$ exposure. HM isolate had no significant effect on the APase of host plants under any of conditions examined in this study (Figure 4.2).

Shoot and root $\mathrm{P}$ concentrations depended on solution $\mathrm{Pi}$ and $\mathrm{Al}$ concentrations and AM fungal presence (Table 4.3). Shoot and root P concentrations of non-mycorrhizal plants were not affected by Pi treatment when no Al was present (Figure 4.3), reflecting the general regulation of $\mathrm{Pi}$ homeostasis in higher plants. Shoot $\mathrm{P}$ concentration of non-mycorrhizal plants was reduced by $\mathrm{Al}$ exposure when $40 \mu \mathrm{M} \mathrm{Pi}$ was applied, but $\mathrm{Al}$ exposure increased root $\mathrm{P}$ concentration under the same condition, exhibiting that Al blocked $\mathrm{P}$ translocation within plants. At $100 \mu \mathrm{M}$ $\mathrm{Pi}$, shoot $\mathrm{P}$ concentration of non-mycorrhizal plants was enhanced by $\mathrm{Al}$ exposure, but $\mathrm{Al}$ exposure had no pronounced effect on root $\mathrm{P}$ at that $\mathrm{Pi}$ level, indicating that easily available Pi ameliorated detrimental effect of $\mathrm{Al}$ on $\mathrm{P}$ uptake. LM isolate reduced shoot $\mathrm{P}$ concentrations of host plants under conditions of $40 \mu \mathrm{M}$ Pi or $100 \mu \mathrm{M}$ Pi plus $200 \mu \mathrm{M}$ Al, but enhanced shoot P concentrations of host plants at $40 \mu \mathrm{M}$ Pi plus $200 \mu \mathrm{M}$ Al, and had no pronounced effect on it at $100 \mu \mathrm{M}$ Pi. HM isolate reduced shoot $\mathrm{P}$ concentrations of host plants under conditions of $40 \mu \mathrm{M}$ Pi or $100 \mu \mathrm{M}$ Pi plus $200 \mu \mathrm{M}$ Al, but enhanced it at $100 \mu \mathrm{M}$ Pi or $40 \mu \mathrm{M}$ Pi plus $200 \mu \mathrm{M}$ Al. Tissue Al concentrations depended on $\mathrm{Pi}$ concentration, Al concentration and mycorrhizal colonization (Table 4.3). Shoot Al concentrations of non-mycorrhizal plants were enhanced by $\mathrm{Al}$ exposure. Under $\mathrm{Al}$ exposure, low $\mathrm{Pi}$ treatment resulted in higher shoot $\mathrm{Al}$ concentrations than high Pi. LM isolate had no significant effect on shoot Al concentration of host plants when no Al was applied without regard to Pi concentration, but reduced shoot $\mathrm{Al}$ concentrations under $\mathrm{Al}$ exposure. $\mathrm{HM}$ isolate significantly reduced shoot $\mathrm{Al}$ concentrations under any condition. Non-mycorrhizal root $\mathrm{Al}$ concentrations were enhanced by $\mathrm{Al}$ exposure at $40 \mu \mathrm{M} \mathrm{Pi}$, but reduced by high Pi under $\mathrm{Al}$ exposure. Both $\mathrm{LM}$ and $\mathrm{HM}$ isolates reduced root $\mathrm{Al}$ concentrations of host plants under any conditions except at $100 \mu \mathrm{M}$ Pi plus $200 \mu \mathrm{M}$ Al for LM isolate and $40 \mu \mathrm{M}$ Pi without $\mathrm{Al}$ for $\mathrm{HM}$ isolate, at where $\mathrm{LM}$ and $\mathrm{HM}$ isolates had no pronounced effect root $\mathrm{Al}$ concentrations of host plants (Figure 4.4). 
Table 4.3. $P$ values from ANOVA for shoot and root $\mathrm{Al}$ and nutrient concentrations of LM mycorrhizal, HM mycorrhizal, and non-mycorrhizal broomsedge (A. virginicus) plants.

\begin{tabular}{|c|c|c|c|c|c|c|}
\hline & Source & Al & $\mathbf{P}$ & $\mathbf{K}$ & $\mathbf{C a}$ & Mg \\
\hline \multirow{7}{*}{ Shoot } & Мyc & $<0.001$ & $<0.001$ & 0.004 & 0.022 & 0.003 \\
\hline & $\mathbf{P i}$ & $<0.001$ & $<0.001$ & $<0.001$ & $<0.001$ & $<0.001$ \\
\hline & Al & $<0.001$ & $<0.001$ & 0.031 & $<0.001$ & 0.015 \\
\hline & Мyc*Pi & 0.027 & 0.008 & $<0.001$ & ns & 0.030 \\
\hline & Myc*Al & $<0.001$ & $\mathrm{~ns}$ & ns & ns & $\mathrm{ns}$ \\
\hline & Pi*Al & $\mathrm{ns}^{*}$ & $<0.001$ & $\mathrm{~ns}$ & $\mathrm{~ns}$ & $\mathrm{~ns}$ \\
\hline & Myc*Pi*Al & 0.018 & $<0.001$ & $\mathrm{~ns}$ & 0.021 & $<0.001$ \\
\hline \multirow{7}{*}{ Root } & Мyc & $<0.001$ & 0.004 & 0.001 & $\mathrm{~ns}$ & $\mathrm{~ns}$ \\
\hline & $\mathbf{P i}$ & $<0.001$ & $<0.001$ & $\mathrm{~ns}$ & $<0.001$ & $<0.001$ \\
\hline & Al & ns & $<0.001$ & 0.002 & $<0.001$ & $<0.001$ \\
\hline & Мyc*Pi & 0.042 & $<0.001$ & ns & ns & $\mathrm{ns}$ \\
\hline & Myc*Al & 0.007 & 0.003 & 0.027 & $\mathrm{~ns}$ & $\mathrm{~ns}$ \\
\hline & $\mathbf{P i} * \mathbf{A l}$ & 0.012 & ns & ns & 0.046 & 0.026 \\
\hline & Myc*Pi*Al & $<0.001$ & $<0.001$ & $\mathrm{~ns}$ & 0.013 & 0.028 \\
\hline
\end{tabular}


Figure 4.3. Influence of $\mathrm{Pi}$ and $\mathrm{Al}$ treatments on shoot $(\mathbf{A})$ and $\operatorname{root}(\mathbf{B}) \mathrm{P}$ concentrations of LM mycorrhizal (solid bar), HM mycorrhizal (hatched bar), and non-mycorrhizal (open bar) broomsedge (A. virginicus) plants. 

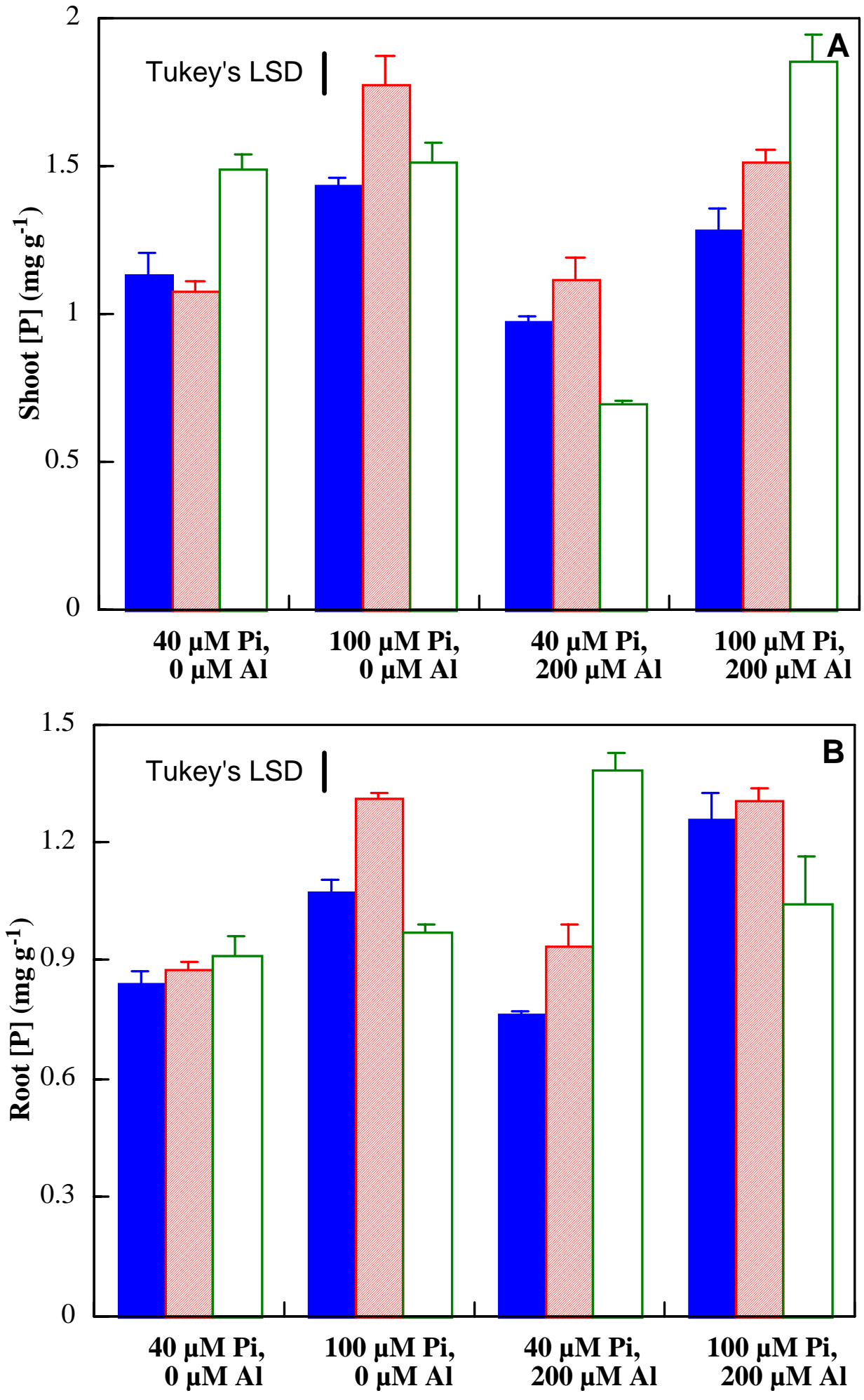
Figure 4.4. Influence of $\mathrm{Pi}$ and $\mathrm{Al}$ treatments on shoot $(\mathbf{A})$ and root $(\mathbf{B}) \mathrm{Al}$ concentrations of LM mycorrhizal (solid bar), HM mycorrhizal (hatched bar), and non-mycorrhizal (open bar) broomsedge (A. virginicus) plants. 

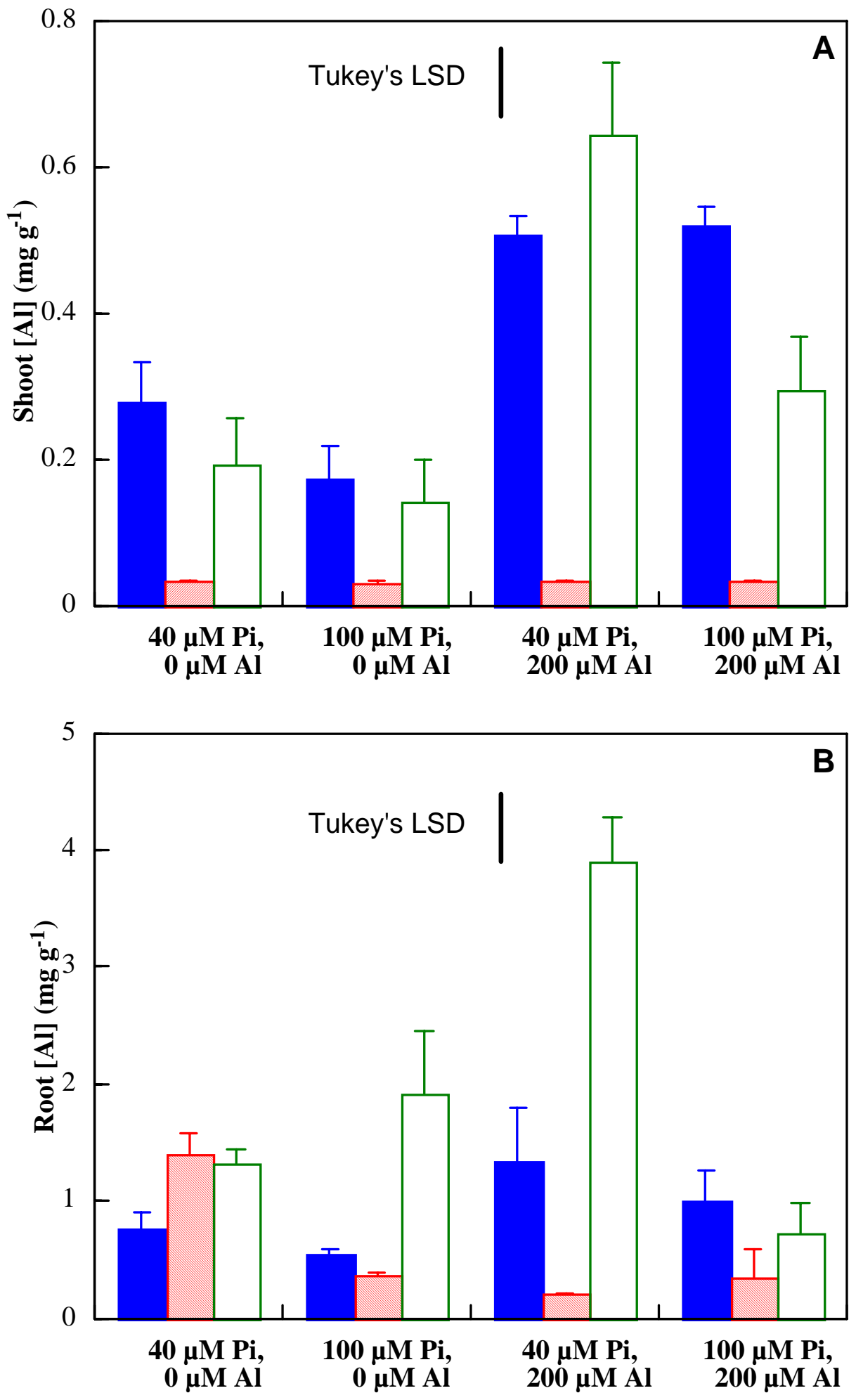
Differences in growth (Figure 4.1), physiology (Table 4.1and 4.2, Figure 4.2), tissue P and $\mathrm{Al}$ concentrations (Figure 4.3 and 4.4) among LM mycorrhizal, HM mycorrhizal, and nonmycorrhizal plants suggest that tissue nutrient concentrations of these plants may have been altered by $\mathrm{Pi}$ and $\mathrm{Al}$ treatments. Shoot $\mathrm{K}$ concentrations of mycorrhizal and non-mycorrhizal plants depended on $\mathrm{Pi}$ concentration, but their root $\mathrm{K}$ concentrations changed as $\mathrm{Al}$ concentrations changes (Table 4.3). Shoot $\mathrm{K}$ concentrations of non-mycorrhizal plants were reduced by high $\mathrm{Pi}$ without regard to $\mathrm{Al}$ exposure, but enhanced by $\mathrm{Al}$ exposure without regard to Pi concentration (Table 4.4), which may be related to dilution effect of growth enhanced by high $\mathrm{Pi}$ and the general regulation of potentials across cell membranes in response to $\mathrm{Al}$ exposure. At $40 \mu \mathrm{M}$ Pi without regard to $\mathrm{Al}$ exposure, both $\mathrm{LM}$ and $\mathrm{HM}$ isolates decreased shoot $\mathrm{K}$ concentrations of host plants. But $\mathrm{HM}$ isolate increased it at $100 \mu \mathrm{M}$ Pi when no $\mathrm{Al}$ was present, and LM isolate had no effect on it under the same conditions. Root $\mathrm{K}$ concentrations of non-mycorrhizal plants were enhanced by high under Al exposure, and also enhanced by $\mathrm{Al}$ exposure at $40 \mu \mathrm{M} \mathrm{Pi}$, but reduced by $\mathrm{Al}$ exposure at $100 \mu \mathrm{M}$ Pi. LM isolate increased root $\mathrm{K}$ concentrations of host plants at $40 \mu \mathrm{M}$ Pi or $100 \mu \mathrm{M}$ Pi plus $200 \mu \mathrm{M}$ Al. HM isolate had no significant effect on root $\mathrm{K}$ except at $40 \mu \mathrm{M}$ Pi plus $200 \mu \mathrm{M} \mathrm{Al}$, where $\mathrm{HM}$ mycorrhizal root $\mathrm{K}$ concentration was lower than that of non-mycorrhizal (Table 4.4).

Tissue $\mathrm{Ca}$ concentrations depended on $\mathrm{Pi}, \mathrm{Al}$, and mycorrhizal treatment (Table 4.3). Shoot $\mathrm{Ca}$ concentrations of non-mycorrhizal plants were enhanced by high Pi without regard to $\mathrm{Al}$ exposure, but reduced by $\mathrm{Al}$ exposure without regard to Pi treatment (Table 4.4), suggesting the general response patterns of $\mathrm{Ca}$ nutrition to high available $\mathrm{Pi}$ and elevated $\mathrm{Al}$ in higher plants. LM and HM isolates both increased shoot Ca concentrations of host plants at $40 \mu \mathrm{M}$ Pi or 100 $\mu \mathrm{M}$ Pi plus $200 \mu \mathrm{M}$ Al. Under conditions of $100 \mu \mathrm{M}$ Pi or $40 \mu \mathrm{M}$ Pi plus $200 \mu \mathrm{M}$ Al, these two isolates had no significant effect on the shoot $\mathrm{Ca}$ (Table 4.4). Root $\mathrm{Ca}$ concentrations of nonmycorrhizal plants were enhanced by high Pi when no Al was present, but reduced by Al exposure at $100 \mu \mathrm{M} \mathrm{Pi}$ (table 4.4). LM isolate increased root Ca concentrations of host plants at $40 \mu \mathrm{M}$ Pi or $100 \mu \mathrm{M}$ Pi plus $200 \mu \mathrm{M} \mathrm{Al}$, but HM isolate decreased root Ca concentration of host plants at $100 \mu \mathrm{M}$ Pi when no $\mathrm{Al}$ was present (Table 4.4).

Shoot and root $\mathrm{Mg}$ concentration depended on solution $\mathrm{Pi}, \mathrm{Al}$ concentrations and $\mathrm{AM}$ fungal presence (Table 4.3). Shoot $\mathrm{Mg}$ concentrations of non-mycorrhizal plants were not 
Table 4.4. Influence of $\mathrm{Pi}$ and $\mathrm{Al}$ treatments on shoot and root $\mathrm{K}\left(\mathrm{mg} \mathrm{g}^{-1}\right), \mathrm{Ca}\left(\mathrm{mg} \mathrm{g}^{-1}\right)$, and $\mathrm{Mg}$ $\left(\mathrm{mg} \mathrm{g}^{-1}\right)$ concentrations of LM mycorrhizal, HM mycorrhizal, and non-mycorrhizal broomsedge (A. virginicus) plants.

\begin{tabular}{|c|c|c|c|c|c|c|}
\hline & \multicolumn{3}{|c|}{ Shoot } & \multicolumn{3}{|c|}{ Root } \\
\hline & $\mathbf{K}$ & $\mathbf{C a}$ & Mg & $\mathbf{K}$ & $\mathbf{C a}$ & Mg \\
\hline \multicolumn{7}{|c|}{$0 \mu \mathrm{M}$ Al, $40 \mu \mathrm{M}$ Pi } \\
\hline LM & 18.411 & 15.445 & 7.064 & 16.402 & 18.257 & 4.287 \\
\hline HM & 17.777 & 16.126 & 6.321 & 11.549 & 15.692 & 4.818 \\
\hline NM & 20.951 & 13.504 & 6.806 & 11.073 & 12.992 & 4.174 \\
\hline \multicolumn{7}{|c|}{$0 \mu \mathrm{M}$ Al, $100 \mu \mathrm{M}$ Pi } \\
\hline LM & 15.564 & 21.457 & 7.102 & 13.291 & 21.540 & 7.978 \\
\hline HM & 17.339 & 19.200 & 7.945 & 12.166 & 20.559 & 6.045 \\
\hline NM & 15.443 & 21.095 & 6.691 & 12.289 & 24.281 & 9.268 \\
\hline \multicolumn{7}{|c|}{$200 \mu \mathrm{M} A \mathrm{Al}, 40 \mu \mathrm{M} \mathrm{Pi}$} \\
\hline LM & 17.188 & 11.614 & 6.545 & 18.046 & 14.172 & 3.486 \\
\hline HM & 17.751 & 10.628 & 6.972 & 10.942 & 13.834 & 2.932 \\
\hline NM & 22.881 & 9.918 & 5.193 & 19.789 & 13.603 & 3.563 \\
\hline \multicolumn{7}{|c|}{$200 \mu \mathrm{M} A \mathrm{l}, 100 \mu \mathrm{M} \mathbf{P i}$} \\
\hline $\mathbf{L M}$ & 17.967 & 16.012 & 6.648 & 16.004 & 20.127 & 6.349 \\
\hline HM & 18.302 & 16.788 & 7.304 & 13.632 & 16.133 & 4.336 \\
\hline NM & 17.794 & 12.030 & 7.008 & 15.230 & 12.964 & 3.383 \\
\hline $\mathbf{L S D}^{\dagger}$ & 1.523 & 2.047 & 0.516 & 2.609 & 3.557 & 1.538 \\
\hline
\end{tabular}

${ }^{\dagger}$ Tukey’s Least significant difference at 0.05 level with $n=3$. 
affected by $\mathrm{Pi}$ treatment without regard to $\mathrm{Al}$ exposure, but reduced by $\mathrm{Al}$ exposure at $40 \mu \mathrm{M} \mathrm{Pi}$ or enhanced by $\mathrm{Al}$ exposure at $100 \mu \mathrm{M}$ Pi (Table 4.4), which exhibited that Pi treatment had no a direct effect on shoot $\mathrm{Mg}$ concentrations and effects of $\mathrm{Al}$ on shoot $\mathrm{Mg}$ depended on $\mathrm{Pi}$ concentrations. LM isolate increased shoot $\mathrm{Mg}$ of host plants at $40 \mu \mathrm{M}$ Pi without regard to $\mathrm{Al}$ exposure. $\mathrm{HM}$ isolate also increased shoot $\mathrm{Mg}$ concentrations of host plants at $100 \mu \mathrm{M} \mathrm{Pi}$ without regard to $\mathrm{Al}$ exposure and at $40 \mu \mathrm{M}$ Pi plus $200 \mu \mathrm{M} \mathrm{Al}$ as well. Root $\mathrm{Mg}$ concentrations of non-mycorrhizal plants was enhanced by high $\mathrm{Pi}$ when no $\mathrm{Al}$ was present, but reduced by $\mathrm{Al}$ exposure at $100 \mu \mathrm{M} \mathrm{Pi}$ (Table 4.4). LM isolate increased root Mg concentration of host plants at $100 \mu \mathrm{M}$ Pi plus $200 \mu \mathrm{M} \mathrm{Al}$, but HM isolate decreased root Mg concentration of host plants at $100 \mu \mathrm{M}$ Pi when no Al was present (Table 4.4).

\section{Discussion}

Plants may adjust physiological activities in response to changes of environmental conditions (Marschner 1995; Lambers et al. 1998). Phosphorus effects on plant physiology are expected because $\mathrm{P}$ is an essential component of energy metabolism and nucleic acids and proteins. Phosphorus deficiency may induce APase activity (Caradus and Snaydon 1987; Duff et al. 1994), alter levels of ATP (Muchhal et al. 1997), and hormones (Morgan 1990), and activate the alternative respiratory pathway (Theodorou and Plaxton 1993). Aluminum impacts on plant physiology have been reported and reviewed (Roy et al. 1988; Taylor 1988a, 1988b; Miyasaka et al. 1989, 1991; Cumming and Weinstein 1990; Delhaize and Ryan 1995; Kochian 1995; Slaski et al. 1996). Elevated Al may inhibit ATPase activity (Matsumoto and Yamaya 1986; Lindberg and Griffiths 1993; Widell et al. 1994), reduce APase activity (Shaw and Read 1989), photosynthesis (Roy et al. 1988; Cumming and Weinstein 1990; Schlegel and Godbold 1991), and root respiration (Roy 1988; Cumming et al. 1992), alter levels of other proteins (Caldwell 1989; Slaski et al. 1996; Basu et al. 1997; Blancaflor et al. 1998), pigments (Roy et al. 1988; Schlegel and Godbold 1991; Ayala-Silva and Al-Hamdani 1997), membrane potentials (Miyasaka et al. 1989; Pineros and Tester 1993; Olivetti et al. 1995; Lindberg and Strid 1997), ion flux (Miyasaka et al. 1989; Huang et al. 1992; Nichol et al. 1993; Calba and Jaillard 1997; Lindberg and Strid 1997), and metabolic pathways (Schlegel and Godbold 1991; Zhang et al. 
1994; Yamaguchi et al. 1999), and induce production of organic acids (Miyasaka et al. 1991; Delhaize et al. 1993; Ma et al. 1997; Larsen et al. 1998; Chapter III).

In this study, Pi treatment increased or decreased leaf chlorophyll, stomatal conductance, photosynthetic rate, respiratory rate, root protein, and root APase activity of non-mycorrhizal plants, depending on $\mathrm{Al}$ presence, and $\mathrm{Al}$ exposure changed leaf chlorophyll, stomatal conductance, photosynthetic rate, respiratory rate, root protein, and root APase activity of nonmycorrhizal plants, depending on Pi levels (Table 4.1 and 4.2, Figure 4.2). The results from This study reveal that toxic $\mathrm{Al}$ presence in root zones may disrupt $\mathrm{P}$ acquisition by a plant and translocation within a plant (Figure 4.3), interfere $\mathrm{Ca}$ and $\mathrm{Mg}$ uptake (Table 4.4), and affect stomatal behaviors, which may directly or indirectly influence photosynthesis and respiration (Table 4.2). All these consequently result in reduced plant growth (Figure 4.1), which are consistent with previous reports (Roy et al. 1988; Taylor 1988; Miyasaka et al. 1989; Cumming and Weinstein 1990; Delhaize and Ryan 1995; Kochian 1995; Slaski et al. 1996). Plants may induce protein production in response to toxic $\mathrm{Al}$ presence (Figure 4.2) as reported (Basu et al. 1997). Easily available Pi may reduce Al influx (Figure 4.4), improve P nutrition (Figure 4.3), support protein induction under Al exposure (Figure 4.2), and ameliorate detrimental effects of $\mathrm{Al}$ on $\mathrm{Ca}$ and $\mathrm{Mg}$ uptake (Table 4.4), consequently leading to enhanced growth (Figure 4.1).

Mycorrhizal symbioses facilitated Pi acquisition under limited Pi availability, but may or may not affect Pi uptake when Pi is easily available (Figure 4.3), and reduced $\mathrm{Al}$ influx and translocation within host plants (Figure 4.4). The differences in $\mathrm{Pi}$ x Al interactions between mycorrhizal and non-mycorrhizal plants on shoot and root $\mathrm{P}$ and $\mathrm{Al}$ concentrations may cause or be a result of changes in physiology of host plants under different environmental conditions (Allen et al. 1981; Hayman 1983; Haselwandter 1995; Smith and read 1997; Aguilera-Gomez et al. 1998; Baker et al. 1998; Boucher et al. 1999). The results from the present study showed that mycorrhizal and non-mycorrhizal plants significantly differed or not in stomatal conductance, photosynthetic rate, leaf respiratory rate (Table 4.2), root protein concentration, root APase (Figure 4.2), and tissue macronutrients (Table 4.4), depending on Pi and Al concentrations in root zones. These changes in physiology and tissue $\mathrm{P}$ and $\mathrm{Al}$ concentrations of broomsedge plants would contribute to the differences in biomass observed in this study (Figure 4.1). However, these changes in physiology of broomsedge plants neither parallel to the differences in tissue $\mathrm{P}$ and $\mathrm{Al}$ concentrations nor to the differences in biomass of broomsedge plants, which 
may suggest complex Pi-by-Al interactions (Clarkson 1966; Snoeyink and Jenkins 1980; Foy 1983; de Miranda and Rowell 1989; Marschner 1995; Ritchie 1995; Yang and Goulart 1997).

HM mycorrhizal plants had higher tissue P concentrations than LM mycorrhizal plants under $\mathrm{Al}$ exposure or high available Pi condition (Figure 4.3), but lower tissue Al concentrations and LM mycorrhizal plants (Figure 4.4). LM mycorrhizal plants tolerated higher Al than HM mycorrhizal plants when they were exposed to Al (Figure 4.1 and 4.4). Differences in physiology between LM and HM mycorrhizal plants thus would be expected, and these differences in physiology would be changed as $\mathrm{Pi}$ and $\mathrm{Al}$ concentrations change (Hayman 1983; Cumming and Weinstein 1990; Koslowsky and Boerner 1989; Zel et al. 1993; BartolomeEsteban and Schenck 1994; Medeiros et al. 1994; Clark 1997). LM mycorrhizal plants had higher stomatal conductance than HM mycorrhizal plants independent of $\mathrm{Pi}$ and $\mathrm{Al}$ treatments (Table 4.2). LM and HM mycorrhizal plants significantly differed or not in photosynthesis, leaf respiration (Table 4.2), root protein concentrations, root APase (Figure 4.2), and tissue macronutrients (Table 4.4), depending on $\mathrm{Pi}$ and $\mathrm{Al}$ concentrations in root zones. These differences may contribute to growth. For example, HM mycorrhizal plants had low leaf respiration (high Pi), high photosynthesis (high Pi) (Table 4.2), low shoot Al (Figure 4.4), high shoot P (high Pi) (Figure 4.3), and high Mg (high Pi) (Table 4.4), consequently leading to large plants under these conditions (Figure 4.1).

LM mycorrhizal plants are able to tolerate Al to certain extent, and HM mycorrhizal plants are capable of mining scarce $\mathrm{P}$ resources. These differences in host plants brought about by colonization of different AM fungal isolates may be associated with the roles these fungi play in their original habitats. $\mathrm{LM}$ fungus was from a low $\mathrm{pH}$ and high $\mathrm{Al}$ site, where elevated $\mathrm{Al}$ is one of the primary factors limiting growth and establishment of plants and fungi. However, HM fungus originated from a high $\mathrm{pH}$ site, where most $\mathrm{Pi}$ would be fixed by $\mathrm{Ca}$ so that available $\mathrm{Pi}$ to plants would be limited. Thus, these AM fungi appear to have adapted to their original environments as revealed through this study and previous study (Chapter III).

This study demonstrated that mycorrhizal fungi play an important role in plants under limited Pi and elevated Al conditions, but different AM fungal isolates differentially affect the host plants under different conditions. With the Al treatment, both fungal isolates significantly enhanced plant growth in comparison to non-mycorrhizal plants. Without the Al treatment, however, the HM fungal isolate performed much better than LM fungal isolate in terms of plant biomass when the plants were supplied with limited Pi (Figure 4.1). The HM fungus may have 
refined its function in aiding host plants to cope with limited $\mathrm{Pi}$ availability in the high $\mathrm{pH}$ soils where most $\mathrm{Pi}$ is precipitated with $\mathrm{Ca}$, and the $\mathrm{LM}$ fungus may have placed its effort in ameliorating $\mathrm{Al}$ toxicity present in the acidic soils. The data from the tissue $\mathrm{P}$ and $\mathrm{Al}$ concentrations (Figure 4.3 and 4.4) further support the concept of the local adaptation of these two AM fungal isolates. HM mycorrhizal plants were still able to maintain the normal Pi uptake and $\mathrm{P}$ translocation and restricted $\mathrm{Al}$ influx into plants under $\mathrm{Al}$ treatment, consequently leading to better growth. On the other hand, LM mycorrhizal plants maintained the normal physiology and growth even though they had considerable Al inside shoots under $200 \mu \mathrm{M}$ Al treatment, which is lower than the $\mathrm{Al}$ concentration in the mining soil from where this fungal isolate was originated. 


\section{SUMMARY}

Limited phosphorus (Pi) availability and elevated aluminum (Al) level associated with soil acidification are a great challenge to the sustainable agricultural systems and environmental quality. Under acidic conditions ( $\mathrm{pH}<5.0), \mathrm{Al}$ exists mainly as $\mathrm{Al}^{3+}$, which is toxic to plants and also forms precipitates with phosphate. Thus, Al toxicity and Pi deficiency often co-occur and are the primary factors limiting plant growth and production in acidic soils.

The most present-living plants are potentially to form symbiotic association with mycorrhizal fungi. Arbuscular mycorrhizal (AM) symbioses are the most commonly mycorrhizal associations between obligately symbiotic fungi and higher plants. Mycorrhizal fungal colonization increases seedlings survival and establishment, and improves plant growth and competition, through facilitation of acquisition of diffusion-limited mineral nutrients, especially, $\mathrm{Pi}$, improvement of water relations, conferment of metal resistance, defense of invasion and infection of pathogenic microbes, and suppression of non-mycorrhizal plant growth. These benefits may be achieved by extensive exploration of a large volume of soil, improvement of plant nutrition and alteration of plant physiology and biochemistry.

This dissertation project, including four studies, examined roles of an arbuscular mycorrhizal fungus, Glomus clarum, played in broomsedge (Andropogon virginicus) plants under limited $\mathrm{Pi}$ and elevated $\mathrm{Al}$ conditions in a series of experiment conducted in a growth chamber. The infective inoculum originated from an abandoned acidic coal-mining site in Morgantown, West Virginia, USA. The inoculum of the same fungal species from INVAM collection a West Virginia University, which originated from an abandoned alkaline coal-mining site in Mingo County, West Virginia, USA, was also used in two of the studies. Broomsedge seedlings were pre-colonized by AM fungi from the above inoculum, then transplanted into an acid-washed sand culture system, and watered with a modified Hoagland's base nutrient solution with an adjusted $\mathrm{pH}$ of 4.0 before delivery.

Mycorrhizal sysmbioses pronouncedly enhanced growth of host broomsedge plants under limited Pi and/or elevated $\mathrm{Al}$ conditions. Under Pi limiting conditions, mycorhizal broomsedge plants made more investment on roots, consequently exploring root zones effectively, drew down the solution Pi concentrations to lower levels, leading to increasing exploited Pi pool, and increased phosphorus use efficiency (PUE). Moreover, mycorrhizal broomsedge plants balanced 
accumulation of nutrients under varying Pi availability. Al these brought about by mycorrhizal association with the AM fungi benefit broomsedge plants overcoming Pi deficiency and supporting optimal growth of broomsedge plants under limited Pi availability.

Broomsedge plants do not have an inherent mechanism to block Al influx into plants and tolerate Al toxicity. Mycorrhizal association with the AM fungi significantly conferred Al resistance in broomsedge plants by facilitating Pi uptake in the early stages, reducing $\mathrm{Al}$ influx into roots, suppressing Al translocation within plants, altering profiles of organic acids, increasing concentrations of organic acids in rhizospheres, improving nutrition of host broomsedge plants. These differences in Pi uptake and utilization, Al influx and translocation, exudation of organic acids, an nutrition between mycorrhizal and non-mycorrhizal broomsedge plants may contribute to the observed differences in growth patterns of mycorrhizal and nonmycorrhizal broomsedge plants in responses to $\mathrm{Pi}$ and $\mathrm{Al}$ availability and variability, and may also be the primary mechanisms for this plants species to grow and establish in many adverse habitats. However, different fungal isolates had differential effects on Pi acquisition of, Al influx into and translocation within, exudation of organic acids from root systems of, and nutrient uptake by broomsedge plants as $\mathrm{Pi}$ and/or $\mathrm{Al}$ concentrations in root zones change. These differences may be associated with the differential adaptations of these two AM fungal strains to their original habitats, which may consequently lead to distribution o this plant s species in the eastern United States.

The differences in Pi acquisition and utilization, and Al influx and translocation between mycorrhizla and non-mycorhizal broomsedge plants under Pi and/or Al levels might cause or be a result of changes in physiology of broomsedge plants. Mycorrhizal and non-mycorrhizal plants may or may not significantly differ in stomatal conductance, photosynthetic rate, leaf respiratory rate, root protein concentration, root acid phosphatase, and tissue macronutrients, depending on $\mathrm{Pi}$ and $\mathrm{Al}$ concentrations in root zones. Different AM fungi differentially altered physiology of host broomsedge plants. For example, mycorrhizal plants colonized by the fungus from low $\mathrm{pH}$ site (LM) had higher stomatal conductance than the mycorrhizal plants colonized by the alkaline fungus(JM), independent of Pi and Al treatments. Moreover, compared to LM mycorrhizal plants, HM mycorrhizal plants had low leaf respiration (at low Pi, no Al), high photosynthesis (at high $\mathrm{Pi}$ ), low shoot $\mathrm{Al}$, high shoot $\mathrm{P}$ (at high $\mathrm{Pi}$ ), and high $\mathrm{Mg}$ (at high $\mathrm{Pi}$ ), consequently leading to large plants under these conditions. 
Evidently, this dissertation project revealed that broomsegde plants rely on AM fungi to overcome limited Pi availability and/or elevated Al toxicity. Forming mycorrhizal associations with AM fungi is the main mechanism for broomsedge to grow and establish in various adverse habitats. 


\section{REFERENCES}

Ae, N. and Otani, T. 1997. The role of cell wall components from groundnut roots in solubilizing sparingly soluble phosphorus in low fertility soils. Plant Soil 196: 265-270.

Aerts, R. and Chapin III, F. S. 2000. The mineral nutrition of wild plants revisited: A reevaluation of processes and patterns. In Advances in Ecological Research. Ed. Fitter, A. H. and Raffaelli, D. G. Academic Press, San Diego. 30: 1-67.

Aguilera-Gomez, L.; Ramirez-Moreles, P.; Frias-Hernandez, J. T.; et al. 1998. Influence of Glomus fasciculatum on physiology and growth of three kinds of maize. Phyton -- Interntl. J. Exp. Bot. 62: 101-107.

Aguilera-Gomez, L; Davis, F. T.; Olalde-Portugal, V; Duray, S. A.; and Phavaphutanon, L. 1999. Influence of phosphorus and endomycorrhiza (Glomus intraradices) on gas exchange and plant growth of chile ancho pepper (Capsicum annuum L. cv. San Luis).

Photosynthetica 36: 441-449.

Allen, E. B. and Allen, M. F. 1980. Natural re-establishment of VA mycorrhizae following stripmine reclamation in Wyoming. J. Appl. Ecol. 17: 139-147.

Allen, M. F.; Moore, Jr. T. S. and Chritense, M. 1980. Phytohormone changes in Bouteloua gracilis infected by vesicular-arbuscular mycorrhizae: I. Cytokinin increases in the host plant. Can. J. Bot. 58: 371-374.

Allen, M. F.; Smith, W. K.; Moore, T. S.; and Christensen, M. 1981. Comparative water relations and photosynthesis of mycorrhizal and non-mycorrhizal Bouteloua gracilis. New Phytol. 88: 683-693.

Allen, M. F. 1996. The ecology of arbuscular mycorrhizas: A look back into the $20^{\text {th }}$ century and a peek into the $21^{\text {st }}$. Mycol. Res. 100: 769-782. 
Andersson, M. 1988. Toxicity and tolerance of aluminum in vascular plants: A literature review. Water Air Soil Pollu. 39: 439-462.

Andersson, M. 1992. Effects of pH and aluminum on growth of Galium odoratum (L.) Scop. in flowing solution culture. Environ. Exp. Bot. 32: 497-504.

Andersson, M. E. and Brunet, J. 1993. Sensitivity to $\mathrm{H}^{-}$and $\mathrm{Al}$ ions limiting growth and distribution of the woodland grass Bromus benekenii. Plant Soil 153: 243-254.

Anonymous, 1985. Aluminum, Eriochrome cyanine R method. In Standard Methods for the Analysis of Water and Wastewater. pp. 183-187. American Public Health Association, Washington, D.C.

Antonovics, J.; Bradshaw, A. D. and Turner, R. G. 1971. Heavy metal tolerance in plants. In Advances in Ecological Research. Ed. Cragg, J. B. Academic Press, London. 7: 1-85. Ayala-Silva, T. and Al-Hamdani, S. 1997. Interactive effects of polyactic acid with different aluminum concentrations on growth, pigment concentrations, and carbohydrate accumulation of Azola. Amer. Fern J. 87: 120-126.

Bago, B.; Donaire, J. P.; and Azcon-Aguilar, C. 1997. ATPase activities of root microsomes from mycorrhizal sunflower (Helianthus annus) and onion (Allium cepa) plants. New Phytol. 136: $305-311$.

Baker, S. J.; Tagu, D.; and Delp, G. 1998. Regulation of root and fungal morphogenesis in mycorrhizal symbioses. Plant Physiol. 116: 1201-1207.

Baon, J. B.; Smith, S. E.; and Alston, A. M. 1993. Mycorrhizal responses of barley cultivars differing in P efficiency. Plant Soil 157: 97-105.

Barrett-Lennard, E. G.; Dracup, M. and Greenway, H. 1993. Role of extracellular phosphatases in the phosphorus-nutrition of clover. J. Exp. Bot. 44: 1595-1600. 
Bartolome-Esteban, H. and Schenck, N. C. 1994. Spore germination and hyphal growth of arbuscular mycorrhizal fungi in relation to soil aluminum saturation. Mycologia 86: 217-226.

Basu, U.; McDonald-Stephens, J. L.; Archambault, D. J.; Good, A. G.; Briggs, K. G.; and Taylor, G. J. 1997. Genetic and physiological analysis of doubled-haploid, aluminumresistant lines of wheat provide evidence for the involvement of a $23 \mathrm{kD}$, root exudate polypeptide in mediating resistance. Plant Soil 196: 283-288.

Benabdellan, K.; Azcon-Aguilar, C.; and Ferrol, N. 1999. Plasma membrane ATPase and $\mathrm{H}^{+}$ transport activities in microsomal membranes from mycorrhizal tomato roots. J. Exp.. Bot. 50: $1343-1349$.

Benabdellan, K.; Azcon-Aguilar, C; and Ferrol, N. 2000. Alterations in the plasma membrane polypeptide pattern of tomato roots (Lycopersicon esculentum) during the development of arbuscular mycorrhiza. J. Exp. Bot. 51: 747-754.

Berta, G.; Fusconi, A.; and Trotta, A. 1993. VA mycorrhizal infection and the morphology and function of root systems. Environ. Exp. Bot. 33: 159-173.

Blamey, F. P. C.; Robison, N. J.; and Asher, C. J. 1992. Interspecific differences in aluminum tolerance in relation to root cation-exchange capacity. Plant Soil 146: 77-82.

Blancaflor, E. B.; Jones, D. L.; and Gilroy, S. 1998. Alterations in the cytoskeleton accompany aluminum-induced growth inhibition and morphological changes in primary roots of maize. Plant Physiol. 118: 159-172.

Bolan, N. S. 1991. A critical review on the role of mycorrhizal fungi on the uptake of phosphorus by plants. Plant Soil 134: 189-207.

Bona, L.; Carver, B. F.; Wright, R. J. and Baligar, V. C. 1994. Aluminum tolerance of segregating wheat populations in acidic soil and nutrient solutions. Commun. Soil Sci. Plant Anal. 25: 327-339. 
Boucher, A.; Dalpe, Y.; and Charest, C. 1999. Effect of arbuscular mycorrhizal colonization of four species of Glomus on physiological responses of maize. J. Plant Nutri. 22: 783-797.

Bradford, M. M. 1976. A rapid and sensitive method for the quantification of microgram quantities of protein utilizing the principle of protein-dye binding. Anal. Biochem. 72: 248254.

Bucking, H. and Heyser, W. 1999. Elemental composition and function of polyphosphates in ectomycorrhizal fungi - An X-ray microanalytical study. Mycol. Res. 103: 31-39.

Calba, H. and Jaillard, B. 1997. Effect of aluminum on ion uptake and $\mathrm{H}^{+}$release by maize. New Phytol. 137: 607-616.

Caldwell, C. R. 1989. Analysis of aluminum and divalent cation binding to wheat root plasma membrane proteins using terbrium phosphorescence. Plant Physiol. 91: 233-241.

Campbell, C. S. 1982. Cleistogamy in Andropogon L. (Gramineae). Amer. J. Bot. 69: 16251635.

Campbell, C. S., 1983. Systematics of the Andropogon virginicus complex (Gramineae). J. Arnold Arbor. 64: 171-254.

Caradual, J. R. and Snaydon, R. W. 1997. Aspects of the phosphorus nutrition of white clover populations. II. Root exocellular acid phosphatase activity. J. Plant Nutri. 10: 287-301.

Carver, B. F. and Ownby, J. D. 1995. Acid soil tolerance in wheat. Advances in Agronomy 54: 117-173.

Chapin, III F. S. 1980. The mineral nutrition of wild plants. Annu. Rev. Ecol. Syst. 11: 233-260. Chapin, III F. S. 1983. Adaptation of selected trees and grasses to low availability of phosphorus. Plant Soil 72: 283-287. 
Chapin, III F. S. 1991. Effects of multiple stresses on nutrient availability and use. In Response of Plants to Multiple Stresses. Ed. H A Mooney, W E Winner and E F Pell. pp 67-88. Academic Press, Inc., San Diego, CA.

Chapman, R. H. and Jones, Jr S. B. 1975. Ecotypic differentiation in Andropogon virginicus (Gramineae). Bull. Torrey Bot. Club 102: 166-171.

Claassen, N. and Barber, S. A. 1974. A method for characterizing the relation between nutrient concentration and flux into roots of intact plants. Plant Physio. 54: 564-568.

Clapperton, M. J. and Reid, D. M. 1992. A relationship between plant growth and increasing VA mycorrhizal inoculum density. New Phytol. 120: 227-234.

Clark, R. B. 1997. Arbuscular mycorrhizal adaptation, spore germination, root colonization, and host plant growth and mineral acquisition at low pH. Plant Soil 192: 15-22.

Clarkson, D. T. 1966. Effect of aluminum on the uptake and metabolism of phosphorus by barley seedlings. Plant Physiol. 41: 165-172.

Clarkson, D. T. and Scattergrod, C. B. 1982. Growth and phosphate transport in barley and tomato plants during the development of, and recovery from, phosphate stress. J. Exp. Bot. 33: $865-875$.

Clarkson, D. T. 1985. Factors affecting mineral nutrient acquisition by plants. Annu. Rev. Plant Physiol. 36: 77-115.

Clarkson, D. T. and Luttge, U. 1991. Mineral nutrition: Inducible and repressible nutrient transport systems. Prog. Bot. 52: 61-83.

Clarkson, D. T. and Hawkesford, M. J. 1993. Molecular biological approaches to plant nutrition. Plant Soil 155/156: 21-31. 
Cook, C. M.; Kostidou, A.; Vardaka, E.; and Lanaras, T. 1997. Effects of copper on the growth, photosynthesis and nutrient concentrations of Phaseolus plants. Photosynthetica 34: 179193.

Cress, W. A.; Throneberry, G. O.; and Lindsey, D. L. 1979. Kinetics of phosphorus absorption by mycorrhizal and non-mycorrhizal tomato roots. Plant Physiol. 64: 484-487.

Cumming, J. R. and Weinstein, L. H. 1990. Aluminum-mycorrhizal interactions in the physiology of pitch pine seedlings. Plant Soil 125: 7-18.

Cumming, J. R. and Weinstein, L. H. 1990. Utilization of $\mathrm{AlPO}_{4}$ as a phosphorus source by ectomycorrhizal Pinus rigida Mill. Seedlings. New Phytol. 116: 99-106.

Cumming, J. R.; Cumming, A. B.; and Taylor, G. J. 1992. Patterns of root respiration associated with the induction of aluminum tolerance in Phaseolus vulgaris L. J. Exp. Bot. 43: 10751081.

Cumming, J. R. 1996. Phosphate-limitation physiology in ectomycorrhizal pitch pine. Tree Physiol. 16: 977-983.

Curl, E. A. and Truelove, B. 1986. The Rhizosphere. Springer-Verlag, Berlin.

Daft, M. J. and Hacskaylo, E. 1976. Arbuscular mycorrhizas in the Anthracite and Bituminous coal wastes of Pennsylvania. J. Appl. Ecol. 13: 523-531.

Daft, M. J. and Nicolson, T. H. 1974. Arbuscular mycorrhizas in plants colonizing coal wastes in Scotland. New Phytol. 73: 1129-1138.

Danielson, R. M. 1985. Mycorrhizae and reclamation of stressed terrestrial environments. In Soil Reclamation Processes: Microbiological Analysis and Applications. Ed. R L Tate III and D A Klein. pp 173-201. Marcel Dekker, Inc., New York. 
Delhaize, E.; Ryan, P. R.; and Randall, P. J. 1993. Aluminum tolerance in wheat (Triticum aestivum L.) II. Aluminum-stimulated excretion of malic acid from root apices. Plant Physiol. 103: 695-702.

Delhaize, E, and Ryan, P. R. 1995. Aluminum toxicity and tolerance in plants. Plant Physiol. 107: $315-321$.

De Miranda, L. N. and Rowell, D. L. 1989. Aluminum-phosphate interactions in wheat. New Phytol. 113: 7-12.

Dighton, J. 1983. Phosphatase production by mycorrhizal fungi. Plant Soil 71: 455-462.

Duff, S. M. G.; Sarath, G.; and Plaxon, W. C. 1994. The role of acid phosphatase in plant phosphorus metabolism. Physiol. Plant. 90: 791-800.

Eissenstat, D. M.; Graham, J. H.; Syvertsen, J. P. and Drouillard, D. L. 1993. Carbon economy of sour orange in relation to mycorrhizal colonization and phosphorus status. Ann. Bot. 71: $1-10$

Foy, C. D. 1983. The physiology of plant adaptation to mineral stress. Iowa S. J. Research 57: 355-391.

Francis, R. and Read, D. J. 1994. The contribution of mycorrhizal fungi to the determination of plant community structure. Plant Soil 159: 11-25.

Fries, L. L.; Pacovsky, R. S.; Safir, G. R.; and Kaminski, J. 1998. Phosphorus effect on phosphatase activity in endomycorrhizal maize. Physiol. Plant. 103: 162-171.

Gadd, G. M. 1993. Interactions of fungi with toxic metals. New Phytol. 124: 24-60.

Galli, U.; Schuepp, H.; and Brunold, C. 1994. Heavy metal binding by mycorrhizal fungi. Physiol. Plant. 92: 364-368 
Gianinazzi-Pearson, V.; Smith, S. E.; Gianinazzi, S.; and Smith, F. A. 1991. Enzymatic studies on the metabolism of vesicular-arbuscular mycorrhizas. V. Is $\mathrm{H}^{+}$-ATPase a component of ATP-hydrolyzing enzyme activities in plant-fungus interfaces? New Phytol. 117: 61-74.

Gibson, D. J. and Risser, P. S. 1982. Evidence for the absence of ecotypic development in Andropogon virginicus (L.) on metalliferous mine wastes. New Phytol. 92: 589-599.

Gildon, A. and Tinker, P. B. 1981. A heavy metal-tolerant strain of a mycorrhizal fungus. Trans. Br. Mycol. Soc. 77: 648-649.

Giovannetti, M. and Mosse, B. 1980. An evaluation of techniques for measuring vesicular arbuscular mycorrhizal infection in roots. New Phytol. 84: 489-500.

Hajabbasi, M. A. and Schumacher, T. E. 1994. Phosphorus effects on root growth and development in two maize genotypes. Plant Soil 158: 39-46.

Harrison, M. J. and Dixon, R. A. 1994. Spatial patterns of expression of flavonoid/isoflavonoid pathway genes during interactions between roots of Medicago truncatula and the mycorrhizal fungus Glomus versiforme. Plant J. 6: 9-20.

Harrison, M. J. 1999. Molecular and cellular aspects of the arbuscular mycorrhizal symbiosis. Annu. Rev. Plant Physiol. Plant Mol. Biol. 50: 361-389

Haselwandter, K. 1995. Mycorrhizal fungi: Siderophore production. Crit. Rev. Biotech. 15: 287-291.

Haug, A. 1984. Molecular aspects of aluminum toxicity. CRC Crit. Rev. Plant Sci. 1: 345-373. Haug, A. and Caldwell, C. R. 1985. Aluminum toxicity in plants: The role of the root plasma membrane and calmodulin. In Frontiers of Membrane Research in Agriculture. Ed. J. B. John, E. Berlin \& P. C. Jackson, pp. 359-381. Rowman \& Allanheld: Totowa.

Hayman, D. S. 1983. The physiology of VA endomycorrhizal symbiosis. Can. J. Bot. 61: 944963. 
Huang, J. W.; Grunes, D. L.; and Kochian, L. V. 1992. Aluminum effects on the kinetics of calcium uptake into cells of the wheat root apex. Planta 188: 414-421.

Huang, J. W.; Shaff, J. E.; Grunes, D. L.; and Kochian, L. V. 1992. Aluminum effects on calcium fluxes at the root apex of aluminum-tolerant and -sensitive wheat cultivars. Plant Physiol. 98: 230-237.

Humphreys, M. O. and Bradshaw, A. D. 1976. Heavy metal toxicities. In Plant Adaptation to Mineral Stress in Problem Soils: Proceedings of a Workshop on. Ed. Wright, M. J. Cornell University. pp. 95-105.

Hunt, R. 1990. Basic Growth Analysis: Plant Growth Analysis for Beginners. Unwin Hyman: London.

Johnson, N. C.; Graham, J. H.; and Smith, F. A. 1997. Functioning of mycorrhizal associations along the mutualism-parasitism continuum. New Phytol. 135: 575-585.

Jones, D. L. and Darrah, P. R. 1994. Role of root derived organic acids in the mobilization of nutrients from the rhizosphere. Plant Soil 166: 247-257.

Jones, D. L.; Prabowo, A. M.; and Kochian, L. V. 1996. Aluminum-organic acid interactions in acid soils. II. Influence of solid phase sorption on organic acid-Al complexation and Al rhizotoxicity. Plant Soil 182: 229-37.

Jones, D. L.; Gilroy, S.; Larsen, P. B.; Howell, S. H.; and Kochian, L. V. 1998. Effect of aluminum on cytoplasmic $\mathrm{Ca}^{2+}$ homostasis in root hairs of Arabidopsis thaliana (L.). Planta 206: $378-387$.

Keltjens, W. G. and Tan, K. 1993. Interactions between aluminum, magnesium and calcium with different monocotyledous and dicotyledonous plant species. Plant Soil 155/156: 485-488.

Kinraide, T. B.; Arnold, R. C.; and Baligar, V. C. 1985. A rapid assay for aluminum phytotoxicity at submicromolar concentrations. Physiol. Plant. 65: 245-250. 
Kinraide, T. B. 1991. Identity of the rhizotoxic aluminum species. Plant Soil 134: 167-178.

Kochian, L. V. 1995. Cellular mechanisms of aluminum toxicity and resistance in plants. Annu. Rev. Plant Physiol. Plant Mol. Biol. 46: 237-260.

Koslowsky, S. D. and Boerner, R. E. J. 1989. Interactive effects of aluminum, phosphorus and mycorrhizae on growth and nutrient uptake of Panicum virgatum L. (Poaceae). Environ. Pollu. 6: 107-125.

Kothari, S. K.; Marschner, H.; and Romheld, V. 1990. Direct and indirect effects of VA mycorrhizal fungi and rhizosphere microorganisms on acquisition of mineral nutrients by maize (Zea mays L.) in a calcareous soil. New Phytol. 110: 637-745.

Kothari, S. K.; Marschner, H.; and Romheld, V. 1991. Contribution of the VA mycorrhizal hyphae in acquisition of phosphorus and zinc by maize grown in a calcareous soil. Plant Soil 131: $177-185$.

Kuhn, A. J.; Schroder, W. H.; and Bauch, J. 2000. The kinetics of calcium and magnesium entry into mycorrhizal spruce roots. Planta 210: 488-496.

Lambers, H.; Chapin, III F. S.; and Pons, T. L. 1998. Plant Physiological Ecology. SpringerVerlag, Inc., New York. 540 p.

Lambert, D. H. and Col, Jr H. 1980. Effects of mycorrhizae on establishment and performance of forage species in mine spoil. Agron. J. 72: 257-260.

Larsen, P. B.; Degenhardt, J.; Tai, C.; Stenzler, L. M.; Howell, S. H.; and Kochian, L. V. 1998. Aluminum-resistant Arabidopsis mutants that exhibit altered patterns of aluminum accumulation and organic acid release from roots. Plant Physiol. 117: 9-18.

Leake, J. R. and Read, D. J. 1989. The biology of mycorrhiza in the Ericaceae. XV. The effect of mycorrhizal infection on calcium uptake by Calluna vulgaris (L.) Hull. New Phytol. 113: 535-544. 
Lindberg, S. and Griffiths, G. 1993. Aluminum effects on ATPase activity and lipid composition of plasma membrane in sugar beet roots. J. Exp. Bot. 44: 1543-1550.

Lindberg, S. and Strid, H. 1997. Aluminum induces rapid changes in cytosolic pH and free calcium and potassium concentrations in root protoplasts of wheat. Physiol. Plant. 99: 405414.

Lindsey, D. L.; Cress, W. A.; and Aldon, E. F. 1977. The effects of endomycorrhizae on growth of rabbitbrush, dourwing slatbush and corn in coal mine spoil material. USDA Forest Service Research Note RM-343: 1-6.

Lux, H. B. and Cumming, J. R. 1999. Effect of aluminum on the growth and nutrition of tulippoplar seedlings. Can. J Forest Res. 29: 2003-2007.

Ma, J. F. ; Zheng, S. J.; Matsumoto, H.; and Hiradate, S. 1997. Detoxifying aluminum with buckwheat. Nature 390: 569-570.

Ma. J. F.; Hiradate, S.; and Matsumoto, H. 1998. High aluminum resistance in buckwheat: II. Oxalic acid detoxifies aluminum internally. Plant Physiol. 117: 753-759.

Ma, J. F. 2000. Role of organic acids in detoxification of aluminum in higher plants. Plant Cell Physiol. 41: 383-390.

Macklon, A. E. S. and Sim, A. 1992. Modifying effects of not-toxic levels of aluminum on the uptake and transport of phosphate in ryegrass. J. Exp. Bot. 43: 915-923.

Macklon, A. E. S.; Lumsdon, D. G.; and Sim, A. 1994. Phosphate uptake and transport in Agrostis capillaris L.: Effects of non-toxic levels of aluminum and the significance of $\mathrm{P}$ and Al speciation. J. Exp. Bot. 45: 887-894.

Marschner, H. 1991. Mechanisms of adaptation of plants to acid soils. Plant Soil 134: 1-20. Marschner, H. 1995. Mineral Nutrition of Higher Plants. Academic Press, San Diego, CA 92101.889 p. 
Matsumoto, H. and Yamaya, T. 1986. Inhibition of potassium uptake and regulation of membrane-associated $\mathrm{Mg}^{2+}$-ATPase activity of pea roots by aluminum. Soil Sci. Plant Nutr. 32: $179-188$.

McArthur, D. J. and Knowles, N. R. 1992. Resistance responses of potato to vesicular-arbuscular mycorrhizal fungi under varying abiotic phosphorus levels. Plant Physiol. 100: 341-351.

McArthur, David A. J.; and Knowles, N. R. 1993. Influence of vesicular-arbuscular mycorrhizal fungi on the response of potato to phosphorus deficiency. Plant Physiol. 101: 147-160.

Medeiros, C. A. B.; Clark, R. B.; and Ellis, J. R. 1994. Effects of excess aluminum on mineral uptake in mycorrhizal sorghum. J. Plant Nutr. 17: 1399-1416.

Mendoza, J. and Borie, F. 1998. Effect of Glomus etunicatum inoculation on aluminum, phosphorus, calcium, and magnesium uptake of two barley genotypes with different aluminum tolerance. Comm. Soil Sci. Plant Anal. 29: 681-695.

Meharg, A. A. and Cairney, J. W. G. 2000. Co-evolution of mycorrhizal symbionts and their hosts to metal-contaminated environments. In Advances in Ecological Research. Ed. Fitter, A. H. and Raffaelli, D. G. Academic Press, San Diego, 30: 69-112.

Miller, R. M.; Hetrick, B. A. D.; and Wilson, G. W. T. 1997. Mycorrhizal fungi affect root stele tissue in grasses. Can. J. Bot. 75: 1778-1784.

Mimura, T. 1995. Homeostasis and transport of inorganic phosphate in plants. Plant Cell Physiol. 36: 1-7.

Miyasaka, S. C.; Kochian, L. V.; Shaff, J. E.; and Foy, C. D. 1989. Mechanisms of aluminum tolerance in wheat: An investigation of genotypic differences in rhizosphere $\mathrm{pH}, \mathrm{K}^{+}$, and $\mathrm{H}^{+}$ transport, and root-cell membrane potentials. Plant Physiol. 91: 1188-1196.

Miyasaka, S. C.; Buta, J. G.; Howell, R. K.; and Foy, C. D. 1991. Mechanism of aluminum tolerance in snapbeans: Root exudation of acidic acid. Plant Physiol. 96: 737-743. 
Mooney, H. A. and Winner, W. E. 1991. Partitioning response of plants to stress. In Response of Plants to Multiple Stresses. Ed. Mooney, H. A.; Winner, W. E.; and Pell, E. J. Academic Press, San Diego. pp.129-141.

Morgan, P. W. 1990. Effects of abiotic stresses on plant hormone systems. In Stress Responses in Plants: Adaptation and Acclimation Mechanisms. Ed. Alscher, R. G. and Cumming, J. R. Willey-Liss, New York: 113-146.

Morton, J. B. 1986. Three new species of Acaulospora (Endogonaceae) from high aluminum, low pH soils in West Virginia. Mycologia 78: 641-648.

Morton, J. B. 1990. Species and clones of arbuscular mycorrhizal fungi (Gloomales, Zyogmycetes): Their role in macro- and microevolutionary processes. Mycotaxon 37: 493515.

Morton, J. B.; Bentivenga, S.; and Wheeler, W. 1993. Germ plasm in the International Collection of Arbuscular and Vesicular-arbuscular Mycorrhizal Fungi (INVAM) and procedures for culture development, documentation, and storage. Mycotaxon 48: 491-528.

Mosse, B. 1973. Advances in the study of vesicular-arbuscular mycorrhiza. Annu. Rev. Phytopathol. : 171-196.

Motomizu, S.; Wakimoto, T.; and Toei, K. 1983. Spectrophotometric determination of phosphate in river water with molybdate and malachite green. Analyst 108: 361-367.

Muchhal, U. S.; Liu, C.; and Raghothama, K. G. 1997. $\mathrm{Ca}^{2+}-$ ATPase is expressed differentially in phosphate-starved roots of tomato. Physiol. Plant. 101: 540-544

Nellessen, J. E. and Ungar, I. A. 1993. Physiological comparisons of old-field and coal-minespoil populations of Andropogon virginicus L. (Broomsedge). Am. Midl. Nat. 130: 90-105. Newsham, K. K.; Fitter, A. H.; and Watkinson, A. R. 1995. Multi-functionality and biodiversity in arbuscular mycorrhizas. Tree 10: 407-411. 
Nichol, B. E.; Oliveira, L. A.; Glass, A. D. M.; and Siddiqi, M. Y. 1993. The effects of aluminum on the influx of calcium, potassium, ammonium, nitrate, and phosphate in an aluminum-sensitive cultivar of barley (Hordeum vulgare). Plant Physiol. 101: 1263-1266.

Olivetti, G. P.; Cumming, J. R.; and Etherton, B. 1995. Plasma membrane electrical potential depolarization precedes aluminum tolerance in Phaseolus vulgaris L. Plant Physiol. 109: 123-129.

Olsen, S. R. and Sommers, L. E. 1982. Phosphorus. In Methods of Soil Analysis Part 2. Chemical and Microbiological Properties. Ed. Page A L, Miller R H and Keeney D. R. pp. 403-430. American Society of Agronomy and Soil Science Society of America, Madison, WI.

Pacovsky, R. S. 1986. Micronutrient uptake and distribution in mycorrhizal or phosphorusfertilized soybeans. Plant Soil 95: 379-388.

Parker, D. R.; Norvell, W. A.; and Chaney, R. L. 1993. GEOCHEM-PC: A chemical speciation program for IBM and compatible computers. In Chemical Equilibrium and Reaction Models. Eds. Leoppert, R. H. et al. SSSA Spec. Publ., SSSA, Madison, WI.

Parker, D. R. and Pedler, J. F. 1998. Probing the "malate hypothesis" of differential aluminum tolerance in wheat by using other rhizotoxic ions as proxies for aluminum. Planta 205: 389396.

Parkinson, J. A. and Allen, S. E. 1975. A wet oxidation procedure suitable for the determination of nitrogen and mineral nutrients in biological material. Comm. Soil Sci. Plant Anal. 6: 111.

Peng, S.; Eissensta, D. M.; Graham, J. H.; William, K. and Hodge, N. C. 1993. Growth depression in mycorrhizal citrus at high-phosphorus supply: Analysis of Carbon Costs. Plant Physiol. 101: 1063-1071. 
Pellet, D. M.; Papernik, L. A.; Jones, D. L.; Darrah, P. R.; Grunes, D. L.; and Kochian, L. V. 1997. Involvement of multiple aluminum exclusion mechanisms in aluminum tolerance in wheat. Plant Soil 192: 63-68.

Pineros, M. and Tester, M. 1993. Plasma membrane $\mathrm{Ca}^{2+}$ channels in roots of higher plants and their role in aluminum toxicity. Plant Soil 155/156: 119-122.

Pinior, A.; Wyss, U.; Piche, Y.; and Vierheilig, H. 1999. Plants colonized by AM fungi regulate further root colonization by AM fungi through altered root exudation. Can. J. Bot. 77: 891897.

Plenchette, C.; Furlan, V.; and Fortin, J. A. 1983. Responses of endomycorrhizal plants grown in a calcined montmorillnite clay to different levels of soluble phosphorus. I. Effect on growth and mycorrhizal development. Can. J. Bot. 61: 1377-1383.

Po, C. and Cumming, J. R. 1997. Mycorrhizal fungi alter the organic acid exudation profile of red clover rhizospheres. In Radical Biology: Advances and Perspectives on the Function of Plant Roots. Ed. Flores, H. E.; Lynch, J. P.; and Eissenstat, D. American Society of Plant Physiologists.

Porra, R. J.; Thompson, W. A.; and Kriedemann, P. E. 1989. Determination of accurate extinction coefficients and simultaneous equations for assaying chlorophylls $\mathrm{a}$ and $\mathrm{b}$ extracted with four different solvents: Verification of the concentration of chlorophyll standards by atomic absorption spectroscopy. Biochica et Biophysica Acta 976: 384-394.

Raghothama, K. G. 1999. Phosphate acquisition. Annu. Rev. Plant Physiol. Plant Mol. Biol. 50: $665-693$.

Randall, P. J. and Vose, P. B. 1963. Effect of aluminum on uptake and translocation of phosphorus by perennial ryegrass. Plant Physiol. 38: 403-409. 
Rengel, Z. and Robinson, D. L. 1989. Aluminum effects on growth and macronutrient uptake by annual ryegrass. Agron. J. 81: 208-215.

Rengel, Z.; Pineros, M.; and Tester, M. 1995. Transmembrane calcium fluxes during Al stress. Plant Soil 171: 125-130.

Rengel, Z. 1996. Uptake of aluminum by plant cells. New Phytol. 134: 389-406.

Ritchie, G. S. P. 1995. Soluble aluminum in acidic soils: Principles and practicalities. Plant Soil 171: $17-27$.

Ross, J. P. 1971. Effect of phosphate fertilization on yield of mycorrhizal and non-mycorrhizal soybean. Phytopathol. 61: 1400-1403.

Roy, A. K.; Sharma, A.; and Talukader, G. 1988. Some aspects of aluminum toxicity in plants. Bot. Rev. 54: 145-178.

Ryan, P. R. and Kochian, L. V. 1993. Interaction between aluminum toxicity and calcium uptake at the root apex in near-isogenic lines of wheat (Triticum aestivum L.) differing in aluminum tolerance. Plant Physiol. 102: 975-982.

Ryan, P. R.; Ditomaso, J. M.; and Kochian, L. V. 1993. Aluminum toxicity in roots: An investigation of spatial sensitivity and the role of the root cap. J. Exp. Bot. 44: 437-446.

Schachtman, D. P.; Reid, R. J.; and Ayling, S. M. 1998. Phosphorus Uptake by Plants: From Soil to Cell. Plant Physiol. 116: 447-453.

Schlegel, H. and Godbold, D. L. 1991. The influence of Al on the metabnolism of spruce needles. Water Air Soil Pollu. 57/58: 131-138.

Shaw, G. and Read, D. J. 1989. The biology of mycorrhiza in the Ericaceae: XIV. Effects of iron and aluminum on the activity of acid phosphatase in the ericoid endophyte Hymenoscyphus ericae (Read) Korf and Kernan. New Phytol. 113: 529-533. 
Slaski, J. J.; Zhang, G. C.; Basu, U.; Stephens, J. L.; and Taylor, G. J. 1996. Aluminum resistance in wheat (Triticun aestivum) is associated with rapid, Al-induced changes in activities of glucose-6-phosphate dehydrogenase and 6-phoisphogluconate dehydrogenase in root apices. Phsyiol. Plant. 98: 477-484.

Smith, S. E.; Gianinazzi-Pearson, V.; Koide, R.; and Cairney, J. W. G. 1994. Nutrient transport in mycorrhizas: Structure, physiology and consequences for efficiency of the symbiosis.

Plant Soil 159: 103-113.

Smith, S. E. and Read, D. J. 1997. Mycorrhizal Symbiosis. 2nd ed. Academic Press, San Diego, CA. 605 p.

Snoeyink, V. L. and Jenjins, D. 1980. Water Chemistry. John Willey \& Sons, New York. 463p.

Staddon, P. L.; Fitter, A. H.; and Robinson, D. 1999. Effects of mycorrhizal colonization and elevated atmospheric carbon dioxide on carbon fixation and below-ground carbon partitioning in Plantago lanceolata. J. Exp. Bot. 50: 853-860.

Strom, L. 1997. Root exudation of organic acids: Importance to nutrient availability and the calcifuge and calcicole behavior of plants. OIKOS 80: 459-466.

Stutz, J. C. and Morton, J. B. 1996. Successive pot cultures reveal high species richness of arbucular endomycorrhizal fungi in arid ecosystems. Can. J. Bot. 74: 1883-1889.

Tabatabai, M. A. and Bremner, J. M. 1969. Use of $p$-nitrophenyl phosphate for assay of soil phosphatase activity. Soil Biol. Biochem. 1: 301-307.

Tan, K. and Keltjens, W. G. 1990. Interaction between aluminum and phosphorus in sorghum plants II. Studies with the aluminum tolerant sorghum genotype SC0283. Plant Soil 124: 2532. 
Tan, K.; Keltjens, W. G.; and Findenegg, G. R. 1993. Evaluating the contribution of magnesium deficiency in the aluminum toxicity syndrome in twelve sorghum genotypes. Plant Soil 149: $255-261$.

Taussky, H. H. and Shoor, E. 1953. A microcolormetric method for the determination of inorganic phosphorus. J. Biol. Chem. 202: 675-685.

Taylor, G. J. 1988a. The physiology of aluminum phytotoxicity. In Metal ions in Biological Systems. Ed. H. Sigel \& A. Sigel. Vol. 24: 123-163. Marcel Dekker, Inc.: New York. Taylor, G. J. 1988b. The physiology of aluminum tolerance. In Metal ions in Biological Systems. Ed. H. Sigel \& A. Sigel. Vol. 24: 165-198. Marcel Dekker, Inc.: New York. Theodorou, M. E. and Plaxton, W. C. 1993. Metabolic adaptations of plant respiration to nutritional phosphate deprivation. Plant Physiol. 101: 339-344.

Thomas, R. B. and Strain, B. R. 1991. Root restriction as a factor in photosynthetic acclimation of cotton seedlings grown in elevated carbon dioxide. Plant Physiol. 96: 627-634.

Tice, K. R.; Parker, D. R. and DeMason, D. A. 1992. Operationally defined apoplastic and symplastic aluminum fractions in root tips of aluminum-intoxicated wheat. Plant Physiol. 100: $309-318$.

von Uexkull, H. R. and Mutert, E. 1995. Global extent, development and economic impact of acid soils. Pland Soil 171: 1-15.

Watanabe, T.; Osaki, M.; Yoshihara, T. and Tadano, T. 1998. Distribution and chemical speciation of aluminum in the $\mathrm{Al}$ accumulator plant, Melastoma malabathricum L. Plant Soil 201: $165-173$.

Wagatsuma, T.; Ishikawa, S.; et al. 1995. Plasma membrane of younger and outer cells is the primary specific site for aluminum toxicity in roots. Plant Soil 171: 105-112. 
Wheeler. D. M. and Dodd, M. B. 1995. Effect of aluminum on yield and plant chemical concentrations of some temperate legumes. Plant Soil 173: 133-145.

Widell, S.; Asp, H.; and Jensen, P. 1994. Activities of plasma membrane-bound enzymes isolated from roots of spruce (Picea abies) grown in the presence of aluminum. Plant Physiol. 92: 459-466.

Wright, D. P.; Scholes, J. D.; and Read, D. J. 1998. Effects of VA mycorrhizal colonization on photosynthesis and biomass production of Trifolium repens L. Plant Cell Environ. 21: 209216.

Yamaguchi, Y.; Yamamoto, Y. et al. 1999. Protective effect of glutathione on the cytotoxicity caused by a combination of aluminum and iron in suspension-cultured tobacco cells. Physiol. Plant. 105: 417-422.

Yang, W. and Goulart, B. L. 1997. Aluminum and phosphorus interactions in mycorrhizal and non-mycorrhizal highbush blueberry plantlets. J. Amer. Soc. Hort. Sci. 122: 24-30.

Yu, Q.; Osborne, L.; and Rengel, Z. 1998. Micronutrient deficiency changes activities of superoxide-dismutase and ascorbate peroxidase in tobacco plants. J. Plant Nutr. 21: 14271437.

Zel, J.; Svetek, J.; Crne, H.; and Schara, M. 1993. Effects of aluminum on membrane fluidity of the mycorrhizal fungus, Amanita muscaria. Physiol. Plant. 89: 1721-176.

Zhang, G. C.; Hoddinott, H.; and Taylor, G. J. 1994. Characterization of 1,3-b-d-glucan (callose) synthesis in roots of Triticum aestivum in response to aluminum toxicity. J. Plant Physiol. 144: $229-234$.

Zhang, F. S.; Ma, J.; and Cao, Y. P. 1997. Phosphorus deficiency enhances root exudation of low-molecular weight organic acids and utilization of sparingly soluble inorganic phosphates 
References

by radish (Raghanus sativus L.) and rape (Brassica napus L.) plants. Plant Soil 196: 261-

264. 


\section{VITAE OF JIANCHANG NING}

\section{Education}

- August of 1995 - December of 2000

$\mathrm{Ph}$. D. in Biology, West Virginia University, Morgantown, WV, USA

- September of 1988 - July of 1991

M. S. in Botany, Institute of Botany, Chinese Academy of Sciences, Beijing, China

- September of 1984 - July of 1988

B. A. in Agronomy and Horticulture, Jilin Agricultural University, Changchun, Jilin, China

\section{Experience}

- Research Assistant and Teaching Assistant, from August of 1995 to December of 2000 in Department of Biology, West Virginia University, Morgantown, WV, USA

- Assistant Professor in Botany, from Jan. of 1994 to May of 1995, Institute of Botany, Chinese Academy of Sciences, Beijing, China

- Research Associate in Botany, from August of 1991 to December of 1994, Institute of Botany, Chinese Academy of Sciences, Beijing, China

- System Administrator and Supervisor of Computing Facilities, from Jan of 1994 to May of 1995, Institute of Botany, Chinese Academy of Sciences, Beijing, China

- Networking Specialist, from August of 1993 to May of 1995, Institute of Botany, Chinese Academy of Sciences, Beijing, China

- Intern of Business and Administration, from July of 1993 to September of 1993, Provincial Warehouse of Jiangxi Province, Nanchang, Jiangxi, China

\section{Honors and Activities}

- HERF Fellowship 1996-1999, West Virginia University

- Candidate for Excellent Research Award 1994, Institute of Botany, Chinese Academy of Sciences

- Award of Outstanding Research Paper 1991, Institute of botany, Chinese Academy of Sciences

- Honors for Excellent Students 1985-1987, Jilin Agricultural University

- Member of Ecological Society of America 1998

- Member of Association of Chinese Palynologists 1993-1995

- Member of Botanical Society of China 1994-1995

- Deputy Chair and Secretary-General of Graduate Association 1990, Institute of Botany, Chinese Academy of Sciences 